\title{
A METHOD FOR ESTIMATING THE FLOCCULATION TIME OF MONODISPERSED SEDIMENT SUSPENSIONS
}

\author{
By \\ Elizabeth Ann Gonzalez
}

SLBMITTED IN PARTIAL FULFILLMENT OF THE REQUIREMENTS FOR THE DEGREE OF

MASTER OF SCIENCE

AT

DALHOUSIE UNIVERSITY

HALIFAX, NOVA SCOTIA

JULY 1997

(C) Copyright by Elizabeth Ann Gonzalez, 1997 
National Library

of Canada

Acquisitions and

Bibliographic Services

395 Wellington Street Ottawa ON K1A ON4

Canada
Bibliothèque nationale

du Canada

Acquisitions et

services bibliographiques

395, rue Wellington

Ottawa ON K1A ON4

Canada
The author has granted a nonexclusive licence allowing the National Library of Canada to reproduce, loan, distribute or sell copies of this thesis in microform, paper or electronic formats.
L'auteur a accordé une licence non exclusive permettant à la Bibliothèque nationale du Canada de reproduire, prêter, distribuer ou vendre des copies de cette thèse sous la forme de microfiche/film, de reproduction sur papier ou sur format électronique.

L'auteur conserve la propriété du droit d'auteur qui protège cette thèse. $\mathrm{Ni}$ la thèse ni des extraits substantiels de celle-ci ne doivent être imprimés ou autrement reproduits sans son autorisation. 


\section{Contents}

List of Tables vi vi

List of Figures viii

1 Introduction 1

2 Background 4

2.1 Coagulation Models . . . . . . . . . . . . . . . . . . 4 4

2.2 Particle Encounter Mechanisms . . . . . . . . . . . . . . 8

2.3 Settling Velocity and Fractal Dimension ............ 11

2.4 Estimates of Flocculation Time . . . . . . . . . . . 13

3 Methods 16

3.1 Sectional Model . . . . . . . . . . . . . . . . . 16

3.2 Monodispersion Estimate of Flocculation Time . . . . . . . . . 21

3.3 Junge-dispersion Estimate of Flocculation Time . . . . . . . . . 21

4 Analysis $\quad 26$

4.1 Model Runs . . . . . . . . . . . . . . . . . 26

4.2 Statistics . . . . . . . . . . . . . . . 30

5 Results and Discussion $\quad 32$

5.1 Turbulent Shear Encounter . . . . . . . . . . . . . . . . . 32

5.2 Turbulent Shear and Differential Settling Encounter . . . . . . . . 34 
5.3 Aggregation with Settling Losses $\ldots . . . \ldots . . . . .42$

6 Implementation $\quad 48$

6.1 Model Validation ... . . . . . . . . . . . . . 48

6.2 Revisiting Published Flocculation Times . . . . . . . . . . . 49

6.3 Limitations of Method . . . . . . . . . . . . . . 52

7 Conclusions $\quad 54$

A Analytical Solutions to the Stochastic Collection Equation $\mathbf{5 5}$

A.1 Initially Monodisperse Suspension and Constant Kernel . . . . . . 55

A.2 Initially Bidisperse Suspension and Sum Kernel . . . . . . . . 56

$\begin{array}{ll}\text { B Physical Constants } & 57\end{array}$

C Plots for $d_{\max }=10 \mathrm{~mm}$ and $d_{\max }=1 \mathrm{~mm}$

$\begin{array}{ll}\text { D Mass Distributions } & 61\end{array}$

$\begin{array}{ll}\text { E MINITAB Output } & 68\end{array}$

$\begin{array}{ll}\text { F New cases for Model Validation } & \mathbf{7 2}\end{array}$ 


\section{List of Tables}

4.1 Model inputs for encounter due to turbulent shear and differential settling with $d_{\max }=10 \mathrm{~mm} \ldots \ldots \ldots \ldots . \ldots \ldots$

4.2 Model inputs for encounter due to turbulent shear and differential settling with $d_{\max }=1 \mathrm{~mm} \ldots \ldots \ldots \ldots 28$

4.3 Model inputs for encounter due to turbulent shear and differential settling with $d_{\max }=0.1 \mathrm{~mm} . \ldots \ldots \ldots \ldots$

5.1 Full-model dimensionless flocculation time for turbulent shear including settling losses. . . . . . . . . . . . . . .

5.2 Full-model dimensionless flocculation time for turbulent shear and differential shear encounter including settling losses for cases with $\rho_{s}<$ $1500 \mathrm{~kg} \mathrm{~m}^{-3}$ and $\rho_{s}>2500 \mathrm{~kg} \mathrm{~m}^{-3} \ldots \ldots \ldots \ldots$

5.3 Ratios of flocculation time to sinking time scale for cases with $\rho_{s}<$ $1500 \mathrm{~kg} \mathrm{~m}^{-3}$ and $\rho_{s}>2500 \mathrm{~kg} \mathrm{~m}^{-3} \ldots \ldots \ldots \ldots$

6.1 Dimensionless flocculation times calculated using the Batterham et al. (1981) model $\left(\tau_{B}\right)$ and the Junge-distribution method, corrected using the predictive equations, $\left(\tau_{J_{\text {corrected }}}\right)$ for a number of new cases not used in the development of the predictive regression equations. . .

6.2 Flocculation times calculated using the Junge-distribution method and inputs from McCave (1985). . . . . . . . . . . . . . 
6.3 Flocculation times calculated using the Junge-distribution method and inputs from Logan et al. (1995) for a coastal ocean and a freshwater lake. . . . . . . . . . . . . . . . . . . 51

6.4 Flocculation times calculated using the Junge-distribution method and inputs from Logan et al. (1995) for a mesocosm experiment. . . . . 51

B.1 Physical constants employed in models. . . . . . . . . . . 57

E.1 MINITAB output for cases with $d_{\max }=1 \mathrm{~mm} \ldots \ldots 69$

E.2 MINITAB output for cases with $d_{\max }=10 \mathrm{~mm} \ldots \ldots$ i 0

E.3 MINITAB output for cases with $d_{\max }=0.1 \mathrm{~mm} . \ldots \ldots$ i1

F.I Model inputs for new cases not used in the development of the predictive regression equations. . . . . . . . . . . . i2 


\section{List of Figures}

2.1 Nondimensional median diameter as a function of nondimensional time for an aggregating, fine sediment suspension. . . . . . . . .

2.2 Median diameter as a function of time predicted by Hill and Nowell $(1995)$ 's aggregation model. . . . . . . . . . . . .

3.1 Comparison of modeled and analytical particle size distributions. . . . 20

3.2 Sample series of mass distributions. . . . . . . . . . . . . 23

3.3 Schematic showing the evolution of a Junge-distributed mass distribution. ............................. 24

5.1 Comparison of dimensionless flocculation times calculated for turbulent shear encounter with three values of $h \ldots \ldots \ldots \ldots \ldots$

5.2 Comparison of dimensionless flocculation times calculared for ail cases with turbulent shear encounter. . . . . . . . . . . . . 34

j.3 Comparison of dimensionless flocculation times calculated with turbulent shear and differential settling encounter for all cases with maximum diameter of $d_{\max }=1 \mathrm{~mm} . \ldots \ldots \ldots \ldots \ldots$

5.4 Dimensionless mass concentration $(m)$ in each section (i) at comparable dimensionless times for (a) case $F 1$, (b) case $\mathrm{Z2}$, and (c) case K3. . . . . . . . . . . . . . . . . .

5.5 Dimensionless mass concentration $(m)$ in each section $(i)$ at comparable dimensionless times for (a) case A2, (b) case Q2, and (c) case CC2. . . . . . . . . . . . . . . . . . . . 
5.6 Comparison of dimensionless flocculation times calculated using the full model and the Junge-dispersion approach for all cases with encounter due to turbulent shear for maximum diameter of $d_{\max }=1 \mathrm{~mm} .39$

5.7 Comparison of dimensionless flocculation times calculated for all cases with turbulent shear and differential settling encounter for $d_{\max }=$ $10 \mathrm{~mm}$ and $d_{\max }=0.1 \mathrm{~mm} . \ldots \ldots \ldots \ldots \ldots$

5.8 Averaged ratios of number concentrations in adjacent sections plotted as a function of fractal dimension. . . . . . . . . . . . . .

5.9 Dimensionless flocculation times for cases A2 through E2 calculated using the Power Law method and the Junge-distribution method. . .

5.10 Dimensionless median diameter versus dimensionless time for turbulent shear encounter with sinking losses. . . . . . . . . . .

5.11 Time-scale ratio for case $\mathrm{C} 1$ plotted versus percentage increase in dimensionless flocculation time from its no-loss value. . . . . . . . .

C.1 Comparison of dimensionless flocculation times calculated with turbulent shear and differential settling encounter for all cases with $d_{\max }=$ $10 \mathrm{~mm}$

C.2 Comparison of dimensionless flocculation times calculated with turbulent shear and differential settling encounter for all cases with $d_{\max }=$ $0.1 \mathrm{~mm}$.

D.1 Nondimensional mass distributions at various times throughout its evolution for case $\mathrm{F} 1 . \ldots \ldots \ldots \ldots \ldots \ldots \ldots \ldots \ldots \ldots \ldots \ldots$

D.2 Nondimensional mass distributions at various times throughout its evolution for case Z2 . . . . . . . . . . . . . . . . . 63

D.3 Nondimensional mass distributions at various times throughout its evolution for case $\mathrm{K} 3 . \ldots \ldots \ldots \ldots \ldots$. . . . . . . . . . . . . 64

D.4 Nondimensional mass distributions at various times throughout its evolution for case A2. . . . . . . . . . . . . . 
D.5 Nondimensional mass distributions at various times throughout its evolution for case Q2. . . . . . . . . . . . . .

D.6 Nondimensional mass distributions at various times throughout its evolution for case CC2. . . . . . . . . . . . . . . . 6 t 


\section{Abstract}

A new method is presented for determining the flocculation time of monodispersed sediment suspensions. This method predicts flocculation times to within $6 \%$ of values predicted by a geometric sectional aggregation model (Batterham et al.. 1981), but uses only a fraction of the computational effort. Flocculation times estimated in this way are superior to estimates of flocculation time scale made using half-life because particle geometry and differential settling encounter are taken into account.

The proposed model is based on typical size distributions calculated using Batterham et al.'s model. These size distributions have approximately equal mass in geometrically increasing size classes. i.e. they are Junge-dispersed. By assuming that the suspension remains Junge-dispersed throughout its evolution. the system of differential equations required to describe the suspension reduces to a single differential equation. Flocculation times are calculated for three values of maximum floc size $\left(d_{\max }=\{10 \mathrm{~mm} .1 \mathrm{~mm} .0 .1 \mathrm{~mm}\}\right)$, a maximum settling velocity of $w_{s}=1 \mathrm{~mm} \mathrm{~s}^{-1}$, and a variety of initial conditions. For a given set of inputs. flocculation times calculated in this way are linearly related to those calculated using the Batterham et al. model, but the slope of the relationship varies with fractal dimension. Multiple linear regression equations are developed to directly relate the two.

The effect of including sinking losses into Batterham et al. 's model is also investigated. If the sinking loss time scale is much longer than the flocculation timc. then the suspension becomes flocculated at ronghly the same time it would have had there been no sinking losses, and the new method can be used. Conversely, if the sinking time scale is equal to or longer than the flocculation time, then the new method cannot be used. 


\section{Symbols}

\begin{tabular}{cl}
\hline symbol & \multicolumn{1}{c}{ description } \\
\hline$A$ & empirical constant in Junge density distribution function \\
$b$ & empirical constant in Junge density distribution function \\
$B$ & coefficient of least squares regression \\
$C_{0}$ & initial particle mass concentration \\
$C_{p}$ & Mallow's statistic \\
$d$ & particle diameter \\
$d_{0}$ & component particle diameter \\
$d_{50}$ & median mass diameter \\
$d_{c}$ & critical diameter \\
$d_{k}$ & maximum diameter containing mass \\
$d_{\text {max }}$ & maximum particle diameter \\
$D 3$ & 3-dimensional fractal dimen ion \\
$E$ & contact efficiency \\
$f$ & number-density distribution cunction \\
$g$ & constant of gravitational acc leration \\
$G$ & shear rate \\
$h$ & number of sections \\
$i$ & section number \\
$j$ & section number \\
$k$ & largest section containing particles \\
$K$ & particle encounter rate \\
$k_{B}$ & Boltzmann's constant \\
$m$ & nondimensional particie mass concentration \\
$n$ & nondimensional particle number concentration \\
$n_{r}$ & ratio of particle number concentration in adjacent sections \\
$N$ & particle number concentration \\
$N_{0}$ & initial particle number concentration \\
$N_{p}$ & number of grains within a floc \\
$N_{T}$ & total particle number concentration \\
$p$ & number of parameters in least squares regression \\
$s^{2}$ & error mean square \\
$t$ & time \\
\hline &
\end{tabular}




\begin{tabular}{|c|c|}
\hline symbol & description \\
\hline$t_{\text {floc }}$ & flocculation time \\
\hline$t_{\operatorname{sink}}$ & sinking time scale \\
\hline $\begin{array}{l}I \\
u\end{array}$ & $\begin{array}{l}\text { absolute temperature } \\
\text { particle volume }\end{array}$ \\
\hline$u_{r}$ & relative velocity \\
\hline$v$ & particle volume \\
\hline$v_{s}$ & solid volume within a floc \\
\hline$V$ & particle volume concentration \\
\hline$V_{0}$ & initial particle volume concentration \\
\hline$V_{T}$ & total particle volume concentration \\
\hline$w_{s}$ & settling velocity \\
\hline $\mathbf{x}$ & predictor variable in least squares regression \\
\hline $\bar{x}$ & mean \\
\hline $\mathbf{y}$ & response variable in least squares regression \\
\hline$z$ & depth of water column \\
\hline$Z_{\mathrm{x}}$ & standardized value of $x$ \\
\hline$\alpha$ & sticking efficiency \\
\hline 3 & encounter rate coefficient \\
\hline$\hat{\beta}$ & dimensionless encounter rate coefficient \\
\hline 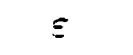 & turbulent kinetic energy dissipation rate \\
\hline$\lambda_{k}$ & Kölmogorov scale \\
\hline$\mu$ & dynamic viscosity \\
\hline$\nu$ & binematic viscosity \\
\hline$\rho$ & density of suspending medium \\
\hline$\rho_{p}$ & floc density \\
\hline$\rho_{s}$ & component grain density \\
\hline$\sigma$ & standard deviarion \\
\hline$\tau$ & dimensionless time \\
\hline$\tau_{B}$ & dimensionless flocculation time predicted using Batterham et al. ‘s model \\
\hline$\tau_{\text {floc }}$ & dimensionless flocculation time \\
\hline$\tau_{J}$ & dimensionless flocculation time predicted using Junge-dispersion assumption \\
\hline$T: M$ & dimensionless flocculation time predicted using monodispersion assumption \\
\hline$\tau_{P}$ & dimensionless flocculation time predicted using power law assumption \\
\hline$\varphi_{0}$ & initial volume fraction \\
\hline
\end{tabular}




\section{Acknowledgements}

I would like to thank Paul Hill, my supervisor, for his keen insight and for being so generous with his time. I would also like to thank Nauzer Kalyaniwalla for assisting me with the statistics in the thesis, and for helping me through the dark hours. Thanks go also to Dan Kelley for sharing with me his computing expertise. Finally. I would like to acknowledge the help of my committee members Tony Bowen and Bernie Boudreau. 


\section{Chapter 1}

\section{Introduction}

The majority of marine particles are present in the form of aggregates (Kranck and Milligan, 1992). The largest of these structures, called marine snow, can attain length scales on the order of several millimetres (Fowler and Knauer. 19S6). It is hypothesized that their size is limited by shear forces that result from turbulence or settling through the water column (Luettich. 1993: Sternberg et al.. 1996; Hill et al., 1997).

Aggregation increases the settling velocity of particles in suspension. Whereas fine. slowly-sinking sediments can be carried for long distances by currents, large aggregates settle more quickly and disperse less. Reduced dispersion of fines has serious implications for civic planning, for example, determining the location of sewage outfalls (Bonner et al., 1992; Hunt et al.. 1992). and pollutant-fate studies. such as determining the fate of surface adsorptive chemicals (Garnier et al., 1993). Accelerated dispersion is also important in the study of diatom blooms, which end abruptly and deposit on the sea floor in much shorter times than single-cell settling would allow (Smetacek, 1985; Jackson, 1990).

When investigating the fate of particles in the water column, the importance of aggregation relative to other removal mechanisms, such as deposition, often is determined by comparing time scales. While deposition time scale is easily calculated. aggregation time scale is not. In any aggregating suspension, there is a wide range of 
particle sizes and types, and for each particle-particle interaction. there is a unique encounter rate. Numerical models that track the evolution of particle size distributions during aggregation (Lick et al., 1992: Lick and Huang, 1993; Hill and Nowell. 1995) are rather difficult to implement and costly to run and. as such, are seldom used to calculate time scales. Instead, particle half-life, the time required for the initial particle number concentration to decrease by half. is used (Friedlander. 197 7 ). Halflife is based on the assumptions that when two particles coalesce the total volume of particles is conserved, and that the particle size distribution remains monodispersed. that is to say, all particles are the same size.

Several authors compute aggregation time scales in this way. McCave (1984) calculates time scales for aggregation by a number of encounter mechanisms to determine the range of particle sizes over which each dominates. McCave (19S5) calculates aggregation and deposition time scales for particles in the nepheloid layer to determine whether aggregation or single-grain deposition prevails. Logan et al. (1995) compare aggregation time scales for transparent exopolymer particles (TEP) and diatoms to determine if the sinking of diatom blooms is controlled by TEP. Alternatively. Hill and Nowell (1990) calculate encounter rates for various species in suspension to infer dominant interactions and, from these. dominant mechanisms by which particles are removed from the water column.

Lick et al. (1992) compare estimates of aggregation time scales calculated using half-life to aggregation times calculated using a numerical model and find that halflives can be as much as 100 times larger than times predicted by the model. Bremer et al. (1995) also suggest that half-life is a poor estimate of aggregation time primarily because it ignores the effect of aggregate packing geometry. They address this effect by relaxing the assumption that effective volume remains constant and deriving an algebraic expression for flocculation time. Their formulation maintains the assumption that the particle size distribution is monodispersed.

Because of the assumption of monodispersity, the Bremer et al. (1995) formulation is limited to aggregation caused by turbulent shear. However, for shear rates typically 
found in the ocean, encounter through differential settling is equally important for particles larger that $\sim 8 \mu \mathrm{m}$ (McCave, 1984). To address the issues discussed above. a new method is presented for calculating aggregation time based on a power law distribution. Because a fixed form of the size distribution is assumed. this method is considerably faster and less complicated than the numerical models mentioned above. 


\section{Chapter 2}

\section{Background}

\subsection{Coagulation Models}

The continuous coagulation equation. or stochastic collection equation. has the form (Müller, 1928)

$$
\begin{aligned}
\frac{\partial f(v, t)}{\partial t} & =-f(v, t) \int_{0}^{\infty} \beta(v, u) f(u, t) d u \\
& +\frac{1}{2} \int_{0}^{v} \beta(u, v-u) f(u, t) f(v-u \cdot t) d u
\end{aligned}
$$

where $f(v, t)$ is the number density for the volume interval $v$ to $v+d v, u$ and $v$ are particle volumes, and $\beta(v, u)$ is a coagulation kernel that describes the frequency of successful particle collisions. Equation (2.1) describes the rate at which the number of particles in a given size interval changes with time as a result of the addition and removal of particles. The first term describes the rate at which particles of volume $v$ contact particles of any volume to form particles larger than $v$. The second term describes the rate at which particles of volume $v$ are formed by interactions of particles whose volumes sum to $v$. The coefficient $\frac{1}{2}$ comes about because a single particle is formed for each two-particle collision. The rate of decrease in the total number concentration of particles, $N_{T}$, can be found by integrating $(2.1)$ over all volumes to 
give (Müller. 1928)

$$
\frac{d N_{T}}{d t}=-\frac{1}{2} \int_{0}^{\infty} \int_{0}^{\infty} \beta(u, v) f(u, t) f(v, t) d u d v
$$

Together, (2.1) and (2.2) describe a system in which total solid particle volume is conserved, but total particle number decreases due to aggregation.

If particles are allowed to leave the system due to settling: then an additional loss term must be included. Friedlander (19iT) gives the expression for the change in number concentration with time with the inclusion of settling losses as

$$
\begin{aligned}
\frac{\partial f(v, t)}{\partial t} & =-f(v, t) \int_{0}^{\infty} \beta(v, u) f(u, t) d u \\
& +\frac{1}{2} \int_{0}^{v} \beta(u, v-u) f(u, t) f(v-u, t) d u-\frac{w_{s}(v)}{z} f(v, t),
\end{aligned}
$$

where $z$ is water depth. and $w_{s}(v)$ is the settling velocity of a particle with volume $v$. In this model, it is assumed that the control volume is a well mixed box and that settling losses are layer averaged. The change in total number concentration is given by (Farley and Morel, 1986)

$$
\frac{d N_{T}}{d t}=-\frac{1}{2} \int_{0}^{\infty} \int_{0}^{\infty} 3(u \cdot v) f(u, t) f(v \cdot t) d u d v-\int_{0}^{\infty} \frac{w_{s}(v)}{z} f(v \cdot t) d v .
$$

and the rate of loss of total volume. $V_{T}$, is given by (Farley and Morel. 1986)

$$
\frac{d V_{T}}{d t}=-\int_{0}^{\infty} v \frac{w_{s}(v)}{z} f(v, t) d v
$$

Scott (1968) derives analytical solutions for (2.1) with Gaussian and bidisperse initial particle size distributions and three forms of the coagulation kernel: proportional to the sum of interacting particle volumes, proportional to the product of interacting particle volumes, and a constant. The first two kernel forms are non-physical in that they do not correspond to any real encounter mechanism, while the constant kernel approximates encounter by Brownian motion. These solutions cannot be used to model marine coagulation because the forms of $\beta$ do not represent the dominant 
encounter mechanisms, and because they do not allow for the inclusion of other processes such as settling losses.

Several approximate methods are available for predicting the size distribution of a coagulating suspension. Among them is the method of moments in which a size distribution is modeled by tracking its moments with time. A second method involves assuming the form of the distribution and tracking its parameters. such as mean and standard deviation. Kostoglou and Karabelas (1994) briefly describe these and other approximate methods.

Another approach. which Kostoglou and Karabelas refer to as direct numerical attack', involves numerically integrating the coagulation equation. Written in discrete form, (2.1) becomes (Drake. 1972)

$$
\frac{d N_{i}}{d t}=-N_{i} \sum_{j=1}^{\infty} \beta_{i, j} N_{j}+\frac{1}{2} \sum_{j=1}^{i-1} \beta_{j, i-j} N_{j} N_{i-j}
$$

where $N_{i}$ is particle number concentration in class $i$ and $i$ and $j$ refer to particle classes. For each particle size. an differential equation similar to (2.6) is required. and the system of differential equations is stepped forward in time. This method is known as the population balance approach. The type of model that will be considered here is the zero-order sectional model. in which the particle size distribution is approximated by a histugram with a constant size distribution in each cell or section. Higherorder sectional models assume a particle size distribution that can be described by a polynomial. In order to accommodate a large range of particle sizes. geometric sectional models employ sections with widths that increase geometrically with particle volume.

In laboratory experiments (Oles, 1992; Lick and Huang, 1993; Spicer and Pratsinis, 1996), it is observed that aggregating fine particle suspensions undergo abrupt transition from the unflocculated to the flocculated state. After a given time. during which median particle size remains close to its initial value, intense aggregation takes place, and median particle size increases exponentially until a steady state size is reached. It is hypothesized that the steady state size results from a balance between 


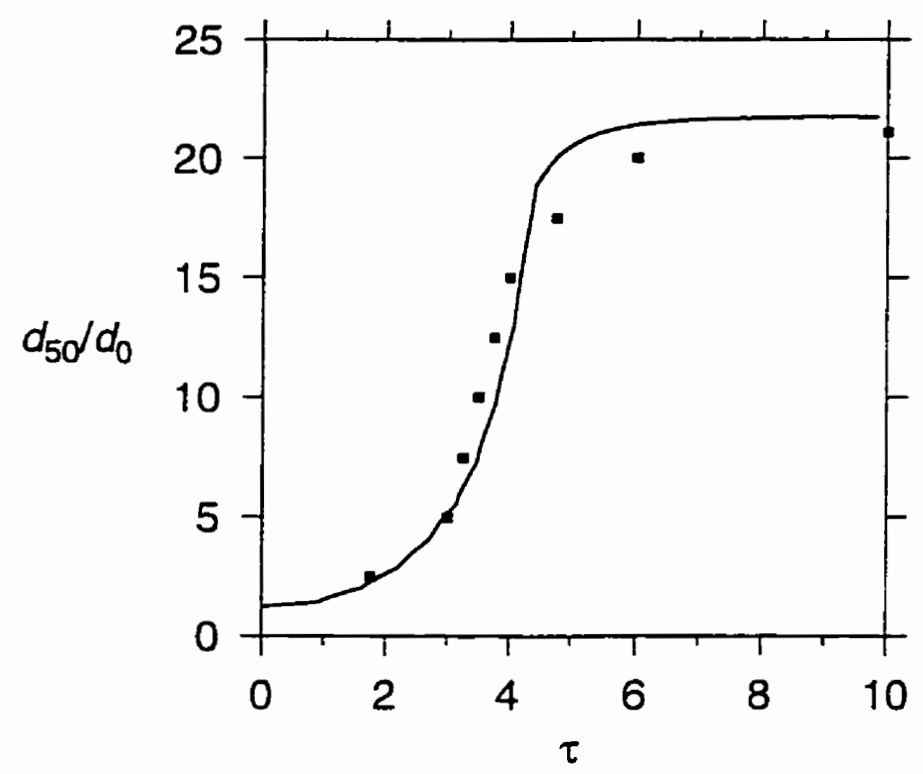

Figure 2.1: Nondimensional median diameter $\left(d_{50} / d_{0}\right)$ as a function of nondimensional time $(\tau)$ for an aggregating, fine sediment suspension showing experimental data from Oles (1992) (squares) overlayed with model output from Hill and Nowell (1995) (solid line).

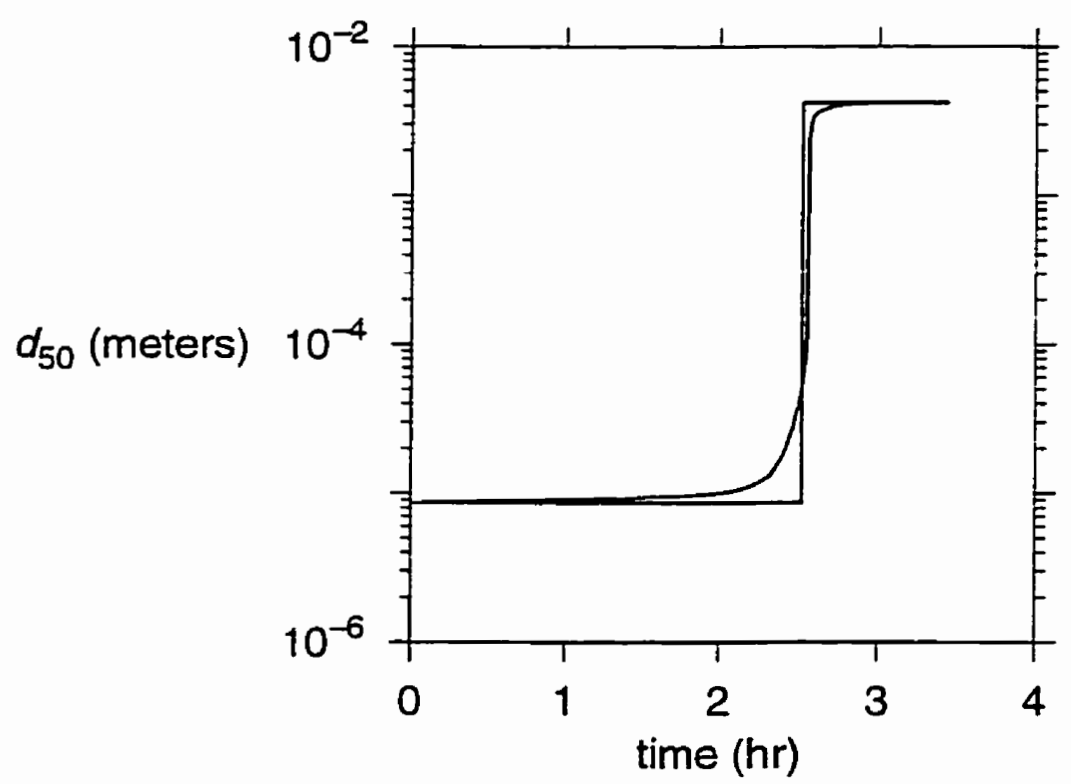

Figure 2.2: Median diameter $\left(d_{50}\right)$ as a function of time $(t)$ predicted by Hill and Nowell (1995)'s aggregation model. Overlaved is a step function approximation to the curve. 
aggregation and breakup forces (Oles. 1992).

Sectional models predict this behaviour (Lick et al.. 1992: Lick and Huang, 1993: and Hill and Nowell. 1995). Median diameter, $d_{50}$, of particles in suspension changes slowly until the flocculation time. after which $d_{50}$ increases rapidly (Figure 2.1). Because there is a clear transition between the two states, this behaviour lends itself to a step-function approximation of the form

$$
d_{50}= \begin{cases}d_{0}, & \text { if } t<t_{\text {floc }} \\ d_{\text {max }}, & \text { if } t \geq t_{\text {floc }},\end{cases}
$$

where $d_{0}$ is the initial mean diameter. $d_{\max }$ is the maximum floc diameter. and $t_{f l o c}$ is the flocculation time (Figure 2.2). A simple method for estimating $t_{\text {floc }}$ would allow for direct calculation of the most important information to come from aggregation models. without the computational effort required to track the entire size distribution with time.

\subsection{Particle Encounter Mechanisms}

The encounter-rate kernel can be broken into three parts so that (Hill et al.. 1992)

$$
3_{i j}=\alpha_{i j} E_{i j} K_{i j}
$$

where $\alpha_{i j}$ is the sticking efficiency between particles of types $i$ and $j . E_{i j}$ is the contact efficiency between these particles, and $K_{i j}^{-}$is their encounter rate. The rate at which a particle of type $i$ sweeps out a volume of fluid and encounters particles of type $j$ is described by its encounter rate

$$
K_{i j}=\frac{\pi}{4}\left(d_{i}+d_{j}\right)^{2} u_{r}
$$

where $d_{i}$ and $d_{j}$ are the diameters of particles of type $i$ and $j$, and $u_{r}$ is the relative velocity between them. which is dependent on the encounter mechanism at work.

Three mechanisms are generally regarded to be the most important in natural aqueous suspensions (O'Melia and Tiller, 1993). The first mechanism, Brownian 
motion, describes the random motion of particles due to thermal effects. The relative velocity for this mechanism is given by (Smoluchowski. 1917)

$$
u_{r}=\frac{8 k_{B} T}{3 \pi \mu d_{i} d_{j}}
$$

where $k_{B}$ is Boltzmann's constant, $T$ is absolute temperature. and $\mu$ is the dynamic viscosity of the fluid medium. This mechanism has been found to dominate for particles of similar size below 1.5 to $8 \mu \mathrm{m}$ in diameter (McCave. 1984).

For particles larger that $d \sim 8 \mu \mathrm{m}$ and conditions representative of the ocean. differential settling and turbulent shear dominate particle encounter (MICCave. 1984). Differential settling encounter results when particles of different sizes and/or densities settle past one another under the force of gravity. In this case. $u_{r}$ is simply given by (Pruppacher and Klett. 1980)

$$
u_{r}=\left|w_{s_{j}}-w_{s_{i}}\right|
$$

where $w_{s_{j}}$ and $w_{s_{i}}$ are the settling velocities of particles of types $j$ and $i$. Turbulent shear is the mechanism by which particles encounter one another through the action of turbulent eddies. The relative velocity is given by (Saffman and Turner. 1956: Delichatsios and Probstein, 1975),

$$
u_{r}= \begin{cases}0.2 G\left(d_{i}+d_{j}\right) & \text { for }\left(d_{i}+d_{j}\right) \ll \lambda_{k} \\ 1.3 \tau\left[\varepsilon\left(d_{i}+d_{j}\right)\right]^{1 / 3} & \text { for }\left(d_{i}+d_{j}\right) \gg \lambda_{k} .\end{cases}
$$

where $G=\left(\frac{\varepsilon}{\nu}\right)^{1 / 2}$ is the shear rate $^{1} . \varepsilon$ is the dissipation rate of turbulent kinetic energy, $\nu$ is the kinematic viscosity of the suspending medium, and $\lambda_{k}=\left(\frac{\nu^{3}}{\varepsilon}\right)^{1 / 4}$ is the Kolmogorov scale (Tennekes and Lumley, 1972), the length scale of the smallest eddies. A discontinuity exists for particles $d_{i}, d_{j} \sim 0\left(\lambda_{k}\right)$. Based on laboratory study, Hill et al. (1992) suggest the lower formulation of $u_{r}$ for $\left(d_{i}+d_{j}\right) \gg \lambda_{k}$ be used for intermediate-sized particles.

\footnotetext{
${ }^{1}$ Although the symbol $\dot{\gamma}$ has been adopted for shear rate by the Society of Rheology (Dealy, 1984), the symbol $G$ is used here in order to be consistent with oceanography literature.
} 
Placing (2.11) and (2.12) into (2.9), the encounter rates for differential settling and turbulent shear are

$$
K_{i, j}^{-}=\frac{\pi}{4}\left(d_{i}+d_{j}\right)^{2}\left|w_{s_{j}}-w_{s_{i}}\right|,
$$

and

$$
\Pi_{i, j}^{-}=0.16 G\left(d_{i}+d_{j}\right)^{3}
$$

respectively. These expressions show that encounter rates for both differential settling and turbulent shear encounter have a strong diameter dependence. Therefore. encounter rate coefficients between large particles are much greater than between small particles.

The stickiness of particles. quantified by their sticking efficiency, is the ratio of the rate at which particles stick to the rate at which they make contact. Particle stickiness is highly variable, ranging from $<10^{-3}$ (Weilenmann et al., 1989) to about 1 (Alldredge and McGillivary. 1991). Stickiness has been found to be sensitive to the presence of dissolved organic matter and the ionic strength of the suspending medium (Weilenmann et al.. 1989), but it is assumed to be independent of particle size.

Contact efficiency, $E_{i j}$, is the ratio of the rate at which particles make contact to the rate at which they encounter one another. The value of $E_{i j}$ depends on the assumed model for particle encounter (Han and Lawler. 1992). In the 'rectilinear' model. all hydrodynamic effects are ignored, and any two particles that encounter one another will make contact. or $E_{i j}=1$. In the "curvilinear' model. particles are assumed to be solid spheres that follow streamlines. Flow divergence around obstacles causes particles initially within an area of interaction to avoid one another. For differential settling (Pruppacher and Klett, 1980)

$$
E_{i j} \approx \frac{p^{2}}{2(1+p)^{2}},
$$

and for turbulent shear (Hill et al., 1992)

$$
E_{i j} \approx \frac{7.5 p^{2}}{(1+2 p)^{2}},
$$


where $p=\frac{d_{i}}{d_{j}}$ is the ratio of particle diameters of type $i$ and $j\left(d_{i} \leq d_{j}\right)$.

Recent experimental work by $\mathrm{Li}$ and Logan (1997a, b) demonstrates that neither model of particle contact accurately predicts observed contact efficiencies. For differential settling encounter, contact efficiencies are an order of magnitude higher than predicted by the curvilinear model and two orders of magnitude lower than predicted by the rectilinear model ( $\mathrm{Li}$ and Logan, 1997a). For turbulent shear encounter. contact efficiencies are five orders of magnitude higher than predicted by the curvilinear model and two orders of magnitude lower than predicted by the rectilinear model ( $\mathrm{Li}$ and Logan, 1997 $\mathrm{b}$ ). They attribute the inaccuracy of these contact models to the high permeability of aggregates. Aggregates are not solids spheres. but rather highly porous structures. As a result. the curvilinear contact model underpredicts contact efficiencies because it does not take into account flow through the aggregate. Stolzenbach (1993) also emphasizes the importance of permeability in particle contact. However, aggregates are not uniformly porous ( $\mathrm{Li}$ and Logan. 199ia). Instead. they contain macropores through which small particles may travel and avoid contact: thus contact efficiencies are lower than predicted by the rectilinear model.

$\mathrm{Li}$ and Logan $(1997 \mathrm{a}, \mathrm{b})$ propose alternate expressions for $E_{i, j}$ as a function of particle size for differential settling and turbulent shear encounter. However. due to the complexity of these expression and the need for unknown inputs. such as filtration efficiency, the simplifying assumption is made that $E_{i, j}=0.01$ since this agrees with their observations for both encounter mechanisms. Future work is needed to incorporate size and geometry dependent expressions.

\subsection{Settling Velocity and Fractal Dimension}

The large particles that result from the aggregation of smaller particles have random structures that can be characterized using fractal geometry (Meakin, 1991). Rather than coalescing to form particles with volumes equal to the sum of the volumes of their component particles, these 'flocs' have effective volumes greater than the sum 
of their components. The relationship between the volume of solid material within a floc, $v_{s}$, and floc diameter. $d$. is given by (Logan and Wilkinson. 1990)

$$
v_{s}=v_{0}\left(\frac{d}{d_{0}}\right)^{D 3} .
$$

where $v_{0}$ is the component grain volume, and $D 3$ is the 3-D fractal dimension. If $D 3=3$, then the particle is a coalesced sphere: if $D 3<3$. then the particle is a floc with a bulk density lower than that of its components.

The fractal dimension of marine flocs typically is determined by comparing floc settling velocities to diameters. Stokes Law gives the settling velocity of a sphere of density $\rho_{p}$ and diameter $d$ as

$$
w_{s}=\frac{\left(\rho_{p}-\rho\right) g d^{2}}{18 \mu} .
$$

where $g$ is the constant of gravitational acceleration, and $\rho$ and $\mu$ are the density and dynamic viscosity of the surrounding medium (water). The excess density of a fractal aggregate $\left(\rho_{p}-\rho\right)$ is related to that of a coalesced sphere $\left(\rho_{s}-\rho\right)$ by

$$
\rho_{p}-\rho=\left(\rho_{s}-\rho\right)\left(\frac{d}{d_{0}}\right)^{D 3-3} \text {. }
$$

so that (2.18) becomes

$$
w_{s}=\frac{\left(\rho_{s}-\rho\right) g d_{0}^{2}}{18 \mu}\left(\frac{d}{d_{0}}\right)^{D 3-1} .
$$

Dyer et al. (1996) report median settling velocities of $1 \mathrm{~mm} \mathrm{~s}^{-1}$ with a range of 0.1 to about $5 \mathrm{~mm} \mathrm{~s}^{-1}$, and floc sizes in the range 50 to $1000 \mu \mathrm{m}$. ten Brinke (1994). Syvitski et al. (1995) and Hill et al. (1997) also report floc diameters and settling velocities on the order of $1 \mathrm{~mm}$ and $1 \mathrm{~mm} \mathrm{~s}$, respectively. Based on (2.19), marine flocs have fractal dimensions in the range $1.5 \leq D 3 \leq 2.5$ (ten Brinke, 1994; Hill et al., 1997).

The fractal nature of flocs has a great effect on the aggregation process. Because flocs have larger effective volumes than coalesced particles, encounter rates are enhanced because of the strong diameter dependence (see (2.13) and (2.14)). 


\subsection{Estimates of Flocculation Time}

The traditional definition of flocculation time is the time required for an initially monodisperse, aggregating suspension to reduce its total particle number by half. in other words, its half-life. Based on theoretical considerations by Smoluchowski (191i) (sensu Friedlander, 19i7), it is assumed that an initially monodisperse suspension remains monodispersed for a short time after the onset of aggregation, and that the effective volume of particles in suspension is constant (i.e. $D 3=3$ ). Substituting turbulent-shear encourtếi-rate coefficients into (2.6), the discrete coagulation equation is

$$
\frac{d N_{i}}{d t}=-N_{i} \sum_{j=1}^{\infty} 0.16 G\left(d_{i}+d_{j}\right)^{3} N_{j}+\frac{1}{2} \sum_{j=1}^{i-1} 0.16 G\left(d_{j}+d_{i-j}\right)^{3} N_{j} N_{i-j}
$$

If the size distribution is monodispersed, then $d_{i} . d_{j}=d$ and

$$
\frac{d N_{i}}{d t}=-N_{i} \sum_{j=1}^{\infty} 0.16(\delta) G d^{3} N_{j}+\frac{1}{2} \sum_{j=1}^{i-1} 0.16(S) G d^{3} N_{j} N_{i-\jmath}
$$

Summing over all $i$ gives

$$
\frac{d N_{T}}{d t}=-0.16(4) G d^{3} N_{T}^{2}
$$

where $N_{T}$ is the total number concentration of particles in suspension. Since the system is volume conserving, $\frac{\pi}{6} d^{3}: N_{T}$ is a constant equal to the volume fraction of particles, $\dot{\phi}_{0}$. Therefore, $(2.22)$ becomes

$$
\frac{d N_{T}}{d t}=-\frac{0.16(24)}{\pi} G \phi_{0} N_{T} .
$$

Integrating (2.23) gives

$$
\ln \frac{N_{T}(0)}{N_{T}}=\frac{0.16(24)}{\pi} G \phi_{0} t
$$

and the equation for half-life is given by

$$
t_{\mathrm{L} / 2}=\frac{\pi \ln 2}{0.16(24) G \phi_{0}} .
$$


By using half-life to calculate flocculation times, McCave (1984. 1985) and Logan et al. (1995) implicitly make the assumptions that the suspension remains monodispersed and that aggregate volume is conserved.

Bremer et al. (1995) draw attention to the fact that calculating flocculation times with half-life ignores the role of aggregate geometry. They present an alternate expression for flocculation time which takes into account the fractal dimension of flocs but retains the assumption that the size distribution remains monodispersed. Under the assumption that all of the particles in suspension are of the same size. the number of component grains in any particle is given by

$$
N_{p}=\left(\frac{d}{d_{0}}\right)^{D 3}
$$

where $d$ is particle diameter, and $d_{0}$ is the diameter of component grains. The loss rate of particles aggregating due to turbulent shear is given by (2.22).

The initial number concentration of particles is equal to the volume fraction of particles divided by the volume of a component particle or.

$$
V_{0}=\frac{6 \phi_{0}}{\pi d_{0}^{3}}
$$

The number concentration of particles at a given time is calculated. then. by dividing the initial number concentration by the number of component grains in each particle. $N_{p}$, so

$$
N_{T}=\frac{6}{\pi} \phi_{0} d_{0}^{D 3-3} d^{-D 3}
$$

The expression for flocculation time, $t_{\text {floc }}$, is determined from

$$
t_{f l o c}=\int_{d_{0}}^{d_{c}} \frac{\mathrm{d} t}{\mathrm{~d} d} \mathrm{~d} d
$$

where $d_{c}$ is some critical particle diameter. Bremer et al. (1995) define this critical size as the particle size above which the aggregation rate increases abruptly. At this time, macroscopic changes in the suspension occur, such as visible sedimentation. 
Differentiating (2.28) with respect to $d$, inverting (2.22), and substituting (2.28), (2.29) becomes

$$
t_{f l o c}=\int_{d_{0}}^{d_{c}} \frac{\pi}{0.16(24)} D 3 G^{-1} \phi_{0}^{-1} d_{0}^{3-D 3} d^{D 3-4} \mathrm{~d} d .
$$

For $D 3<3$, the flocculation time is given by

$$
t_{f l o c}=\frac{\pi}{0.16(24)} \frac{D 3}{3-D 3} G^{-1} \phi_{0}^{-1}\left(1-q^{D 3-3}\right) .
$$

where $q=\frac{d_{c}}{d_{0}}$.

For $D 3=3$, the flocculation time derived using the Bremer et al. (1995) method is equivalent to the expression given by (2.24). Solving (2.30) for $D 3=3$ gives

$$
t_{f l o c}=\frac{3 \pi}{0.16(24)} G^{-1} \phi_{0}^{-1} \ln q .
$$

At the half-life. $N_{T}=\frac{1}{2} N_{T}(0)$ so $N_{p}=2$. Rearranging (2.26), $q=N_{p}^{1 / 3}$ and

$$
t_{f l o c}=\frac{\pi \ln 2}{0.16(24) G \phi_{0}} .
$$

Bremer et al. (1995) propose the expression given by (2.31) as a means of determining the flocculation time of a given suspension. but they provide minimal experimental evidence and fail to compare it to model results. Because the size distribution is assumed to be monodispersed, (2.31) cannot be used to calculate the flocculation time of a suspension undergoing aggregation due to differential settling. All particles in a monodispersion settle at the same speed, so particles cannot overtake one another and make contact in that way. Simply ignoring this mechanism of particle encounter leads to inaccurate estimates of flocculation time, because for particles larger than $8 \mu \mathrm{m}$, differential settling is an important encounter mechanism. Except for high-shear environments, both mechanisms must be considered. Therefore, a second method that assumes a different form for the size distribution is needed. 


\section{Chapter 3}

\section{Methods}

The aim of this work is to develop a method for estimating the time required for an aggregating suspension to go from the unflocculated to fully flocculated state. without the computational complexity of full numerical models. The criterion to be used is that the median diameter of particles in suspension is midway between the component grain diameter and the maximum diameter that flocs can attain. This criterion is an arbitrary one. but it allows for comparison among methods. In addition. the time interval over which the transition occurs is short compared to the flocculation time. so any reasonable criterion would give similar results.

\subsection{Sectional Model}

In their review of zero-order coagulation models, Kostoglou and Karabelas (1994) report that models of the type proposed by Batterham et al. (1981) give the best overall performance. The model of Batterham et al. conserves particle mass. and it most closely approximates the analytical solutions for constant and sum encounter kernels. Also, its form is computationally efficient.

The Batterham et al. (1981) model is a discrete geometric sectional model. This means that the zero-order particle-size distribution is further simplified by assuming that only particles of discrete volumes may exist, so that particles in section $j$ have 
volume equal to $2^{j-1} v_{0}$ where $v_{0}$ is the initial mean volume of particles in suspension. The lower and upper boundaries of a given section $j$ are (Koh et al., 1987)

$$
\begin{aligned}
& \text { lower boundary }=\frac{3}{4} 2^{j-1} v_{0} \\
& \text { upper boundary }=\frac{3}{2} 2^{j-1} v_{0} .
\end{aligned}
$$

Section boundaries are always midway between neighbouring discrete volumes.

According to the population balance approach, an ordinary differential equation expressing the rate of change of dimensionless particle number, $n$, with dimensionless time, $\tau$, is required for each section. For section $i$. the Batterham et al. (1981) model states

$$
\begin{gathered}
\frac{d n_{i}}{d \tau}=\frac{3}{8} \hat{\beta}_{i-2 . i-1} n_{i-2} n_{i-1}+\frac{3}{4} \hat{\beta}_{i-1 . i} n_{i-1} n_{i}+\hat{\beta}_{i-1 . i-1} n_{i-1}^{2} \\
+\sum_{m=0}^{i-2} \frac{2^{i}+2^{m}}{2^{i}} \hat{\beta}_{i, m} n_{i} n_{m}-\sum_{m=0}^{h-1} q_{i, m} \hat{3}_{i, m} n_{i} n_{m} \\
q_{i, m}= \begin{cases}2, & \text { if } i=m \\
1, & \text { otherwise. }\end{cases}
\end{gathered}
$$

where for the sections below, only the indicated terms are used:

$$
\begin{aligned}
& i=1, \text { fifth term } \\
& i=2 . \text { second, third and fifth terms } \\
& i=h . \text { first and third terms. }
\end{aligned}
$$

The coefficients $\hat{\beta}$ are dimensionless encounter-rate kernels, $h$ is the number of sections, and

$$
\tau=\beta\left(v_{0}, v_{0}\right) N_{0} t,
$$

where $\beta\left(v_{0}, v_{0}\right)$ is the encounter-rate kernel for particles in the first section, $N_{0}$ is the initial particle number concentration, and $t$ is time. 
The first four terms in (3.1) are growth terms for section $i$. The first two of these handle interactions that produce boundary-sized aggregates. These aggregates are divided such that half of the volume is put into the lower section. and half into the upper section. The first term accounts for interactions between particles from the two preceding sections. Aggregates formed in this way have a volume of $\left(2^{i-3}+2^{i-2}\right) v_{0}$. If, for example, $i=4$, then the aggregate volume is $6 v_{0}$, which is half-way between $4 v_{0}$ and $8 v_{0}$. As a result, $\frac{1}{2}\left(\frac{2^{i-3}+2^{i-2}}{2^{i-1}}\right)$. or $\frac{3}{8}$, of a particle is put into section $i$. Similarly, the second term describes the rate at which particles in section $i$ aggregate with particles in the preceding section. Again for $i=4$, aggregate volume is $12 v_{0}$, midway between $8 v_{0}$ and $16 v_{0}$, and $\frac{1}{2}\left(\frac{2^{i-2}+2^{i-1}}{2^{i-1}}\right)$, or $\frac{3}{4}$, of a particle is put into section $i$. The third term describes the rate at which discrete-sized particles are formed from interactions between particles in the preceding section. The fourth growth term accounts for interactions between particles in section $i$ and particles in sections below and including $i-2$. These interactions produce particles larger that $2^{i-1} v_{0}$, but within the section boundary. For these aggregates, all of the volume remains in section $i$. but the number is adjusted accordingly. Finally, the loss rate of particles from section $i$ is described by the fifth term.

Dimensionless encounter-rate kernels, $\hat{3}$. are defined as

$$
\hat{3}_{i, j}=\frac{3\left(v_{2}, v_{j}\right)}{3\left(v_{0}, v_{0}\right)}
$$

where $\beta\left(v_{i}, v_{j}\right)$ is the encounter-rate kernel for particles of volume $v_{i}$ and $v_{j}$. The forms of $\beta\left(v_{i}, v_{i}\right)$ and $\beta\left(v_{0}, v_{0}\right)$ depend on encounter mechanism. If. for example. the sum kernel described in Section 2.1 is used, then

$$
\begin{aligned}
\hat{\beta}_{i, j} & =\frac{v_{i}+v_{j}}{v_{0}+v_{0}} \\
& =\frac{1}{2}\left(\hat{v}_{i}+\hat{v}_{j}\right),
\end{aligned}
$$

where $\hat{v}_{i}=\frac{v_{i}}{v_{0}}$ is the dimensionless volume of a particle in section $i$, or $\hat{v}_{i}=2^{i-1}$. To include the fractal nature of flocs, $\hat{\beta}$ is calculated using the diameter that a floc in 
section $j$ must have if its solids volume is $2^{j-t} v_{0}$. Rearranging (2.17) for floc diameter gives

$$
d=d_{0}\left(\frac{v_{s}}{v_{0}}\right)^{\frac{1}{D 3}}
$$

or

$$
d_{j}=d_{0}\left(2^{j-1}\right)^{\frac{1}{D 3}}
$$

Therefore, for a value of $h$. the maximum particle diameter varies depending on the fractal dimension.

In order to study the effects of settling losses, it is necessary to modify (3.1) according to the rate expression of Friedlander (197i) given by (2.3). The resulting model rate equation is

$$
\begin{aligned}
\frac{d n_{i}}{d \tau} & =\frac{3}{S} \hat{\beta}_{i-2, i-1} n_{i-2} n_{i-1}+\frac{3}{4} \hat{\beta}_{i-1, i} n_{i-1} n_{i}+\hat{\beta}_{i-1, i-1} n_{i-1}^{2} \\
& +\sum_{m=0}^{i-2} \frac{2^{i}+2^{m}}{2^{i}} \hat{\beta}_{i, m} n_{i} n_{m}-\sum_{m=0}^{h-1} q_{i, m} \hat{\beta}_{i, m} n_{i} n_{m}-\frac{1}{3_{0} V_{0}} \frac{w_{s_{i}}}{z} n_{i} .
\end{aligned}
$$

The settling velocity of a floc is related to that of its component grains by $w_{s_{i}}=$ $w_{s_{0}}\left(\frac{d_{i}}{d_{0}}\right)^{D 3-1}$.

To summarize, this model predicts the dimensionless particle number concentration in each size class as a function of dimensionless time according to (3.1) or (3.5). depending on whether settling losses are included. Model inputs are $d_{0}, V_{0} . G, \alpha$. $E, D 3$, and $h$. If (3.5) is used, then $\rho_{s}$, the density of component grains. must also be specified. The model is run using a numerical solving routine. The chosen routine is a third order semi-implicit Runge-Kutta ODE solver. with adjustable step and pre-specified accuracy (Villadsen and Michelsen, 1978).

To check the accuracy of the model. it was run using the constant kernel for an initially monodisperse suspension and the sum kernel for an initially bidisperse suspension, with $D 3=3$ in each case, and then compared against the analytical solutions given in Appendix A. The results are shown in Figure 3.1. The model gives very good agreement for the case of an initially monodisperse suspension with the 

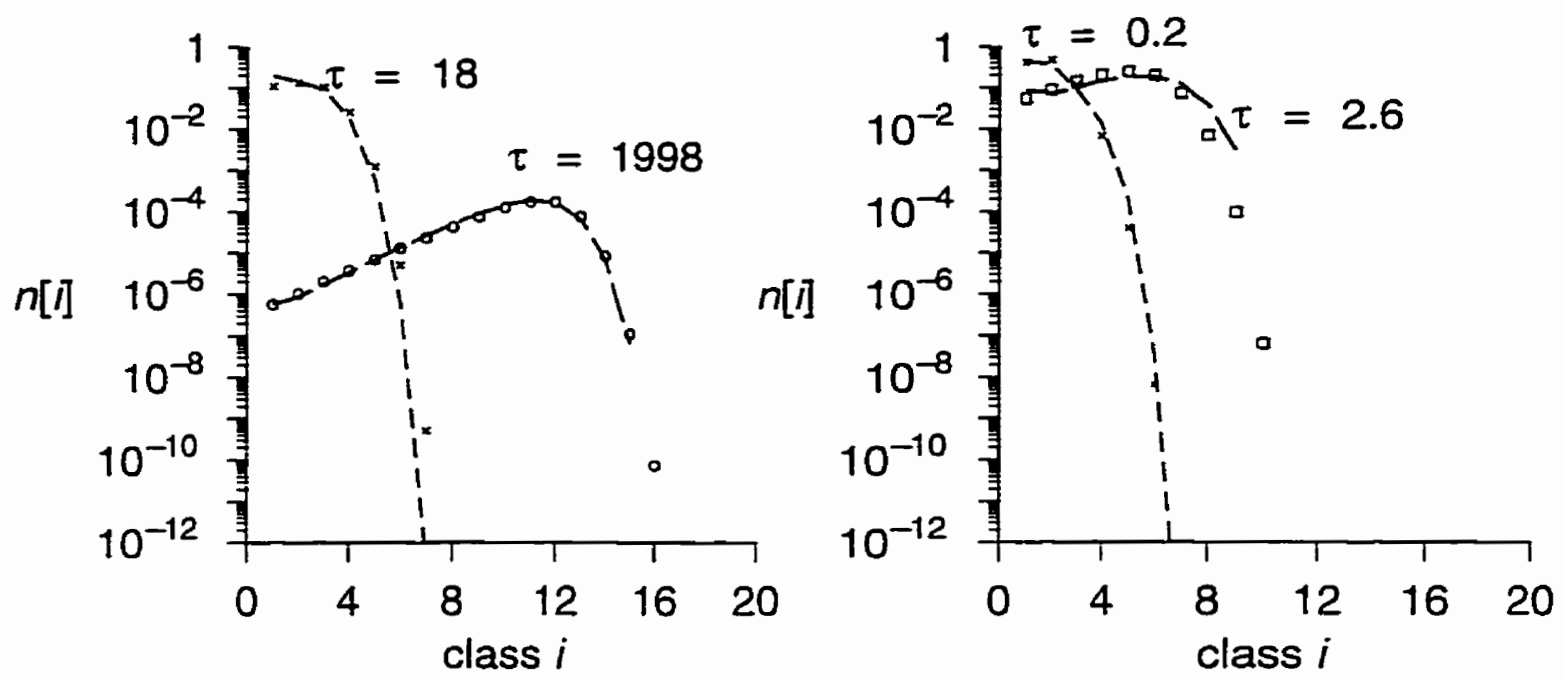

Figure 3.1: Comparison of modeled and analytical particle size distributions for (left) the sum kernel and a monodisperse initial suspension, and (right) the sum kernel and a bidisperse initial condition. Plotted is nondimensional number concentration $(n)$ in each section at various nondimensional times $(\tau)$. Dashed lines represent the analytical solution and symbols represent model output.

constant kernel. For the initially bidisperse suspension. a smearing effect becomes noticeable because the initial distribution used in the model is only an approximation of that in the analytical solution. Also, the model cannot represent a truly polydisperse initial distribution. Instead. it is initialized with equal mass in the first and second size classes. so that there are monomers and dimers composed of particles of the same diameter.

The dimensionless flocculation time is determined based on the dimensionless median diameter, $d_{50}$. i.e. the diameter below which half of the mass in the system resides. Dimensionless median diameter is calculated by summing the mass of particles in increasing sections until over half of the mass has been accounted for. Then. linear interpolation is used to determine the exact value of $d_{50}$. Once $d_{50}$ is greater than half the dimensionless diameter of particles in the largest section, the actual flocculation time is determine by interpolating between the current step and the previous step. A small step size is used to ensure that linear interpolation does not introduce large errors.

Because of the way in which encounter-rate kernels are nondimensionalized, any 
effect of stickiness or encounter efficiency is removed. since they are assumed constant here for a given system and not related to particle size (see (3.3)). Dimensionless flocculation time is also independent of initial number concentration. according to (3.2), so $\alpha, E$, and $N_{0}$ do not appear in the discussion that follows. The forms of $\beta$ are derived from (2.8) and either (2.13) or (2.13) and (2.14), depending on the encounter mechanisms to be considered. Encounter-rate coefficients are additive (O'Melia and Tiller, 1993) so the encounter rate for turbulent shear with differential settling encounter is equal to the sum of the encounter-rate coefficients given by (2.13) and (2.13).

To simplify notation. the Batterham et al. model is referred to as the 'full' model. as opposed to the 'reduced' model to be proposed in Section 3.3, and the dimensionless flocculation time predicted by this model is represented by $\tau_{B}$.

\subsection{Monodispersion Estimate of Flocculation Time}

To implement Bremer et al. (1995)'s formulation for flocculation time, (2.31), the volume fraction of particles must be calculated. It is given by

$$
\varphi_{0}=N_{0} v_{0}
$$

where $V_{0}$ is the initial number concentration of particle, and $v_{0}$ is the volume of a component particle. The flocculation time estimated using (2.31) is nondimensionalized as in (3.2), and is given the symbol $\tau_{M}$.

\subsection{Junge-dispersion Estimate of Flocculation Time}

In situ observations of marine particles reveal that they are distributed such that there is equal mass in geometrically increasing size bins (Lerman et al., 1977). This Junge distribution has the general form (Junge, 1963)

$$
f(d)=A d^{-b}
$$


where $A$ and $b$ are empirical constants. For the specific case described above. $b=4$. The number concentration of particles from $d$ to $d+\mathrm{d} d$ is given by (Hunt. 1980)

$$
\mathrm{d} N=f(d) \mathrm{d} d
$$

Mass distributions predicted by the Batterham et al. model are also approximately Junge distributed (see Figure 3.2). Mass concentration is roughly equal for small sections. but drops off for larger sections. In addition, the series of particle size distributions shows that the system evolves as a Junge distribution. As aggregation proceeds, mass is lost equally from the small sections and deposited into larger sections so that the mass distribution remains flat.

A method of estimation which is based on the assumption that the particle size distribution has the Junge form throughout its evolution has several advantages. First, it mimics the distributions predicted by the sectional model. as well as natural marine size distributions. Second. particles are allowed to have different sizes. which permits estimation of flocculation times for encounter due to differential settling. Finally, the aggregation equations become simplified.

For the purposes of illustration. the evolution of a continuous mass distribution will now be discussed. An alternate form of (3.6) is

$$
f(d)=f\left(d_{0}\right)\left(\frac{d}{d_{0}}\right)^{-4}
$$

where $f\left(d_{0}\right)$ is the particle size density function at $d_{0}$. If the suspension is undergoing aggregation, then $f(d)$ is also a function of time and the equation becomes

$$
f(d, t)=f\left(d_{0}, t\right)\left(\frac{d}{d_{0}}\right)^{-t}
$$

Using this expression for the particle-size density function, the behaviour of the entire suspension can be modeled simply by tracking $f\left(d_{0}, t\right)$ according to (2.6). Only the loss term is included because, for the smallest size, there is no source of particles. Expressed in terms of particle diameter rather than volume this gives,

$$
\frac{\partial f\left(d_{0}, t\right)}{\partial t}=-f\left(d_{0}, t\right) \int_{d_{0}}^{d_{k}} \beta\left(d_{0}, d\right) f(d, t) \mathrm{d} d .
$$



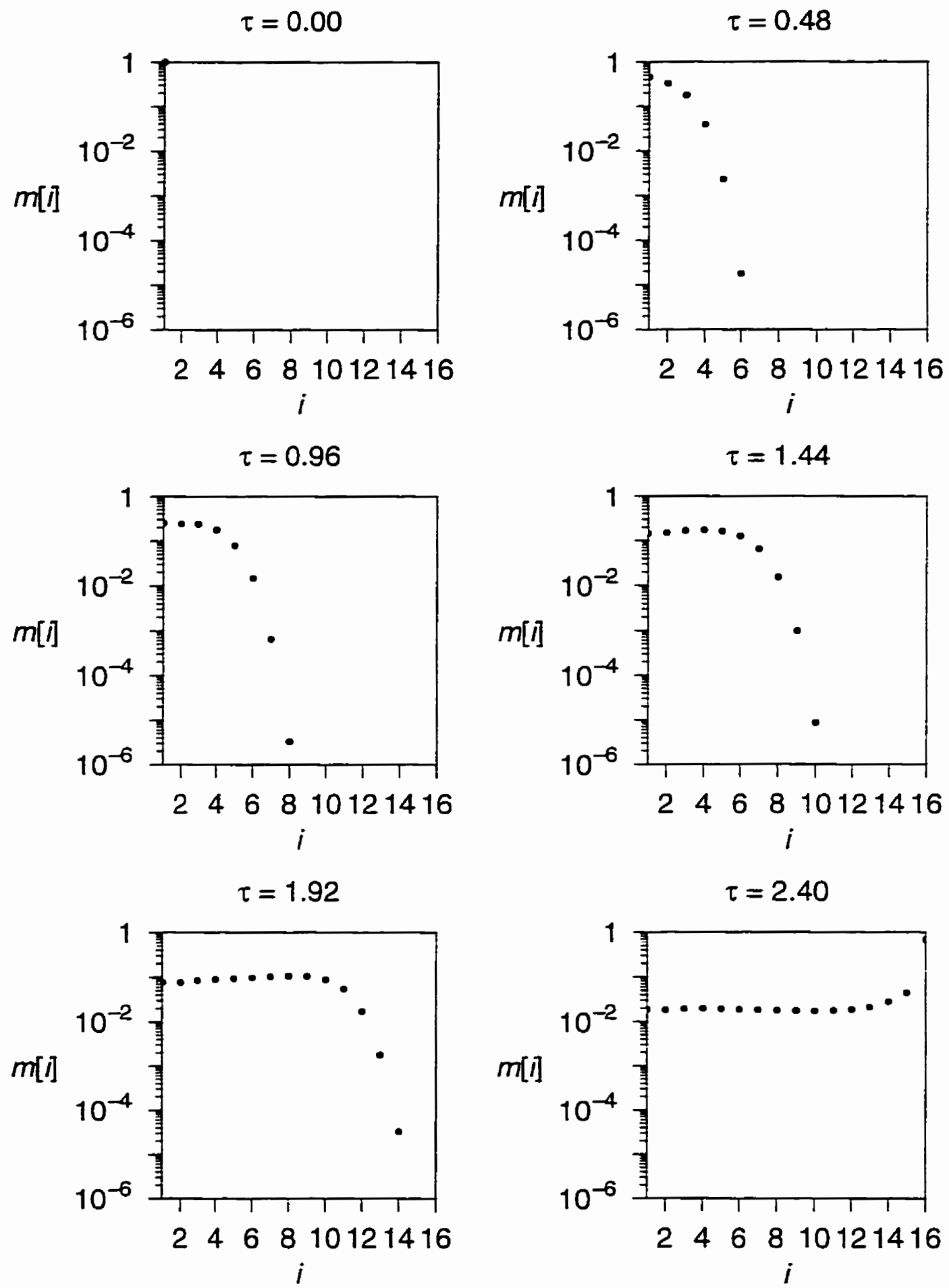

Figure 3.2: Sample series of mass distributions. Each plot shows nondimensional mass concentration $(m)$ in each section $(i)$ at a given nondimensional time $(\tau)$. This case is for turbulent shear encounter with 16 sections, and a fractal dimension of $D 3=2.0$. The flocculation time is $\tau_{\text {floc }}=2.228$. 


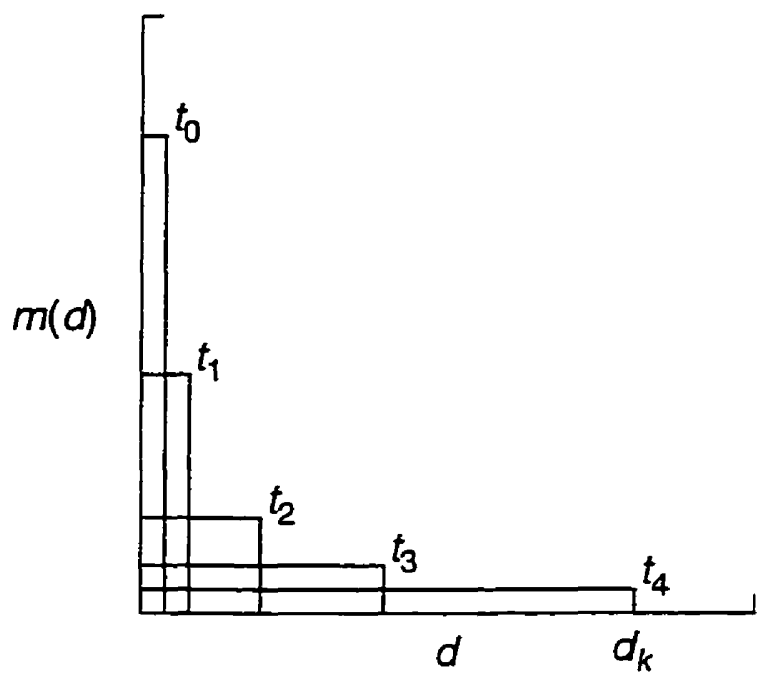

Figure 3.3: Schematic showing the evolution of a Junge-distributed mass distribution. At $t_{0}$, a given mass of particles is equally distributed over a narrow diameter range. As aggregation proceeds and the maximum diameter $\left(d_{k}\right)$ of particles increases. the mass of particles at each size decreases.

Since total solids volume must be conserved, the maximum particle size, $d_{k}$. must increase as aggregation proceeds and number decreases. Figure 3.3 illustrates the evolution of the mass distribution in time. Imposing the form of the size distribution in this way reduces the system of $h$ equations given in (2.6) to a single equation. which greatly reduces the model run time.

The numerical method is based on the discrete Junge distribution. A discrete distribution has several advantages over a continuous one. although both are equal with respect to computational efficiency. First. and most importantly, a model based on the discrete distribution more closely mimics the assumed size distribution of the full sectional model. In addition. such a model uses the same encounter rates based on discrete particle sizes. The use of the discrete distribution also removes any ambiguity regarding how to initialize the size distribution.

The evolution of the suspension is tracked based on the rate of loss of particles from the first section,

$$
\frac{d n_{1}}{d \tau}=-n_{1} \sum_{j=1}^{k} \hat{\beta}_{1, j} n_{j}
$$


where $k$ is the largest section containing particles. Initially, all of the volume resides in the first section. As the number of particles in that section begins to decrease. the equivalent volume is put into the second section so that the total volume is conserved and $k=2$. When the total volume of particles in the second section reaches that in the first, the total volume in the first and second sections are kept equal. The subsequent volume lost from sections 1 and 2 is put into the third section ( $k=3$ ), until such a time as the total volume in the first three sections is equal. This continues until there is equal volume in $h-1$ sections, at which time all of the volume lost from these sections is put into the last section.

By assuming a form of the size distribution. the number concentration of particles in any section is related to the number concentration of particles in the first. For those sections that contain equal total volume, the number concentration is given by

$$
n_{i}=\frac{n_{1} v_{0}}{2^{i-1} v_{0}}=2^{1-i} n_{1} .
$$

The total volume in the $k$ th section is calculated based on the total volume of particles in the system using the equation

$$
V_{T}=(k-1) n_{\mathrm{l}} v_{0}+n_{k} 2^{k-1} v_{0} .
$$

Because the system of equations described in (3.10) consists of a single differential equation. a simple fourth-order Runge-Kutta solver from Press et al. (1992) is used to step the equation forward in time. At each time step, $n_{1}$ and $k$ are evaluated, and the volume is distributed accordingly. Model inputs and the forms of $\beta$ are exactly the same as for the full model, as is the method for determining the dimensionless flocculation time. This model is referred to as the 'reduced' model, and the dimensionless flocculation time it estimates is given the symbol $\tau_{J}$. 


\section{Chapter 4}

\section{Analysis}

\subsection{Model Runs}

Full-model dimensionless flocculation times $\left(\tau_{B}\right)$ are compared to reduced-model dimensionless flocculation times $\left(\tau_{J}\right)$ or dimensionless flocculation times calculated using the formulation of Bremer et al. $\left(\tau_{M}\right)$ for three scenarios: (1) encounter due to turbulent shear. (2) encounter due to both turbulent shear and differential settling. and (3) aggregation with settling losses for (a) turbulent shear and (b) turbulent shear and differential settling. A variety of cases are compared in each scenario. The results are presented in Chapter 5 .

For the first scenario. there are four model inputs: $d_{0} . G, D 3$, and the size of the largest allowable particle, which is determined by the number of sections used, $h$. Of these. the variation in only two, $D 3$ and $h$. can affect dimensionless flocculation time. Because the only encounter mechanism is turbulent shear, and encounter-rate coefficients are nondimensionalized with respect to turbulent shear encounter between particles of size $d_{0}$, dimensionless flocculation times for all values of shear rate and initial particle size with respect to $D 3$ and $h$ collapse onto a single curve. Therefore. the model is run using six maximum particle sizes, $h=\{10,12,14,16,18,20\}$, and for each, six fractal dimensions are tested, $D 3=\{2.5,2.3,2.1,1.9,1.7,1.5\}$.

For the second, a number of cases are tested in which the relative importance of 


\begin{tabular}{|c|c|c|c|c|}
\hline name & $h$ & $D 3$ & $d_{0}[\mu \mathrm{m}]$ & $\rho_{\mathbf{s}}\left[\mathrm{kg} \mathrm{m}^{-3}\right]$ \\
\hline A1 & 14 & 1.5 & 24.6 & 1185 \\
\hline B1 & 16 & 1.5 & 9.8 & 1636 \\
C1 & & 1.6 & 15.1 & 1199 \\
\hline D1 & 18 & 1.6 & 6.3 & 1586 \\
E1 & & 1.7 & 9.8 & 1185 \\
\hline F1 & 20 & 1.6 & 2.7 & 2890 \\
G1 & & 1.7 & 4.3 & 1469 \\
H1 & & 1.8 & 6.6 & 1154 \\
\hline
\end{tabular}

Table 4.1: Model inputs for encounter due to turbulent shear and differential settling with $d_{\max }=10 \mathrm{~mm}$.

turbulent shear and differential settling is varied. Because large particles dominate aggregation. the maximum particle diameter and maximum settling velocity must be set to realistic values. From (3.4). the maximum particle diameter is a function of $D 3$ and $h$, i.e.

$$
d_{\max }=d_{0}\left(2^{h-1}\right)^{\frac{1}{D 3}}
$$

The value of $d_{0}$ is calculated based on $d_{\max }=\{10 \mathrm{~mm} .1 \mathrm{~mm} .0 .1 \mathrm{~mm}\}$. values which are based on the observed range of floc sizes (Dyer et al. 1996). The expression

$$
u_{s \max }=\frac{\left(\rho_{s}-\rho\right) g d_{0}^{2}}{18 \mu}\left(\frac{d_{\max }}{d_{0}}\right)^{D 3-1} .
$$

is used to calculate the value of $\rho_{s}$ which gives a maximum settling velocity of $1 \mathrm{~mm} \mathrm{~s}^{-1}$ (ten Brinke, 1994: Syvitski et al., 1995; Hill et al., 1997). Only those inputs which give reasonable density values, ranging from $\rho_{s}=1100 \mathrm{~kg} \mathrm{~m}^{-3}$ for diatoms (Smayda. 1970) to a typical mineral value of $\rho_{s}=3000 \mathrm{~kg} \mathrm{~m}^{-3}$ (Hurlbut and Klein. 197T). are used. The lists of test cases are shown in Tables 4.1 through 4.3. For given $D 3$ and $h$ values, the relative importance of turbulent shear encounter is varied by changing the shear rate, $G=\left\{0.1 \mathrm{~s}^{-1}, 0.5 \mathrm{~s}^{-1}, 1.0 \mathrm{~s}^{-1}, 5.0 \mathrm{~s}^{-1}, 10.0 \mathrm{~s}^{-1}\right\}$. These shear rates span deep-sea nepheloid-layer values of $0.084 \mathrm{~s}^{-1}$ (McCave, 1984) to continental shelf 


\begin{tabular}{|c|c|c|c|c|}
\hline name & $h$ & $D 3$ & $d_{0}[\mu \mathrm{m}]$ & $\rho_{\mathrm{s}}\left[\mathrm{kg} \mathrm{m}^{-3}\right]$ \\
\hline A2 & 10 & 1.5 & 15.6 & 1974 \\
B2 & & 1.6 & 20.3 & 1465 \\
C2 & & 1.7 & 25.5 & 1251 \\
D2 & & 1.5 & 31.3 & 1152 \\
E2 & & 1.9 & 37.5 & 1103 \\
\hline F2 & 12 & 1.6 & 8.5 & 2484 \\
G2 & & 1.7 & 11.3 & 1660 \\
H2 & & 1.8 & 14.5 & 1331 \\
I2 & & 1.9 & 18.1 & 1187 \\
J2 & & 2.0 & 22.1 & 1118 \\
\hline K2 & 14 & 1.7 & 5.0 & 2839 \\
L2 & & 1.8 & 6.7 & 1781 \\
V2 & & 1.9 & 8.7 & 1373 \\
N2 & & 2.0 & 11.0 & 1201 \\
O2 & & 2.1 & 13.7 & 1122 \\
\hline P2 & 16 & 1.8 & 3.1 & 2914 \\
Q2 & & 1.9 & 4.2 & 1790 \\
R2 & & 2.0 & 5.5 & 1367 \\
S2 & & 2.1 & 7.1 & 1193 \\
T2 & & 2.2 & 8.9 & 1115 \\
\hline U2 & 18 & 1.9 & 2.0 & 2719 \\
V2 & & 2.0 & 2.5 & 1699 \\
W2 & & 2.1 & 3.7 & 1321 \\
X2 & & 2.2 & 4.7 & 1168 \\
Y2 & & 2.3 & 6.0 & 1101 \\
\hline Z2 & 20 & 2.0 & 1.4 & 2364 \\
AA2 & & 2.1 & 1.9 & 1554 \\
BB2 & & 2.2 & 2.5 & 1256 \\
CC2 & & 2.3 & 3.3 & 1136 \\
\hline
\end{tabular}

Table 4.2: Model inputs for encounter due to turbulent shear and differential settling with $d_{\max }=1 \mathrm{~mm}$. 


\begin{tabular}{|c|c|c|c|c|}
\hline name & $h$ & $D 3$ & $d_{0}[\mu \mathrm{m}]$ & $\rho_{\mathbf{s}}\left[\mathrm{kg} \mathrm{m}^{-3}\right]$ \\
\hline A3 & 10 & 2.2 & 5.9 & 2808 \\
B3 & & 2.3 & 6.6 & 2260 \\
C3 & & 2.4 & 7.4 & 1908 \\
D3 & & 2.5 & 8.2 & 1674 \\
\hline E3 & 12 & 2.3 & 3.6 & 2903 \\
F3 & & 2.4 & 4.2 & 2269 \\
G3 & & 2.5 & 4.7 & 1878 \\
\hline H3 & 14 & 2.4 & 2.3 & 2781 \\
I3 & & 2.5 & 2.7 & 2147 \\
\hline J3 & 16 & 2.5 & 1.6 & 2503 \\
\hline K3 & 18 & 2.5 & 0.9 & 2972 \\
\hline
\end{tabular}

Table 4.3: Model inputs for encounter due to turbulent shear and differential settling with $d_{\max }=0.1 \mathrm{~mm}$.

values of $\sim 10 \mathrm{~s}^{-1}$ (Milligan, 1996). The properties of the surrounding medium are chosen to be representative of sea water and can be found in Table B.1.

It may seem as if this method unnecessarily constrains the properties of the suspension, but in reality large flocs are never composed of a single component grain type. They are composed of component grains with a wide range of diameters and densities. However, observed maximum floc diameters and settling velocities are commonly on the order of those given above. Limiting the particle size and settling velocity in this way makes it possible to determine realistic flocculation times for a variety of initial particle diameters and fractal dimensions.

For scenario three, only including turbulent shear encounter, the number of sections is held constant at $h=12$, and a number of cases are run varying $=(0.1 \mathrm{~m} \leq$ $z \leq 1000 \mathrm{~m}$ ), and $D 3$. The solids density is fixed at $\rho_{s}=2650 \mathrm{~kg} \mathrm{~m}^{-3}$. For turbulent shear and differential shear encounter, a number of the cases described above are re-run with the inclusion of settling losses. For these, model inputs are as shown in Tables 4.1 through 4.3 , with $G=1 \mathrm{~s}^{-1}$. 


\subsection{Statistics}

In order for the method of estimation developed here to be useful for predicting the flocculation time, the correction that directly relates the $\tau_{J}$ to $\tau_{B}$ must be determined. This is achieved using multiple linear regression. If the relationship between the two dimensionless flocculation times is linear, then the correction has the form

$$
\mathbf{y}=B_{0}+B_{1} \mathbf{x}_{1}+B_{2} \mathbf{x}_{2}+\cdots+B_{k} \mathbf{x}_{\mathbf{k}}
$$

where $\mathbf{y}$ is the response variable. i.e. $\tau_{B}, \mathbf{x}_{1}$ is $\tau_{J}$, and the other predictors ( $\mathbf{x}_{2}$ through $\mathbf{x}_{\mathbf{k}}$ ) may be $D 3$, or any of the other model inputs which affect the flocculation time. The coefficients $B_{0}, \ldots B_{k}$ are the parameters of least squares regression. If the relationship is second order then

$$
\begin{aligned}
\mathbf{y} & =B_{0}+B_{1} \mathbf{x}_{1}+B_{2} \mathbf{x}_{2}+\cdots+B_{m} \mathbf{x}_{\mathbf{m}}+B_{m+1} \mathbf{x}_{1}{ }^{2}+B_{m+2} \mathbf{x}_{1} \mathbf{x}_{2}+\cdots+B_{2 m} \mathbf{x}_{1} \mathbf{x}_{\mathbf{m}} \\
& +B_{2 m+1} \mathbf{x}_{\mathbf{2}}{ }^{2}+B_{2 m+2} \mathbf{x}_{2} \mathbf{x}_{3}+\cdots+B_{2 m+(m-1)} \mathbf{x}_{2} \mathbf{x}_{\mathbf{m}}+\cdots+B_{k} \mathbf{x}_{\mathbf{m}}{ }^{2}
\end{aligned}
$$

It must be stressed that the predictors for each correction are not chosen because of their physical significance. Flocculation times calculated by the various models are all estimates of the same quantity. but they are entirely independent of one another. The corrections are used purely for predictive purposes. so the form of the equations is chosen only based on how robustly they relate the estimate to the Batterham et al. model value. Also, the calculated parameters are not used to infer the relative significance of one term with respect to another.

In the regression analysis performed here. predictor variables tend to be highly correlated. The dimensionless flocculation time $\tau_{J}$ is a function of D3. G, and $h$, and these inputs are also variables in the regression equation. Therefore, any term containing $\tau_{J}$ will tend to be correlated with terms containing $D 3, G$, and $h$. Correlation among predictors is reduced by standardizing each array of predictor observations by its mean and standard deviation. That is,

$$
Z_{\mathbf{x}}=\frac{\mathbf{x}-\vec{x}_{\mathbf{x}}}{\sigma_{\mathbf{x}}}
$$


where $\mathbf{x}$ is an array of observations, and $\bar{x}_{\mathbf{x}}$ and $\sigma_{\mathbf{x}}$ are the mean and standard deviation of $\mathbf{x}$, respectively. A regression equation based on standardized predictors can easily be converted back into non-standardized.

Statistical analysis is performed using MINITAB. This statistical package provides a systematic method for determining which predictors are required to properly describe the relationship between the two calculated flocculation times. The criteria used to select the best regression equations are $C_{p}$ and $s^{2}$. The $C_{p}$ statistic is a function of the number of parameters in a model and the error mean square, $s^{2}$. According to Walpole and Myers (1989), the $C_{p}$ statistic is developed from considerations of the proper compromise between excessive bias incurred when one underfits and excessive prediction variance produced when one overfits." If $C_{p}>p$. where $p$ is the number of parameters $(k+1)$, then the model is biased due to underfit: if $C_{p} \leq p$. then the model is a reasonable one. For comparable values of $C_{p}$, the model with the lower $s^{2}$ value is preferable. 


\section{Chapter 5}

\section{Results and Discussion}

\subsection{Turbulent Shear Encounter}

The relationship between modeled and estimated flocculation time for turbulent shear encounter is shown in Figure 5.1. Each point represents a different fractal dimension: $\tau$ increases with $D 3$. These graphs show that the monodispersion estimation gives $\tau_{\text {floc }}$ values that are on the same order as those predicted by the full model and that the relationship between the two is highly linear. However. $\tau_{i}$ always overestimates $\tau_{B}$.

It is rather surprising that $\tau_{M}$ should predict $\tau_{B}$ so well. given the particle size distributions shown in Figure 3.2. These plots show that the suspension becomes highly dispersed within a very short time. so the assumption that the suspension remains monodispersed is invalid. Nevertheless. the formulation of Bremer et al. (1995) manages to capture the overall behaviour of the suspension. The assumption of monodispersity means that there is only one loss rate to consider at any time. but the size of particles in suspension is constantly increasing; as is the encounter rate.

Figure 5.2 shows the results for all of the cases described in Section 4.1. Because the relationship between $\tau_{B}$ and $\tau_{M}$ is linear, only order one predictors are used to determine the regression equation. With $\tau_{M}$, the model inputs affecting flocculation 
(a)

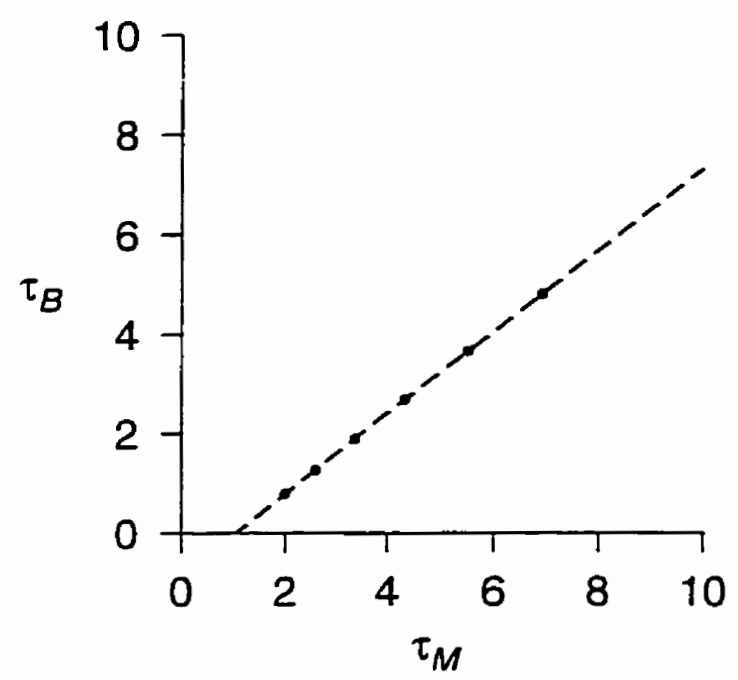

(b)

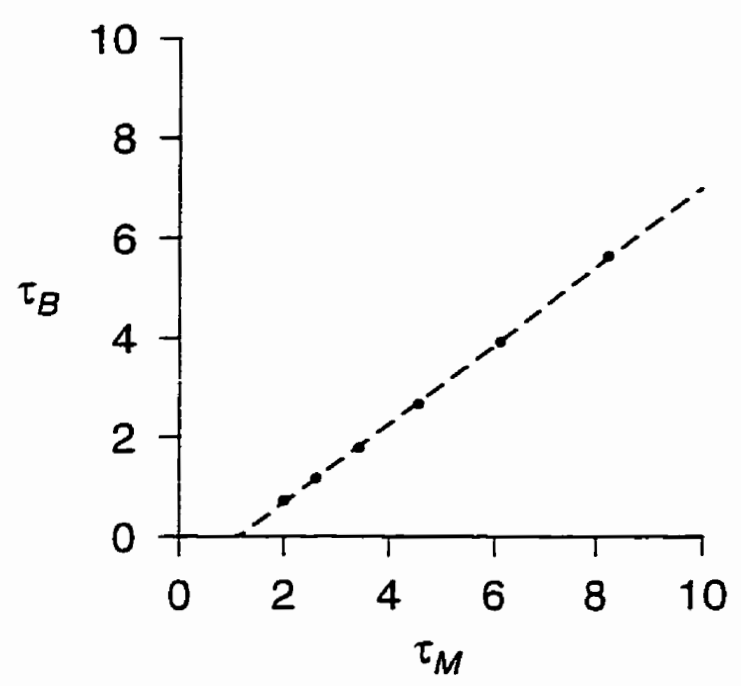

(c)

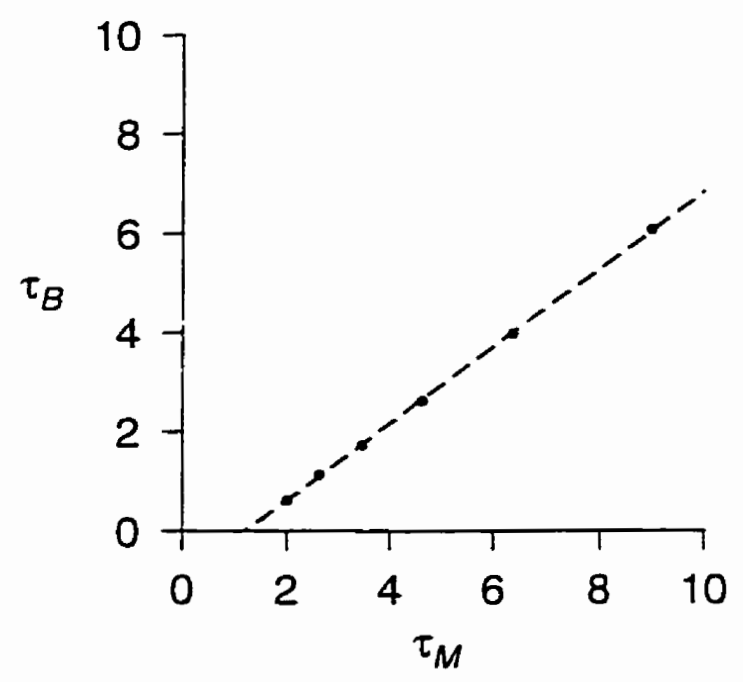

Figure 5.1: Comparison of dimensionless flocculation times for turbulent shear encounter calculated using the full model $\left(\tau_{B}\right)$ and the monodispersion approach $\left(\tau_{M}\right)$. The number of sections in (a). (b), and (c) is 12, 16, and 20, respectively. For all regression lines, $R^{2}>0.99$. 


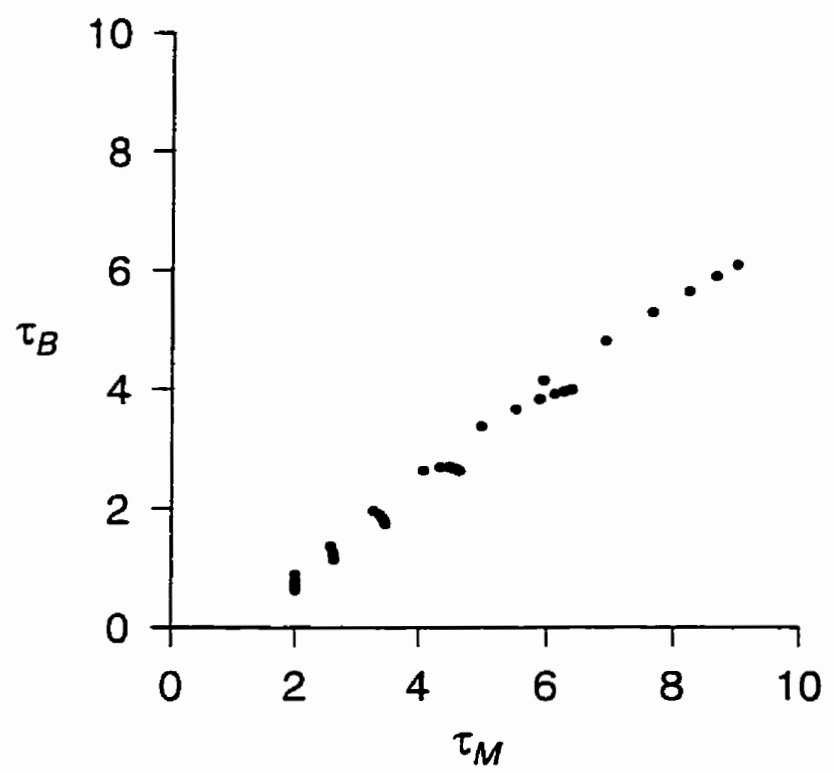

Figure 5.2: Comparison of dimensionless flocculation times for turbulent shear encounter calculated using the full model $\left(\tau_{B}\right)$ and the monodispersion approach $\left(\tau_{M}\right)$ for all cases with encounter due to turbulent shear.

time are $D 3$ and $h$. The influence of all other inputs is removed in the nondimensionalization of $t$. Uising MINITAB. an adequate value of $C_{p}$ is achieved only when all three predictors are included. The best fit is

$$
\tau_{B}=0.7 \tau 2 \tau_{J}+0.128 D 3-0.03 \tau h-0.463 .
$$

where $h$ can be calculated using

$$
h=D 3 \ln \left(\frac{d_{\max }}{d_{0}}\right) .
$$

This model should be restricted to the range of values of $h$ and $D 3$ used to develop (5.1), i.e. $10 \leq h \leq 20$ and $1.5 \leq D 3 \leq 2.5$.

\subsection{Turbulent Shear and Differential Settling En- counter}

In this scenario we investigate the relationship between $\tau_{B}$ and $\tau_{J}$ as a function of the shear rate. Because the differential settling encounter rate is a function of $d_{0}$ and $\rho_{s}$. 

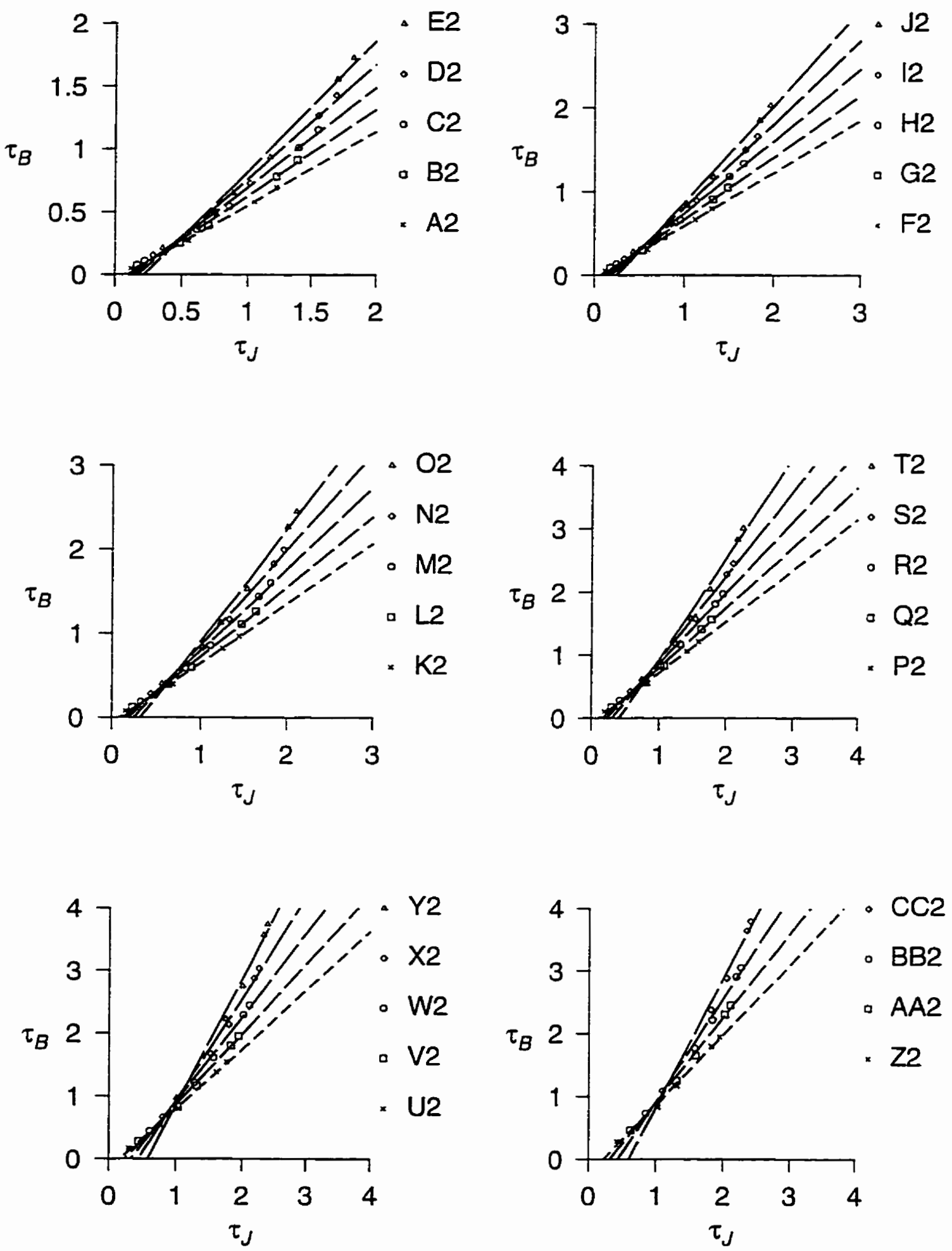

Figure 5.3: Comparison of dimensionless flocculation times for turbulent shear and differential settling encounter calculated using the full model $\left(\tau_{B}\right)$ and the Jungedispersion approach $\left(\tau_{J}\right)$ for all cases with maximum diameter of $d_{\max }=1 \mathrm{~mm}$. Each plot shows the cases with the same number of sections. Regression lines are drawn through points within the same case $\left(R^{2}>0.99\right.$ for all regression lines). 
only those dimensionless flocculation times calculated for suspensions with the same $D 3$ and $h$ are comparable. Figure 5.3 shows a series of plots with all of the cases for $d_{\max }=1 \mathrm{~mm}$. Each plot shows cases with the same value of $h$, but different $D 3$. Regression lines are drawn through points of varying $G$ within the same case. Similar figures for cases with $d_{\max }=0.1 \mathrm{~mm}$ and $d_{\max }=10 \mathrm{~mm}$ are shown in Appendix C.

These plots show a highly linear relationship between $\tau_{B}$ and $\tau_{J}$ with changing $G$. For both models, flocculation time increases with $G$. It increases when the magnitude of one mechanism is increased because it is inversely proportional to $G$ (see (3.2)). Therefore the real time decreases with increasing $G$. For cases with the same number of sections, the slope of the regression line increases regularly with increasing $D 3$. For $D 3<2.0, \tau_{J}$ generally underestimates $\tau_{B}$, while for $D 3>2.0, \tau_{J}$ overestimates $\tau_{B}$. By visual inspection, the change in slope with $h$ is less pronounced. This suggests that the relationship between the full and reduced models is more strongly determined by the fractal dimension and that increasing $h$ merely increases $\tau_{\text {floc }}$ for both models.

The increase in slope with $D 3$ can be explained by examining mass distributions for several cases. as shown in Figure 5.4. This figure shows the particle size distribution at comparable times during its evolution for three cases: F1. Z2, and $K 3$. (Figures D.1 through D.3 in Appendix D show the entire size distribution evolution for each of these cases.) These cases are chosen because they represent the full range of $D 3$. and they all have high $h$ values: they have different $d_{\text {max }}$.

These plots show that the simplifying assumption of a perfectly.Junge-distributed size distribution is not supported by the full model for all values of $D 3$. The case shown in Figure 5.4(a) is F1 at $\tau=0.4$. For this case, $D 3=1.6$ and $h=20$. This mass distribution has quite a pronounced initial negative slope, while for case $\mathrm{Z} 2$ at $\tau=0.96(D 3=2.0, h=20)$, shown in Figure 5.4(b), the slope is very close to zero for small $i$. Finally, the initial slope of the mass distribution shown in Figure 5.4(c) of case $\mathrm{K} 3$ at $\tau=1.44(D 3=2.5, h=18)$ is positive. (The slope is negative in sections with high $i$ for all cases because number concentration drops off at some size.) Therefore, the general trend of an increase in the slope of the relationship between 
(a)

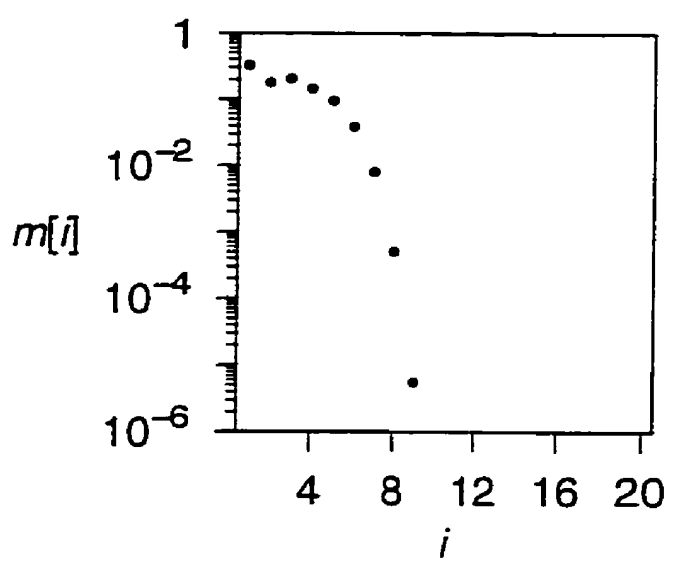

(b)

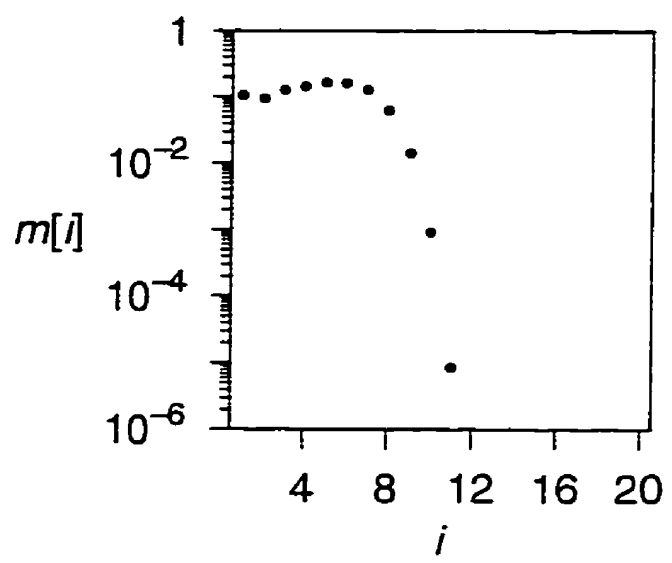

(c)

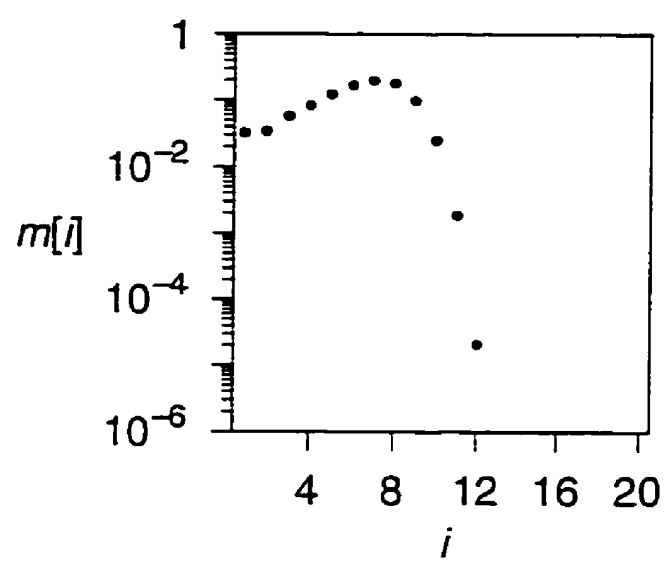

Figure 5.4: Dimensionless mass concentration $(m)$ in each section $(i)$ at comparable dimensionless times for (a) case F1, (b) case Z2, and (c) case $\mathrm{K} 3$.

$\tau_{B}$ and $\tau_{J}$ corresponds to an increase in the initial slope of the mass distribution predicted by the full model. For $D 3=2.0$, the slope of the mass distribution is zero. and there is a near $1: 1$ correspondence between $\tau_{B}$ and $\tau_{J}$.

Figure 5.5 shows plots for cases with the same $d_{\text {max }}$, but increasing $D 3$ and $h$. (The evolution of the mass distribution for each of these cases is also shown in Appendix D.) The mass distributions shown are $\mathrm{A} 2$ at $\tau=0.24(D 3=1.5, h=10), \mathrm{Q} 2$ at $\tau=0.664(D 3=1.9, h=16)$, and CC2 at $\tau=2.32(D 3=2.3, h=20)$. These show the same trend of increasing slope in the first few sections of the mass 
(a)

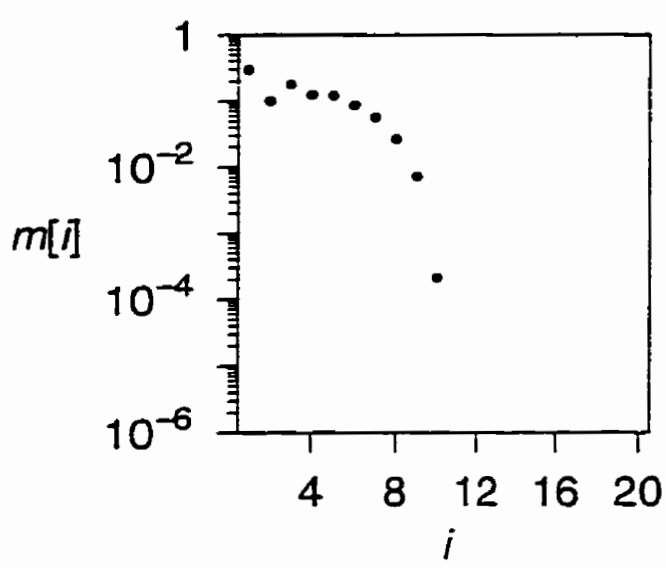

(b)

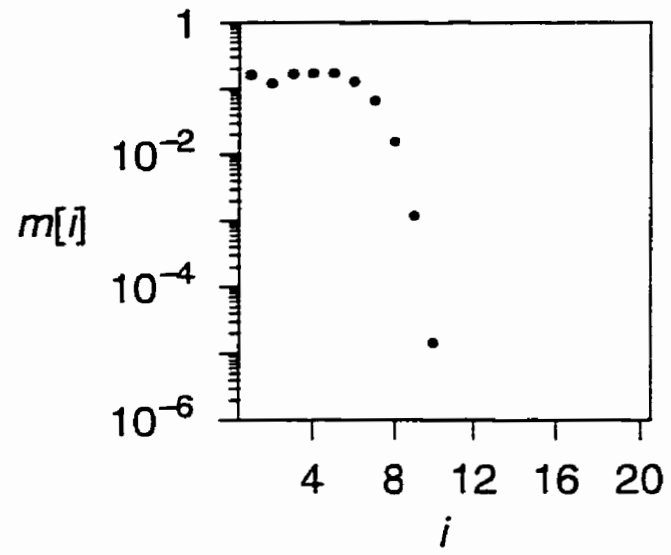

(c)

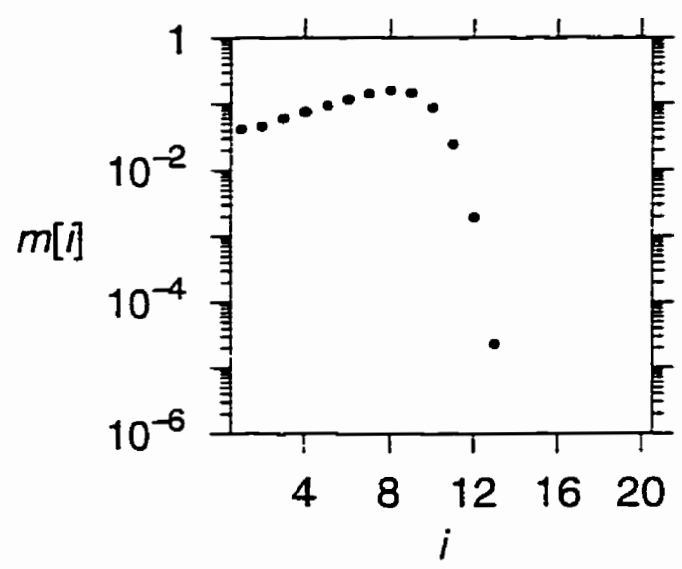

Figure 5.5: Dimensionless mass concentration $(m)$ in each section (i) at comparable dimensionless times for (a) case A2. (b) case Q2, and (c) case CC2.

distribution with increasing fractal dimension. Accompanying the increase in slope of the mass distribution is a decrease in the number of particles in the first section, which must occur if there is to be more mass in higher sections.

Figure 5.6 shows dimensionless flocculation times for all of the cases with $d_{\max }=$ $1 \mathrm{~mm}$. Plotted together, the overall relationship between $\tau_{B}$ and $\tau_{J}$ is not linear, but of a higher order. If a second-order equation is fit to this curve, then a total of 14 terms is possible. These terms arise from the first and second powers of the predictor variables $\left(\tau_{J}, G, D 3\right.$, and $\left.h\right)$, and second-order interaction terms. As the MINITAB 


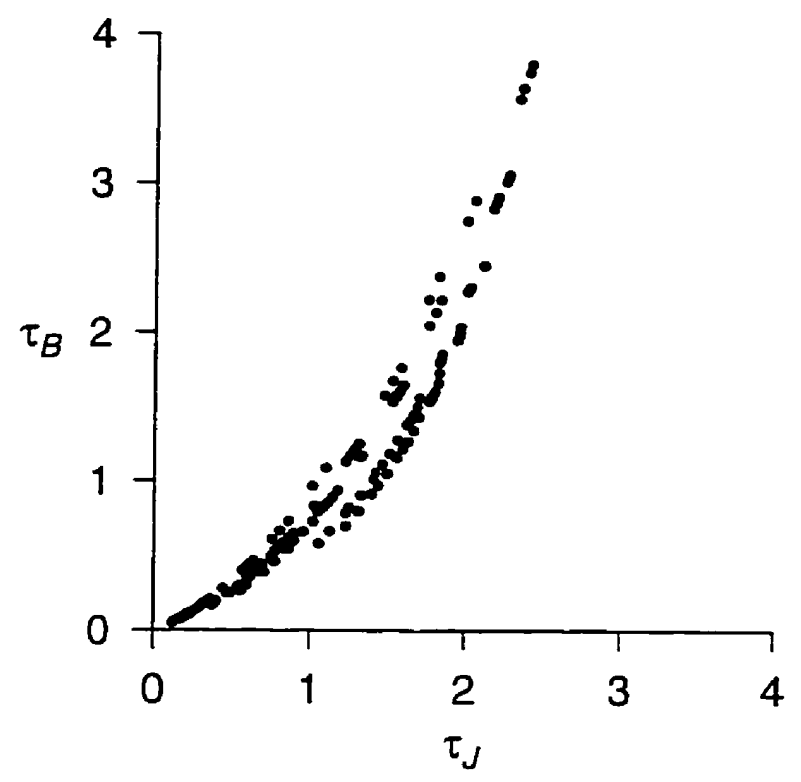

Figure 5.6: Comparison of dimensionless flocculation times calculated using the full model $\left(\tau_{B}\right)$ and the Junge-dispersion approach $\left(\tau_{J}\right)$ for all cases with encounter due to turbulent shear for maximum diameter of $d_{\max }=1 \mathrm{~mm}$.

results given in Appendix $E$ indicate, to obtain an acceptable value of $C_{p}, 11$ variables must be included, for a total of 12 parameters. The inclusion of more variables does not significantly reduce $s^{2}$. The regression equation is

$$
\begin{aligned}
\tau_{B} & =-2.438 \tau_{J}-0.152 G+1.433 D 3-0.202 h \\
& +0.236 \tau_{J}^{2}-0.842 D 3^{2}-0.208 \tau_{J} G+1.452 \tau_{J} D 3 \\
& +0.312 G D 3-0.002 G h+0.102 D 3 h+0.42 \tau .
\end{aligned}
$$

where $h$ is calculated using (5.2).

Similarly for $d_{\max }=10 \mathrm{~mm}$. shown in Figure $5.7(\mathrm{a})$, the best fit is given by

$$
\begin{aligned}
\tau_{B} & =-0.941 \tau_{J}-0.030 G-0.279 D 3-0.018 h \\
& +0.076 \tau_{J}^{2}+0.0006 G^{2}+0.0006 h^{2}-0.023 \tau_{J} G \\
& +0.964 \tau_{J} D 3-0.005 \tau_{J} h+0.035 G D 3+0.554
\end{aligned}
$$

For $d_{\max }=0.1 \mathrm{~mm}$, Figure $5.7(\mathrm{~b})$, all 14 variables must be included, and the best 

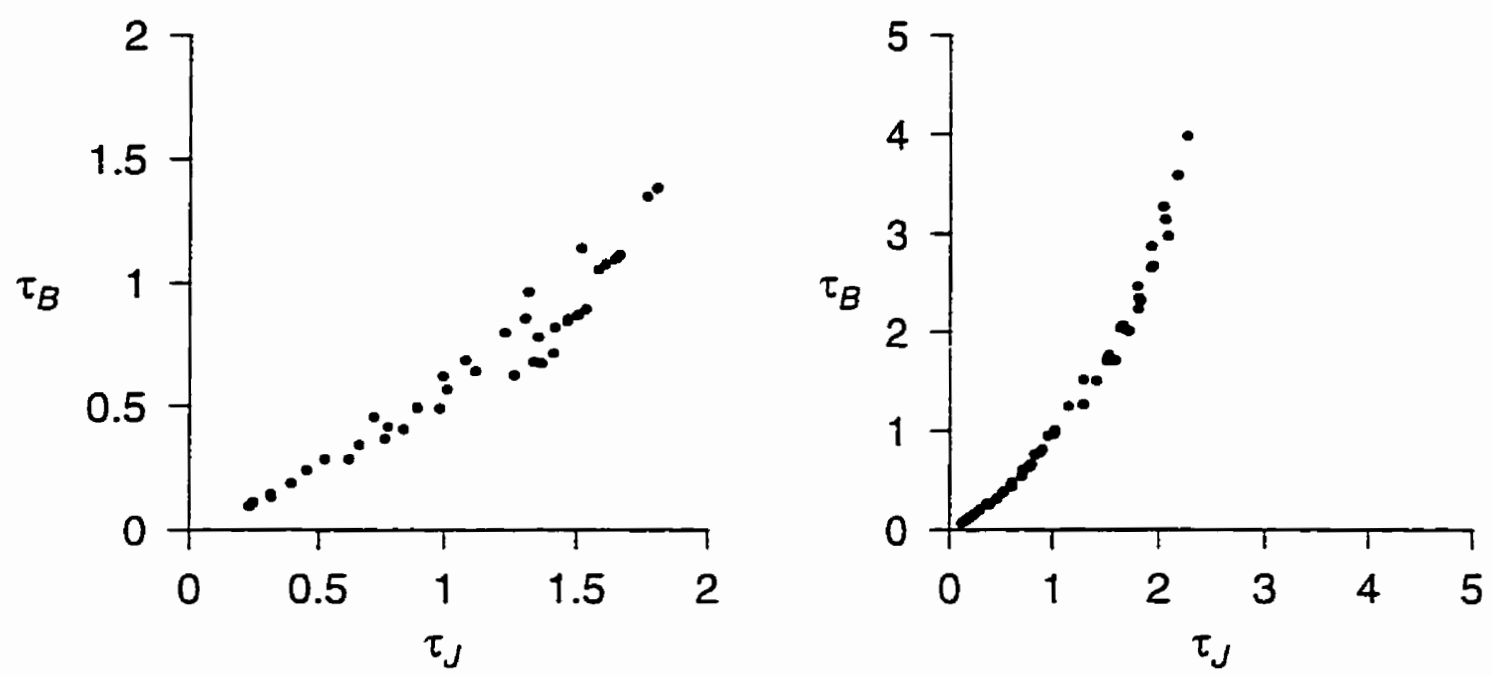

Figure 5. $\bar{i}$ : Comparison of dimensionless flocculation times calculated using the full model $\left(\tau_{B}\right)$ and the Junge-dispersion approach $\left(\tau_{J}\right)$ for all cases with encounter due to turbulent shear with a maximum diameter of (left) $d_{\max }=10 \mathrm{~mm}$ and (right) $d_{\max }=0.1 \mathrm{~mm}$.

model is

$$
\begin{aligned}
\tau_{B} & =-3.010 \tau_{J}-0.411 G+1.510 D 3-0.434 h \\
& +0.424 \tau_{J}^{2}+0.004 G^{2}-0.849 D 3^{2}-0.004 h^{2} \\
& -0.288 \tau_{J} G+1.0 \tau_{J} D 3+0.04 \tau_{J} h+0.33 \tau G D 3 \\
& +0.016 G h+0.222 D 3 h+0.794 .
\end{aligned}
$$

Based on the clear trend in the slope between $\tau_{B}$ and $\tau_{J}$ with respect to $D 3$. and the fact that the slope of the mass distribution is also a function of $D 3$. another approach to this problem is apparent. It seems reasonable that if the assumed mass distribution were chosen to be more representative of the mass distributions predicted by the full model for a particular value of fractal dimension, then the relationship between $\tau_{B}$ and $\tau_{J}$ would be $1: 1$. That is, rather than assume a flat mass distribution for all values of $D 3$, one should determine the relationship between $D 3$ and the slope of the mass distribution, and assume a different form of the mass distribution for each value of D3. This method is called the Power Law Estimate because the size distribution is assumed to have the form of a power law distribution, of which the Junge distribution 


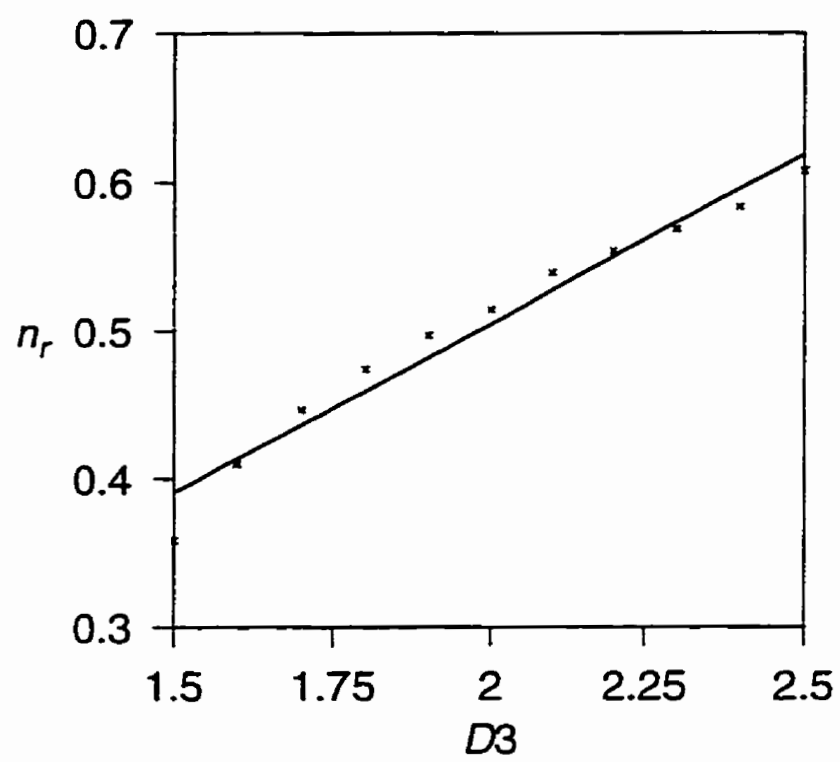

Figure 5.S: A veraged ratios of number concentrations in adjacent sections $\left(n_{r}\right)$ plotted as a function of fractal dimension ( $D 3)$. The regression equation is $n_{r}=0.048+$ $0.228 D 3 . R^{2}=0.96$

is a specific case. Dimensionless flocculation times calculated using this method are given the symbol $\tau_{P}$.

To determine the relationship between mass distribution slope and $D 3$. the full model was run for turbulent shear encounter and the full range of values of $D 3$. The ratio of number concentrations between neighbouring sections $\left(\frac{n_{i}}{n_{i-1}}\right)$ was calcuiated, and the average of these was determined for each time step. Because number concentration drops off at some section, only those ratios that were within $10 \%$ of neighbouring ratios were included in the average. These averaged ratios show a linear trend with $D 3$ (Figure 5.S). For $D 3=2$, the average ratio is close to 0.5 . Since particle volume doubles from one section to the next, a number concentration ratio of 0.5 corresponds to a mass concentration ratio between neighbouring sections of 1 . i.e. a flat mass distribution. Using simple regression, the relationship between number concentration ratio, $n_{r}$, and $D 3$ is

$$
n_{r}=0.048+0.228 D 3
$$

With this relationship, a number of cases with $d_{\max }=1 \mathrm{~mm}$ were re-run. These 

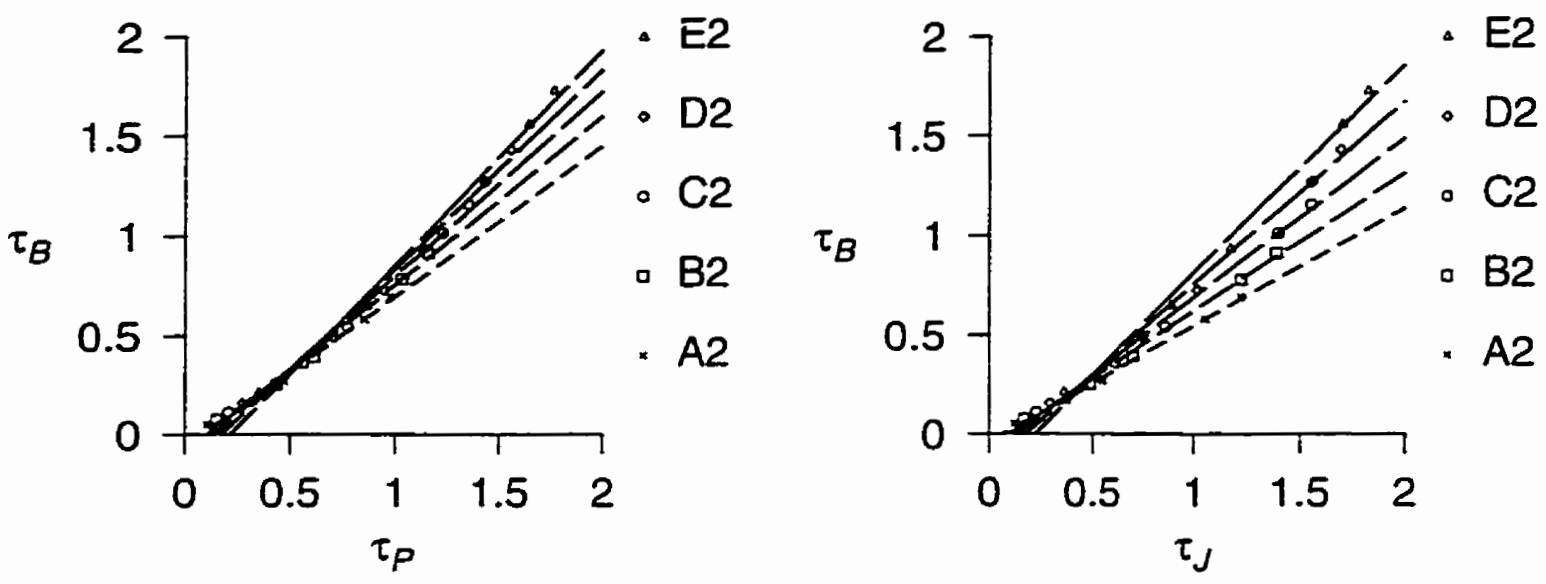

Figure 5.9: Dimensionless flocculation times for cases A2 through E2 calculated using (left) the Power Law method $\left(\tau_{P}\right)$ and (right) the Junge-distribution method $\left(\tau_{J}\right)$ plotted against dimensionless flocculation time calculated using the full model $\left(\tau_{B}\right)$.

are shown in Figure 5.9. Like the Junge-distribution method, this new approach produces dimensionless flocculation times which are linearly related to $\tau_{B}$ with respect to $G$. Although, the relationship between $\tau_{P}$ and $\tau_{B}$ is closer to one for all values of fractal dimension, using (5.6) to determine the form of the size distribution does not collapse the points onto a single curve, and it would remain necessary to develop a corrective expression which directly relates the two. Since there is no reduction in computational effort. the Junge-distribution method is retained.

\subsection{Aggregation with Settling Losses}

The behaviour of a suspension undergoing aggregation, while losing particles by settling out of the water column, is shown in Figure 5.10. For large $z$. settling loss is insignificant and the total volume of particles in suspension decreases only slightly throughout the evolution of the size distribution. As a result, $d_{50}$ increases in the characteristic way. As settling losses become more important, and the total volume decreases significantly, the suspension no longer flocculates. Because the largest particles are removed preferentially, as settling loss rate is proportional to settling velocity, median diameter remains small. However, the time at which the transition to the flocculated state begins is more or less the same regardless of the rate of settling 


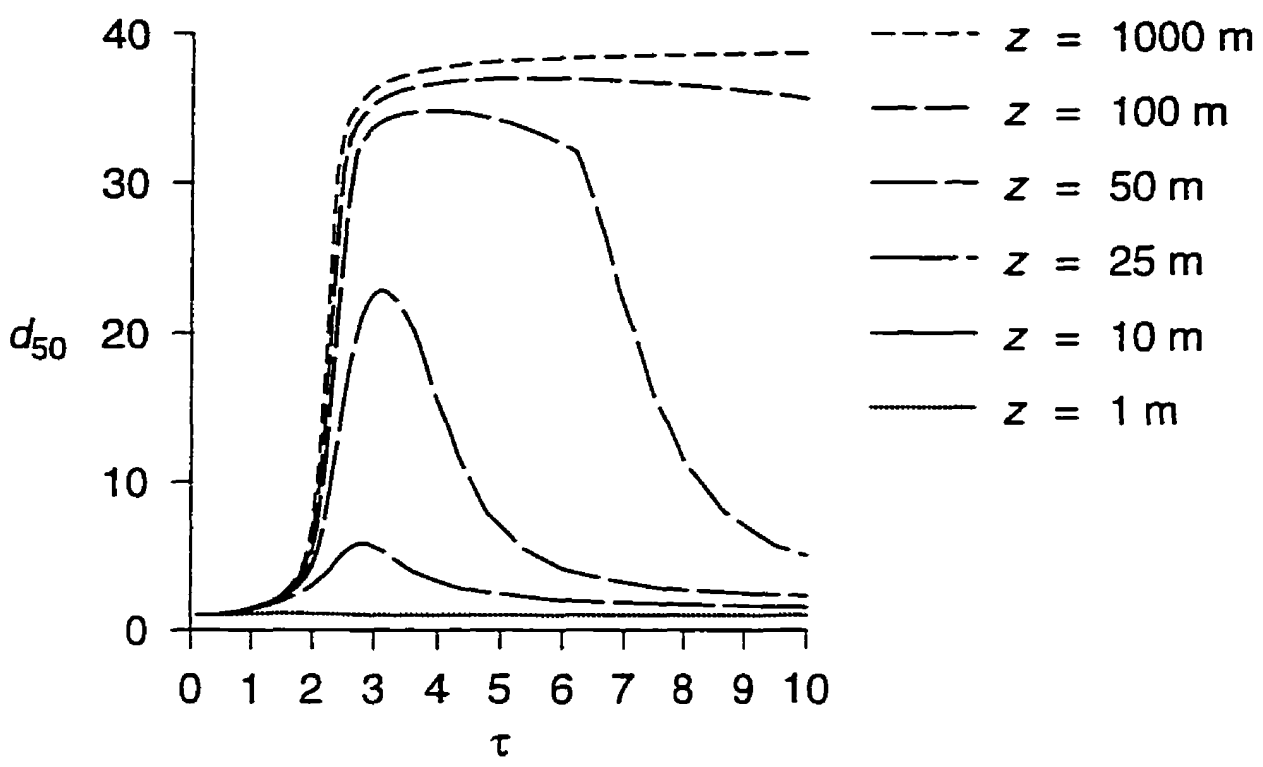

Figure 5.10: Dimensionless median diameter $\left(d_{50}\right)$ versus dimensionless time $(\tau)$ for turbulent shear encounter with sinking losses and with a fractal dimension of $D 3=2$ and 12 sections. Water column depth $(z)$ decreases as shown in the legend.

loss.

Table 5.1 shows the trend in $\tau_{B}$ with decreasing water depth for turbulent shear encounter. As water depth decreases. modeled flocculation time increases until the loss rate is such that the suspension never becomes flocculated. The flocculation times shown in Table 5.1 increase by $\sim 10 \%$ of the value calculated with no settling lusses. Given the other simplifications and assumptions in the model. an increase of this magnitude is modest.

The results for turbulent shear and differential settling encounter are shown in Table 5.2. The cases are separated on the basis of solids density; those cases with densities less than $1500 \mathrm{~kg} \mathrm{~m}^{-3}$ are shown in the top table. whereas those with densities greater than $2500 \mathrm{~kg} \mathrm{~m}^{-3}$ are shown in the bottom table. In both tables. cases are grouped according to $d_{m a x}$, and within each group. cases are listed in order of increasing $D 3$ and $h$. For the cases shown, the relative increase in flocculation time is more variable with a range of $3 \%$ to $68 \%$.

The large variability in the relative increase in $\tau_{f l o c}$ is to some degree due to the choice of $z$ values. As $z$ decreases to its critical value for a particular case, i.e. the 


\begin{tabular}{|c|c|c|c|c|c|c|c|c||c|}
\hline$D 3$ & no loss & $250 \mathrm{~m}$ & $100 \mathrm{~m}$ & $50 \mathrm{~m}$ & $25 \mathrm{~m}$ & $10 \mathrm{~m}$ & $5 \mathrm{~m}$ & $1 \mathrm{~m}$ & $\frac{\Delta \tau}{\tau_{\text {noloss }}}$ \\
\hline 1.5 & 0.79 & 0.80 & 0.80 & 0.80 & 0.81 & 0.82 & 0.87 & $\mathrm{NF}$ & $10.1 \%$ \\
1.7 & 1.27 & 1.27 & $1.2 \mathrm{~S}$ & 1.29 & 1.32 & 1.41 & $\mathrm{NF}$ & $\mathrm{NF}$ & $11.2 \%$ \\
1.9 & 1.90 & 1.91 & 1.94 & 2.00 & 2.11 & $\mathrm{NF}$ & $\mathrm{NF}$ & $\mathrm{NF}$ & $11.1 \%$ \\
2.1 & 2.70 & 2.74 & 2.84 & 3.07 & $\mathrm{NF}$ & $\mathrm{NF}$ & $\mathrm{NF}$ & $\mathrm{NF}$ & $13.7 \%$ \\
2.3 & 3.67 & 3.81 & 4.15 & $\mathrm{NF}$ & $\mathrm{NF}$ & $\mathrm{NF}$ & $\mathrm{NF}$ & $\mathrm{NF}$ & $13.1 \%$ \\
2.5 & 4.80 & 5.15 & $\mathrm{NF}$ & $\mathrm{NF}$ & $\mathrm{NF}$ & $\mathrm{NF}$ & $\mathrm{NF}$ & $\mathrm{NF}$ & $7.9 \%$ \\
\hline
\end{tabular}

Table 5.1: Full-model dimensionless flocculation times $\left(\tau_{B}\right)$ for turbulent shear encounter including settling losses for component grain density of $\rho_{s}=2650 \mathrm{~kg} \mathrm{~m}^{3}$, initial diameter of $d_{0}=10 \mu \mathrm{m}$, shear rate of $G=1 \mathrm{~s}^{-1}$, initial number concentration of $N_{0}=10^{11} \mathrm{~m}^{-3}$ and various water column depths (12 sections). NF indicates that the suspension does not flocculate. The maximum relative increase in dimensionless flocculation time with respect to the value obtained with no depositional losses is shown in the last column.

depth at which the suspension no longer becomes flocculated, $\tau_{\text {floc }}$ increases from its no loss value. For some cases. the depths chosen happen to fall close to the critical value, while for others. they do not. The lack of a clear trend with $\rho_{s}$ (high or low) suggests that removal of particles from the largest section is the dominant loss term because the largest particles. regardless of $h$ or $D 3$. settle at same speed.

The ratio of time scales for aggregation and sinhing provides a toul for gauging whether or not sinking losses are important. This ratio has the form

$$
\frac{t_{\text {floc }}}{t_{\text {sink }}}=\frac{t_{\text {floc }} w_{s \max }}{z}
$$

where $t_{f l o c}$ is determined based on the dimensionless flocculation time predicted using the Junge-distribution method $\left(\tau_{J}\right)$, and re-dimensionalized using the expression given by (3.2). If this ratio is less than one, then the time scale for sinking is greater than the flocculation time, and sinking losses are insignificant. If, however, the ratio is close to or greater than one, then sinking losses become important, and the mass of particles in suspension cannot be assumed to be constant.

In Table 5.3, the ratio given in (5.7) is calculated for the cases listed in Table 5.2. 


\begin{tabular}{|c|c|c|c|c|c|c|c|c||c|}
\hline name & no loss & $25 \mathrm{~m}$ & $10 \mathrm{~m}$ & $5 \mathrm{~m}$ & $1 \mathrm{~m}$ & $0.5 \mathrm{~m}$ & $0.1 \mathrm{~m}$ & $0.05 \mathrm{~m}$ & $\frac{\Delta \tau}{\tau_{\text {noloss }}}$ \\
\hline $\mathrm{A} 1$ & 0.49 & 0.49 & 0.49 & 0.49 & 0.49 & 0.50 & 0.54 & 0.60 & $22 \%$ \\
$\mathrm{C} 1$ & 0.64 & 0.64 & 0.64 & 0.64 & 0.65 & 0.67 & 0.85 & $\mathrm{NF}$ & $32 \%$ \\
$\mathrm{E} 1$ & 0.85 & 0.86 & 0.86 & 0.86 & 0.90 & 0.94 & $\mathrm{NF}$ & $\mathrm{NF}$ & $10 \%$ \\
$\mathrm{H} 1$ & 1.14 & 1.14 & 1.15 & 1.16 & 1.24 & 1.39 & $\mathrm{NF}$ & $\mathrm{NF}$ & $22 \%$ \\
\hline $\mathrm{E} 2$ & 0.94 & 0.94 & 0.94 & 0.94 & 0.94 & 0.95 & 1.02 & 1.13 & $20 \%$ \\
$\mathrm{~J} 2$ & 1.17 & 1.17 & 1.17 & 1.18 & 1.20 & 1.23 & $\mathrm{NF}$ & $\mathrm{NF}$ & $5 \%$ \\
$\mathrm{O} 2$ & 1.53 & 1.54 & 1.54 & 1.55 & 1.63 & 1.79 & $\mathrm{NF}$ & $\mathrm{NF}$ & $17 \%$ \\
$\mathrm{~T} 2$ & 2.05 & 2.06 & 2.08 & 2.11 & $\mathrm{NF}$ & $\mathrm{NF}$ & $\mathrm{NF}$ & $\mathrm{NF}$ & $3 \%$ \\
$\mathrm{Y} 2$ & 2.75 & 2.78 & 2.85 & 3.02 & $\mathrm{NF}$ & $\mathrm{NF}$ & $\mathrm{NF}$ & $\mathrm{NF}$ & $10 \%$ \\
$\mathrm{CC} 2$ & 2.89 & 3.04 & $\mathrm{NF}$ & $\mathrm{NF}$ & $\mathrm{NF}$ & $\mathrm{NF}$ & $\mathrm{NF}$ & $\mathrm{NF}$ & $5 \%$ \\
\hline
\end{tabular}

\begin{tabular}{|c|c|c|c|c|c|c|c|c|c||c|}
\hline name & no loss & $250 \mathrm{~m}$ & $100 \mathrm{~m}$ & $50 \mathrm{~m}$ & $25 \mathrm{~m}$ & $10 \mathrm{~m}$ & $5 \mathrm{~m}$ & $1 \mathrm{~m}$ & $0.5 \mathrm{~m}$ & $\frac{\Delta \tau}{\tau_{\text {noloss }}}$ \\
\hline F1 & 0.49 & 0.49 & 0.50 & 0.50 & 0.51 & 0.55 & 0.64 & $\mathrm{NF}$ & $\mathrm{NF}$ & $30 \%$ \\
\hline F2 & 0.31 & 0.31 & 0.31 & 0.31 & 0.31 & 0.31 & 0.32 & 0.37 & 0.52 & $68 \%$ \\
$\mathrm{~K} 2$ & 0.40 & 0.40 & 0.40 & 0.40 & 0.40 & 0.42 & 0.44 & $\mathrm{NF}$ & $\mathrm{NF}$ & $11 \%$ \\
$\mathrm{P} 2$ & 0.55 & 0.55 & 0.56 & 0.56 & 0.58 & 0.63 & $0.7 \mathrm{~S}$ & $\mathrm{NF}$ & $\mathrm{NF}$ & $42 \%$ \\
$\mathrm{U} 2$ & 0.59 & 0.80 & 0.82 & 0.84 & 0.90 & $\mathrm{NF}$ & $\mathrm{NF}$ & $\mathrm{NF}$ & $\mathrm{NF}$ & $13 \%$ \\
$\mathrm{Z} 2$ & 1.16 & 1.19 & 1.23 & 1.32 & $\mathrm{NF}$ & $\mathrm{NF}$ & $\mathrm{NF}$ & $\mathrm{NF}$ & $\mathrm{NF}$ & $14 \%$ \\
\hline A3 & 0.45 & 0.45 & 0.45 & 0.45 & 0.46 & 0.48 & 0.52 & $\mathrm{NF}$ & $\mathrm{NF}$ & $3 \%$ \\
E3 & 0.64 & 0.65 & 0.66 & 0.67 & 0.70 & 0.90 & $\mathrm{NF}$ & $\mathrm{NF}$ & $\mathrm{NF}$ & $40 \%$ \\
$\mathrm{H} 3$ & 0.97 & 1.00 & 1.03 & 1.11 & $\mathrm{NF}$ & $\mathrm{NF}$ & $\mathrm{NF}$ & $\mathrm{NF}$ & $\mathrm{NF}$ & $13 \%$ \\
J3 & 1.51 & 1.61 & $\mathrm{NF}$ & $\mathrm{NF}$ & $\mathrm{NF}$ & $\mathrm{NF}$ & $\mathrm{NF}$ & $\mathrm{NF}$ & $\mathrm{NF}$ & $6 \%$ \\
\hline
\end{tabular}

Table 5.2: Full-model dimensionless flocculation times $\left(\tau_{B}\right)$ for turbulent shear and differential shear encounter including settling losses for cases with componen grain densities of (top) $\rho_{s}<1500 \mathrm{~kg} \mathrm{~m}^{-3}$ and (bottom) $\rho_{s}>2500 \mathrm{~kg} \mathrm{~m}^{-3}$. Each case is run with a shear rate of $G=1 \mathrm{~s}^{-1}$ and initial number concentration of $N_{0}=10^{11}$ for various water column depths. NF indicates that the suspension does not become flocculated. The maximum relative increase in flocculation time with respect to the value obtained with no depositional losses is shown in the last column. 


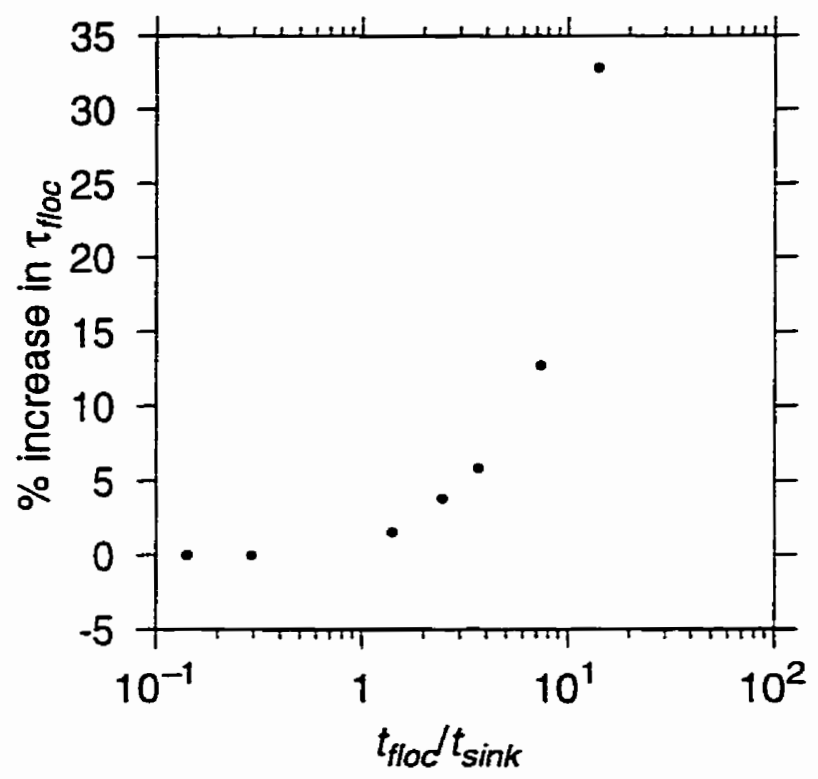

Figure 5.11: Time-scale ratio for case $\mathrm{Cl}$ plotted versus percentage increase in dimensionless flocculation time from its no-loss value.

The last column gives the depth at which the ratio of time scales is equal to one. This ratio gives a good indication of the degree to which the flocculation time predicted by the model increases from the value with no losses. For $z$ values that give timescale ratios greater than one, the flocculation time predicted by the full model is significantly greater than the no-loss case. For example, for case $\mathrm{C} 1 . \tau_{\text {floc }}$ increase from 0.64 to 0.67 when $z=0.5 \mathrm{~m}$, which corresponds to a ratio of 2.9 . The ratio climbs to 29 for $z=0.05 \mathrm{~m}$. and for this water depth. the suspension does not flocculate. This is shown graphically in Figure 5.11. Thus, for turbulent shear and differential settling encounter. the flocculation time predicted by the reduced model is valid only if the ratio of time scales is less than one. If the ratio is greater than one, then the full model should be used. 


\begin{tabular}{|c|c|c|c|c|c|c|c||c|}
\hline name & $25 \mathrm{~m}$ & $10 \mathrm{~m}$ & $5 \mathrm{~m}$ & $1 \mathrm{~m}$ & $0.5 \mathrm{~m}$ & $0.1 \mathrm{~m}$ & $0.05 \mathrm{~m}$ & $(z)_{\text {ratio }=1}$ \\
\hline $\mathrm{A} 1$ & 0.01 & 0.02 & 0.05 & 0.25 & 0.51 & 2.5 & 5.1 & $0.25 \mathrm{~m}$ \\
$\mathrm{C} 1$ & 0.05 & 0.14 & 0.29 & 1.4 & 2.9 & 14 & 29 & $1.4 \mathrm{~m}$ \\
$\mathrm{E} 1$ & 0.28 & 0.71 & 1.4 & 7.1 & 14 & 71 & 142 & $7.1 \mathrm{~m}$ \\
$\mathrm{H} 1$ & 1.2 & 3.0 & 6.0 & 30 & 60 & 303 & 607 & $30 \mathrm{~m}$ \\
\hline $\mathrm{E} 2$ & 0.005 & 0.01 & 0.02 & 0.13 & 0.27 & 1.3 & 2.7 & $0.13 \mathrm{~m}$ \\
$\mathrm{~J} 2$ & 0.03 & 0.08 & 0.16 & 0.84 & 1.6 & 8.4 & 16 & $0.84 \mathrm{~m}$ \\
$\mathrm{O} 2$ & 0.18 & 0.46 & 0.93 & 4.6 & 9.3 & 46 & 93 & $4.6 \mathrm{~m}$ \\
$\mathrm{~T} 2$ & 0.24 & 0.62 & 1.2 & 6.2 & 12 & 62 & 124 & $6.2 \mathrm{~m}$ \\
$\mathrm{Y} 2$ & 1.2 & 3.0 & 6.1 & 30 & 61 & 308 & 617 & $30 \mathrm{~m}$ \\
$\mathrm{CC} 2$ & 4.2 & 10 & 21 & 106 & 213 & 1068 & 2136 & $106 \mathrm{~m}$ \\
\hline
\end{tabular}

\begin{tabular}{|c|c|c|c|c|c|c|c|c||c|}
\hline name & $250 \mathrm{~m}$ & $100 \mathrm{~m}$ & $50 \mathrm{~m}$ & $25 \mathrm{~m}$ & $10 \mathrm{~m}$ & $5 \mathrm{~m}$ & $1 \mathrm{~m}$ & $0.5 \mathrm{~m}$ & $(z)_{\text {ratio }=1}$ \\
\hline $\mathrm{F} 1$ & 0.81 & 2.0 & 4.0 & 8.1 & 20 & 40 & 202 & 405 & $202 \mathrm{~m}$ \\
\hline $\mathrm{F} 2$ & 0.01 & 0.03 & 0.07 & 0.15 & 0.39 & 0.78 & 3.9 & 7.8 & $3.9 \mathrm{~m}$ \\
$\mathrm{~K} 2$ & 0.10 & 0.25 & 0.50 & 1.0 & 2.5 & 5.0 & 25 & 50 & $25 \mathrm{~m}$ \\
$\mathrm{~F} 2$ & $0.5 \overline{1}$ & 1.4 & 2.8 & 5.7 & 14 & 28 & 144 & $2 S 8$ & $144 \mathrm{~m}$ \\
$\mathrm{U} 2$ & 2.9 & 7.4 & 14 & 29 & 74 & 148 & 742 & 1485 & $742 \mathrm{~m}$ \\
$\mathrm{Z} 2$ & 13 & 34 & 68 & 137 & 344 & 688 & 3440 & 6880 & $3440 \mathrm{~m}$ \\
\hline $\mathrm{A} 3$ & 0.06 & $0.1 \bar{\tau}$ & 0.34 & 0.69 & $1 . \overline{7}$ & 3.4 & 17 & 34 & $17 \mathrm{~m}$ \\
$\mathrm{E} 3$ & 0.41 & 1.0 & 2.0 & 4.1 & 10 & 20 & 104 & 208 & $104 \mathrm{~m}$ \\
$\mathrm{H} 3$ & 2.3 & 5.9 & 11 & 23 & 59 & 118 & 590 & 1181 & $590 \mathrm{~m}$ \\
$\mathrm{~J} 3$ & 12 & 30 & 61 & 123 & 309 & 618 & 3092 & 6184 & $3092 \mathrm{~m}$ \\
\hline
\end{tabular}

Table 5.3: Ratios of flocculation time to sinking time scale for cases with component grain densities of (top) $\rho_{s}<1500 \mathrm{~kg} \mathrm{~m}^{-3}$ and (bottom) $\rho_{s}>2500 \mathrm{~kg} \mathrm{~m}^{-3}$. In the last column is shown the value of water column depth (z) that gives a ratio of one. 


\section{Chapter 6}

\section{Implementation}

\subsection{Model Validation}

Before using the reduced model to calculate flocculation times, it is important to validate the Ir sdel by comparing $\tau_{B}$ and corrected values of $\tau_{J}$ for cases other than those which were used in the development of the regression equations. Inputs for new cases were created using a random number generator in the computer algebra system Maple. A function within this package selects random numbers from within a user-specified range. Values of $h . D 3, d_{\max }$, and $G$ were generated from within the range of values used in the previous cases. and $d_{0}$ and $\rho_{s}$ were calculated from these. Again, only those cases with $1100 \mathrm{~kg} \mathrm{~m}^{-3}<\rho_{s}<3000 \mathrm{~kg} \mathrm{~m}^{-3}$ were allowed. Model inputs for the new cases can be found in Appendix F (Table F.1). Table 6.1 lists the dimensionless flocculation times calculated using both methods for these cases. These results show that the corrected reduced model gives dimensionless flocculation times generally within $\sim 3 \%$ of the full model value. The relative difference does not exceed $6 \%$ for the cases tested. 


\begin{tabular}{|c|c|c|c|}
\hline$\#$ & $\tau_{B}$ & $\tau_{J_{\text {corrected }}}$ & $\frac{\Delta \tau}{\tau_{B}}$ \\
\hline 1 & 2.202 & 2.192 & $0.4 \%$ \\
2 & 1.945 & 1.997 & $-2.7 \%$ \\
3 & 0.689 & 0.649 & $5.8 \%$ \\
4 & $0.36 \tau$ & 0.378 & $-3.0 \%$ \\
5 & 2.245 & 2.309 & $2.9 \%$ \\
6 & $1.61 \tau$ & 1.639 & $-1.4 \%$ \\
$\tau$ & 1.366 & 1.346 & $1.4 \%$ \\
8 & 1.143 & 1.140 & $0.2 \%$ \\
9 & 2.006 & 2.095 & $-4.4 \%$ \\
10 & 1.097 & 1.150 & $-4.8 \%$ \\
11 & 0.995 & 0.980 & $1.5 \%$ \\
12 & 0.902 & 0.870 & $3.5 \%$ \\
13 & 2.049 & 2.106 & $-2.8 \%$ \\
14 & 0.940 & 0.887 & $5.6 \%$ \\
15 & 1.887 & 1.893 & $-0.3 \%$ \\
16 & 0.856 & 0.844 & $1.4 \%$ \\
$1 \tau$ & 2.322 & 2.371 & $-2.1 \%$ \\
18 & 0.802 & 0.789 & $1.6 \%$ \\
19 & 1.060 & 1.055 & $0.5 \%$ \\
20 & 1.813 & 1.817 & $-0.2 \%$ \\
\hline
\end{tabular}

Table 6.1: Dimensionless flocculation times calculated using the Batterham et al. (1981) model $\left(\tau_{B}\right)$ and the Junge-distribution method, corrected using the predictive equations, $\left(\tau_{J}\right.$ corrected $)$ for a number of new cases not used in the development of the predictive regression equations.

\subsection{Revisiting Published Flocculation Times}

The published estimates of flocculation time presented in the introduction will now be re-examined. McCave (1985) compares time scales for particle removal for three particle sizes $\left(d_{0}=\{1 \mu \mathrm{m}, 5 \mu \mathrm{m} .20 \mu \mathrm{m}\}\right)$ and conditions representative of bottom boundary layers. He calculates a half-life for aggregation due to turbulent shear only for $d_{0}=20 \mu \mathrm{m}$ as Brownian motion dominates for particles smaller than $8 \mu \mathrm{m}$ (McCave, 1984). With values of $C_{0}=100 \mu \mathrm{g} \mathrm{I}^{-1}, G=0.084 \mathrm{~s}^{-1}, \rho_{s}=1.282 \mathrm{~g} \mathrm{~cm}^{-3}$, 


\begin{tabular}{|c|c|c|}
\hline$d_{\max }$ & $D 3$ & $t_{\text {floc }}$ \\
\hline $1 \mathrm{~mm}$ & 2.0 & 4.0 years \\
& 1.5 & 4.1 years \\
\hline $10 \mathrm{~mm}$ & 1.6 & 3.3 years \\
& 1.5 & 2.1 years \\
\hline
\end{tabular}

Table 6.2: Flocculation times $\left(t_{\text {floc }}\right)$ calculated using the Junge-distribution method and inputs from McCave (1985). For both values of maximum floc diameter $\left(d_{\max }\right)$, flocculation times are calculated with the maximum and minimum values of fractal dimension ( $D 3$ ) that produce values of component grain density in the specified range.

and $E=0.1$, he calculates a half-life of $2 \tau$ years. In contrast. the time scale for deposition for this case is only 12 days $\left(z=50 \mathrm{~m}, w_{s}=4.09 \times 10^{-3} \mathrm{~cm} \mathrm{~s}^{-1}\right)$ : consequently, $\mathrm{McC}$ ave has concluded that deposition is the dominant removal mechanism for particles of this size.

A different result is obtained using the Junge-distribution model. With McCave's reported maximum floc size of 2 to $4 \mathrm{~mm}$ and an initial number concentration of $N_{0}=1.9 \times 10^{7} \mathrm{~m}^{-3}$. the range of flocculation times presented in Table 6.2 are calculated. Since fractal dimension is not reported, the maximum and minimum fractal dimensions that produce reasonable solids densities for each value of $d_{\max }$ are used. These flocculation times are considerably shorter than $2 \tau$ years. but longer than the half-life for deposition. so McCave's conclusion remains unchallenged. However. if the mass concentration is increased to $10 \mathrm{mg} \mathrm{l}^{-1}$, a concentration which is observed in bottom boundary layers in the deep sea (Hollister et al., 1984), then the flocculation times presented above decrease by a factor of 100 and the depositional and flocculation time scales are of the same order.

Logan et al. (1995) calculate flocculation half-lives for a number of different environments and two particle species, TEP and phytoplankton. For conditions in the coastal ocean $\left(N_{0}=380 \mathrm{ml}^{-1}, d_{0}=20 \mu \mathrm{m}, d_{m a x}=1000 \mu \mathrm{m}, G=1 \mathrm{~s}^{-1}\right.$, and $\alpha=1)$, they advanced a half-life of 3.4 days. For a freshwater lake $\left(N_{0}=860 \mathrm{ml}^{-1}\right.$. $d_{0}=20 \mu \mathrm{m}$ ), they obtained a half-life of $I$ day. The flocculation times calculated for 


\begin{tabular}{|c|c|c|}
\hline environment & $D 3$ & $t_{\text {floc }}$ \\
\hline coastal ocean & 2.0 & 3.4 days \\
& 1.5 & $22 . \overline{\text { hours }}$ \\
\hline freshwater lake & 2.0 & 1.5 days \\
& 1.5 & 10.0 hours \\
\hline
\end{tabular}

Table 6.3: Flocculation times calculated using the Junge-distribution method and inputs from Logan et al. (1995). Flocculation times are obtained using a maximum floc diameter of $d_{\max }=1 \mathrm{~mm}$ and maximum and minimum values of fractal dimension (D3) that produce values of component grain density in the specified range.

\begin{tabular}{|c|l|c|c|}
\hline day & particle & $D 3$ & $t_{\text {floc }}$ \\
\hline \multirow{\imath}{*}{} & TEP & 2.0 & 3.8 days \\
& & 1.5 & 1.0 days \\
\cline { 2 - 4 } & phytoplankton & 1.7 & 9.5 days \\
& & 1.5 & 6.1 days \\
\hline 11 & phytoplankton & $1 . \bar{y}$ & 1.0 days \\
& & 1.5 & 16.2 hours \\
\hline
\end{tabular}

Table 6.4: Flocculation times calculated using the Junge-distribution method and inputs from Logan et al. (1995). Flocculation times are obtained using a maximum floc diameter of $d_{m a x}=1 \mathrm{~mm}$ and maximum and minimum values of fractal dimension (D3) that produce values of component grain density in the specified range. For day 11, component grain densities calculated using the Junge-distribution method for TEP were outside of the acceptable range for all values of $D 3$.

these suspensions are given in Table 6.3.

Logan et al. (1995) also compare half-lives from a mesocosm experiment and conclude that the characteristic sinking of diatom blooms is controlled by TEP. They measure concentrations and calculate half-lives for 6 days, after an initial incubation period of 6 days. For TEP on day $i, \alpha=0.21, N_{0}=1400 \mathrm{ml}^{-1}$, and $d_{0}=20 \mu \mathrm{m}$. while for phytoplankton, $\alpha=0.015, N_{0} \approx 220 \mathrm{ml}^{-1}$. and $d_{0}=53 \mu \mathrm{m}$. The shear rate in the tank is calculated to be $G=1.3 \mathrm{~s}^{-1}$. On day 11, TEP concentration and diameter are $N_{0} \approx 550 \mathrm{ml}^{-1}$, and $d_{0}=112 \mu \mathrm{m}$, and phytoplankton concentration 
is $N_{0} \approx 2000 \mathrm{ml}^{-1}$. The half-lives they calculate for TEP and phytoplankton on the seventh day are 2 days and 10 days, respectively, and for day 11, they calculate halflives of 0.01 days and 0.2 days. Table 6.4 lists flocculation times for these suspensions for various values of $D 3$, since none are reported.

The half-lives calculated by Logan et al. (1995) are better estimates of flocculation time than in the previous example. Although flocculation times triple over the range of fractal dimensions, half-lives are consistently of the same order as flocculation times. This discrepancy likely results from the magnitude of the shear rate for each case. A deep-sea bottom boundary layer is a low-shear environment $\left(G=0.084 \mathrm{~s}^{-1}\right)$; thus differential settling encounter is the dominant mechanism in this situation. However. the half-life calculated is for turbulent shear encounter alone. On the other hand. a mesocosm is a relatively high-shear environment $\left(G=1.3 \mathrm{~s}^{-1}\right)$, where turbulent shear is a more important mechanism; consequently, half-life is a more appropriate estimate of flocculation time for this case.

\subsection{Limitations of Method}

This new method for estimating flocculation time has several limitations, some of which are the same as those for the sectional model. For instance. neither the full nor the reduced model includes particle disaggregation. Limiting the mavimum particle size can be thought of as setting all sticking coefficients in sections larger than $h$ to zero, so that any particle larger than $2^{h-1} v_{0}$ is broken instantly upon formation. However, particles smaller than $2^{h-1} v_{0}$ are also subject to breakup forces, and no attempt is made to include these forces into either model. Another limitation of both models is that only initially monodispersed suspensions can be modeled. Modeling truly polydispersed suspensions involves tracking individual component grains throughout the evolution of the size distribution. While it is possible to do this, such a model would be difficult to implement and computationally expensive to run.

Other limitations are unique to the reduced model. One is that it does not allow 
both $d_{0}$ and $\rho_{s}$ to be specified. This restriction is necessary to ensure that maximum floc size and settling velocity are limited to realistic values. However, there may be situations, e.g. diatom blooms. when mean size and density are known. Also, no dilution effects have been included into the reduced model. Dilution is distinct from settling loss in that there is no size discrimination. It is an important factor in the study of plumes. 


\section{Chapter 7}

\section{Conclusions}

Bremer et al. (1995)'s formulation provides an easy method for calculating flocculation time, if one is willing to neglect differential settling encounter. It is a considerable improvement over half-life, which includes no effect of particle geometry. As these results have shown, fractal dimension is an important parameter in any calculation of flocculation time.

For a robust estimate of flocculation time, one in which both turbulent shear and differential settling are considered. the Junge-distribution model offers a fast method of calculation. On a SPARC station 10 Model 41. typical model run-time is reduced from 1 to 2 hours to between 15 and 30 seconds. Although the relationship between $\tau_{J}$ and $\tau_{B}$ varies. the regression equations provide corrected $\tau_{J}$ values to within $\sim 6 \%$ of $\tau_{B}$.

In addition to aggregation, processes such as sinking out of the water column, dilution, and particle breakup also contribute to changing number concentrations with time. For sinking loss, the ratio of flocculation time to sinking time determines whether the Junge-distribution method can be used. The effects of dilution and particle break up remain to be investigated. 


\section{Appendix A}

\section{Analytical Solutions to the Stochastic Collection Equation}

\section{A.1 Initially Monodisperse Suspension and Con- stant Kernel}

For the case where $\beta=C$. the solution to (2.1) for a monodisperse initial particle size distribution is given by (Kostoglou and Karabelas. 1994)

$$
\begin{aligned}
& n_{1}=\left(1+\frac{\tau}{2}\right)^{-2} \\
& n_{2}=\left(1+\frac{\tau}{2}\right)^{-2}\left(\frac{\tau}{2+\tau}+\frac{1}{2}\left(\frac{\tau}{2+\tau}\right)^{2}\right) \\
& n_{k}=\left(1+\frac{\tau}{2}\right)^{-2} \sum_{i=\frac{3}{4} 2^{k-1}}^{i=\frac{3}{4} 2^{k}} q_{i}\left(\frac{\tau}{2+\tau}\right)^{i-1}
\end{aligned}
$$

where

$$
q_{i}= \begin{cases}\frac{1}{2}, & \text { if } i=\frac{3}{4} 2^{k-1} \text { or } i=\frac{3}{4} 2^{k} \\ 1, & \text { otherwise }\end{cases}
$$




\section{A.2 Initially Bidisperse Suspension and Sum Ker- nel}

For the case where $\beta=b(u+v)$, the solution to (2.1) for a bidisperse initial particle size distribution is given by (Scott. 1968)

$$
\phi(x, \tau)=(1-\tau) e^{-x \tau} \sum_{k=0}^{\infty}(x \tau)^{k} \sum_{j=0}^{k+1} \frac{\left(\frac{N_{1}}{N_{0}}\right)^{k+1-j}\left(\frac{N_{m}}{N_{0}}\right)^{j} \delta\left[x-\frac{v_{1}}{v_{0}}(m j+k+1-j)\right]}{j !(k+1-j) !} .
$$

where

$$
\begin{aligned}
\phi(x . \tau) & =\frac{v_{0}}{N_{0}} n(v, t) \text { is the dimensionless spectrum function. } \\
x & =\frac{v}{v_{0}} \text { is the dimensionless volume. } \\
\tau & =1-e^{-b N_{0} v_{0} t} \text { is the dimensionless time. } \\
v_{0} & =\frac{\left(N_{1}+m N_{m}\right) v_{1}}{N_{0}} \text { is the initial mean particle volume. } \\
N_{0} & =N_{1}+N_{m} \text { is the initial number of particles. }
\end{aligned}
$$

$t$ is time, $b$ is a constant, $N_{\mathrm{L}}$ is the initial number of particles of volume $v_{\mathrm{L}}$, and $\mathrm{V}_{m}$ is the initial number of particle of volume $v_{m}$, where $v_{m}=m v_{1}$ and $m$ is a constant. For the case shown in Figure $3.1, d_{1}=10^{-5} \mathrm{~m} . m=3 . N_{1}=145 . N_{m}=48 . b=1.53 \times 10^{3}$. 


\section{Appendix B}

\section{Physical Constants}

\begin{tabular}{|l|c|}
\hline property & value \\
\hline density of seawater, $\rho$ & $1035 \mathrm{~kg} \mathrm{~m}^{-3}$ \\
\hline viscosity of seawater. $\mu$ & $0.001 \mathrm{~Pa} \mathrm{~s}$ \\
\hline constant of gravitation acceleration, $g$ & $9.81 \mathrm{~m} \mathrm{~s}^{-2}$ \\
\hline
\end{tabular}

Table B.1: Physical constants employed in models. 
Appendix C

\section{Plots for $d_{\max }=10 \mathrm{~mm}$ and $d_{\max }=1 \mathbf{m m}$}



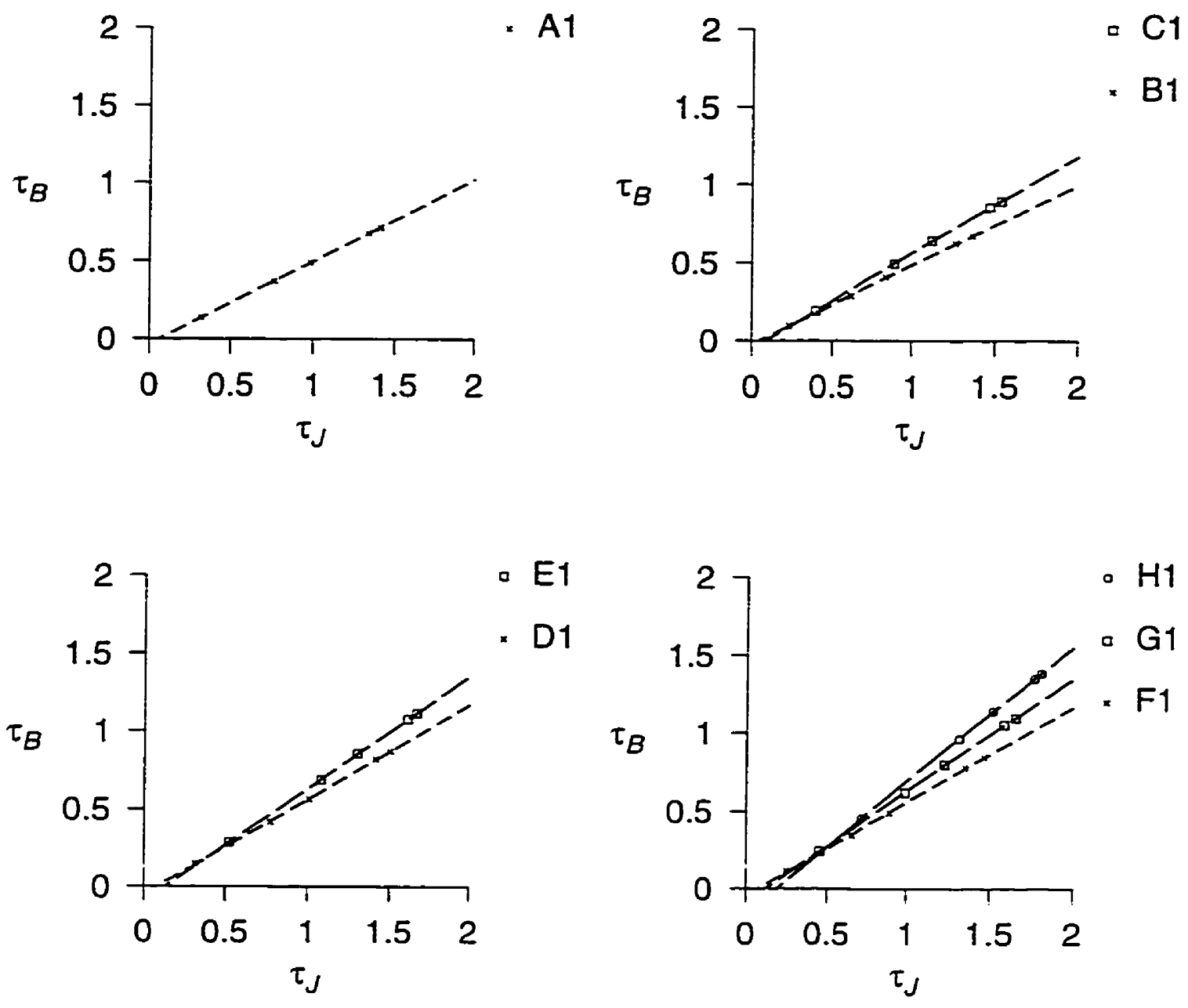

Figure C.1: Comparison of dimensionless flocculation times for turbulent shear and differential settling encounter calculated using the full model $\left(\tau_{B}\right)$ and the Jungedispersion approach $\left(\tau_{J}\right)$ for all cases with maximum diameter of $d_{\max }=10 \mathrm{~mm}$. Each plot shows the cases with the same number of sections. Regression lines are drawn through points within the same case $\left(R^{2}>0.99\right.$ for all regression lines). 

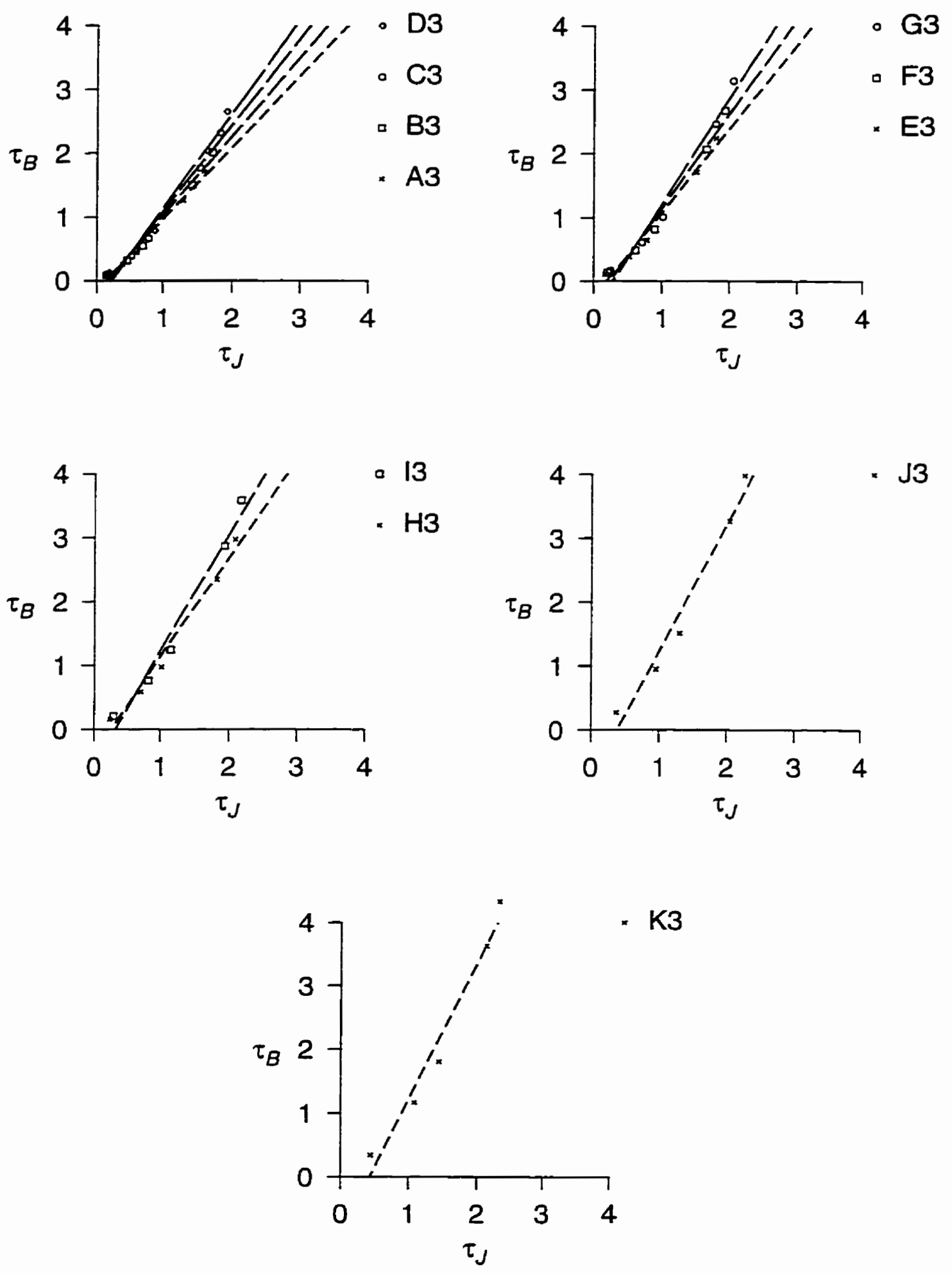

Figure C.2: Comparison of dimensionless flocculation times for turbulent shear and differential settling encounter calculated using the full model $\left(\tau_{B}\right)$ and the Jungedispersion approach $\left(\tau_{J}\right)$ for all cases with maximum diameter of $d_{\max }=0.1 \mathrm{~mm}$. Each plot shows the cases with the same number of sections. Regression lines are drawn through points within the same case $\left(R^{2}>0.99\right.$ for all regression lines). 
Appendix D

Mass Distributions 

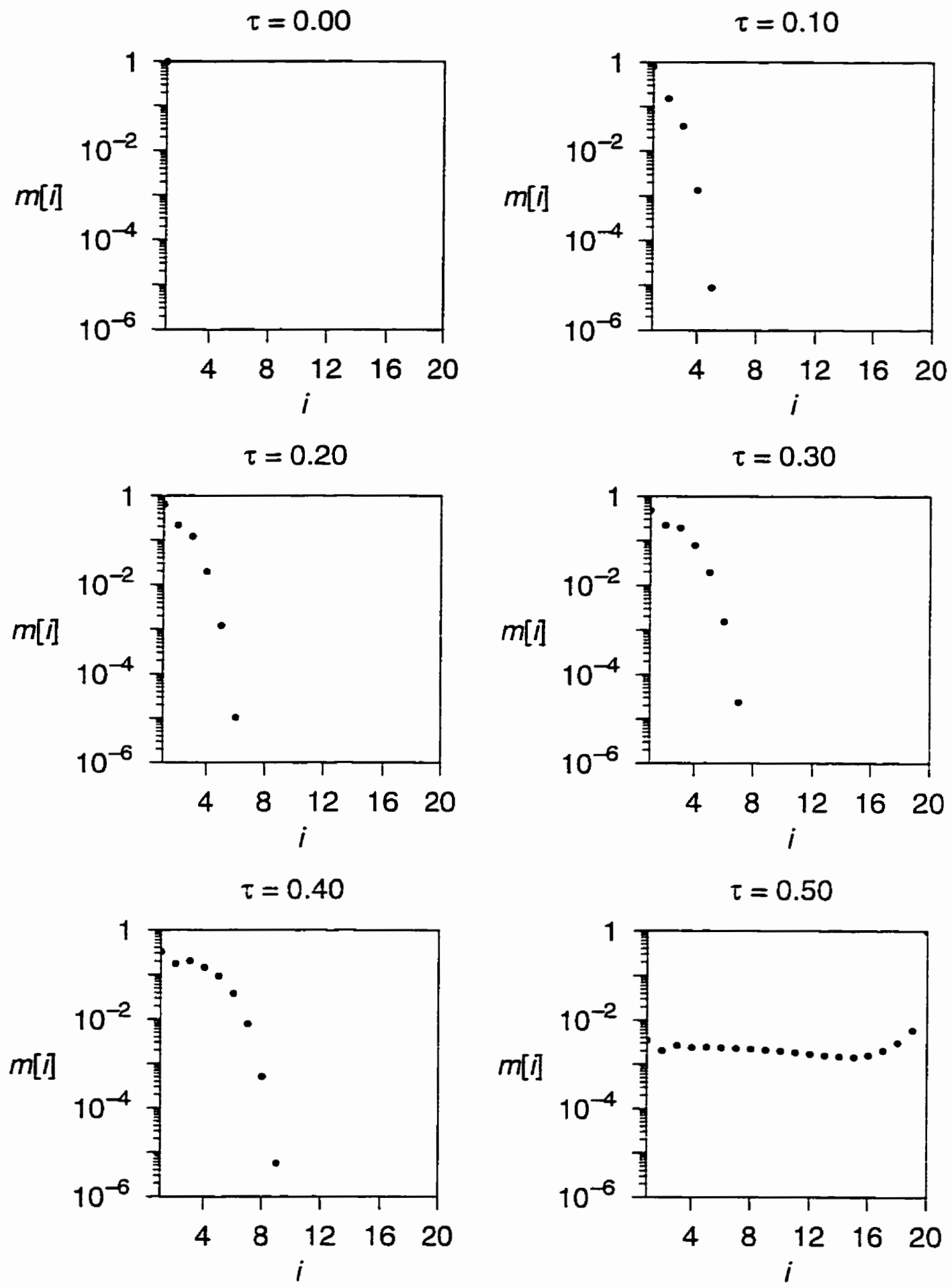

Figure D.1: Nondimensional mass distributions at various times throughout its evolution for case $F 1, G=1 \mathrm{~s}^{-1}$. The flocculation time is $\tau_{\text {floc }}=0.491$. 

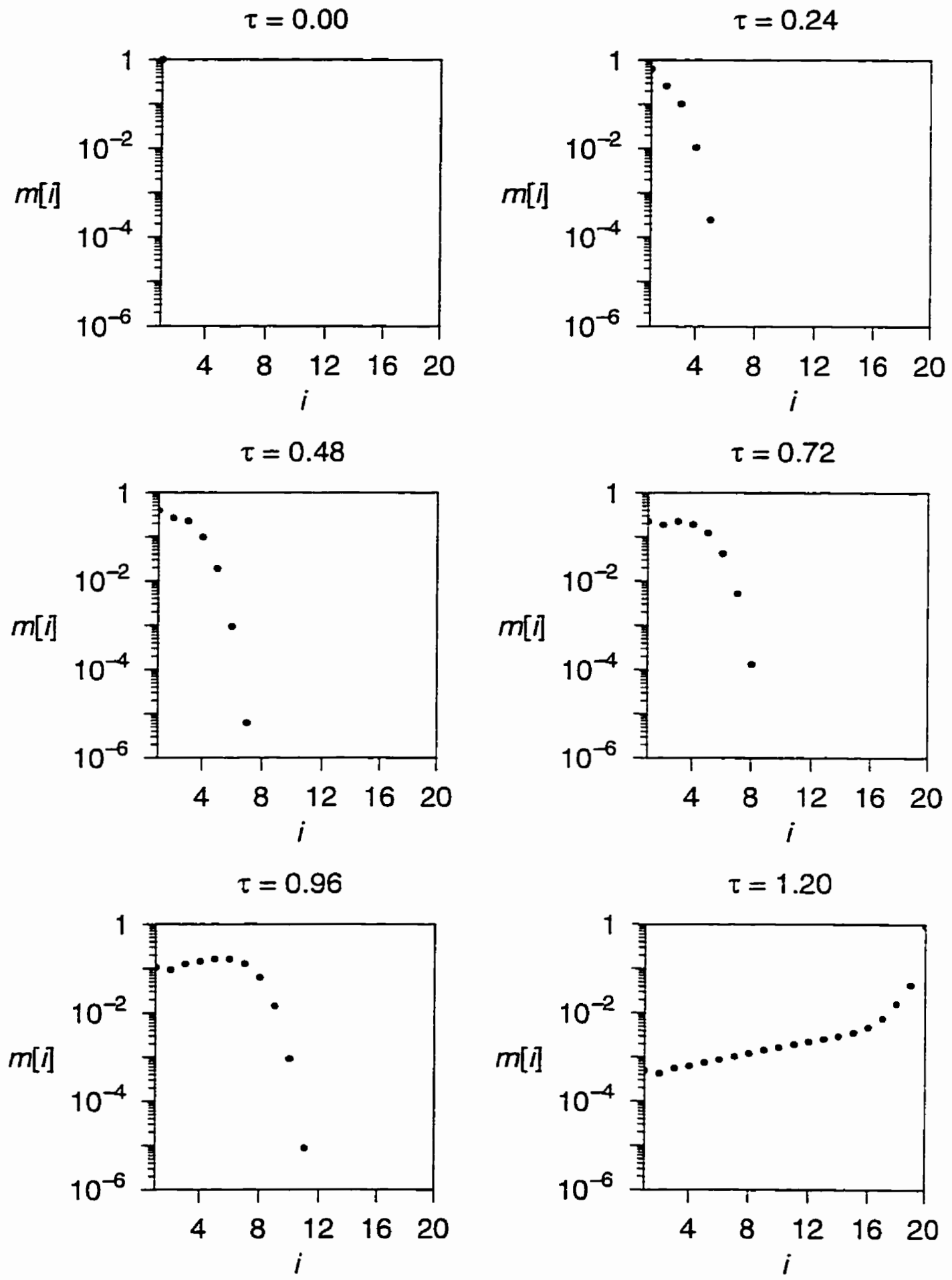

Figure D.2: Nondimensional mass distributions at various times throughout its evolution for case $\mathrm{Z} 2, G=1 \mathrm{~s}^{-1}$. The flocculation time is $\tau_{\text {floc }}=1.163$. 

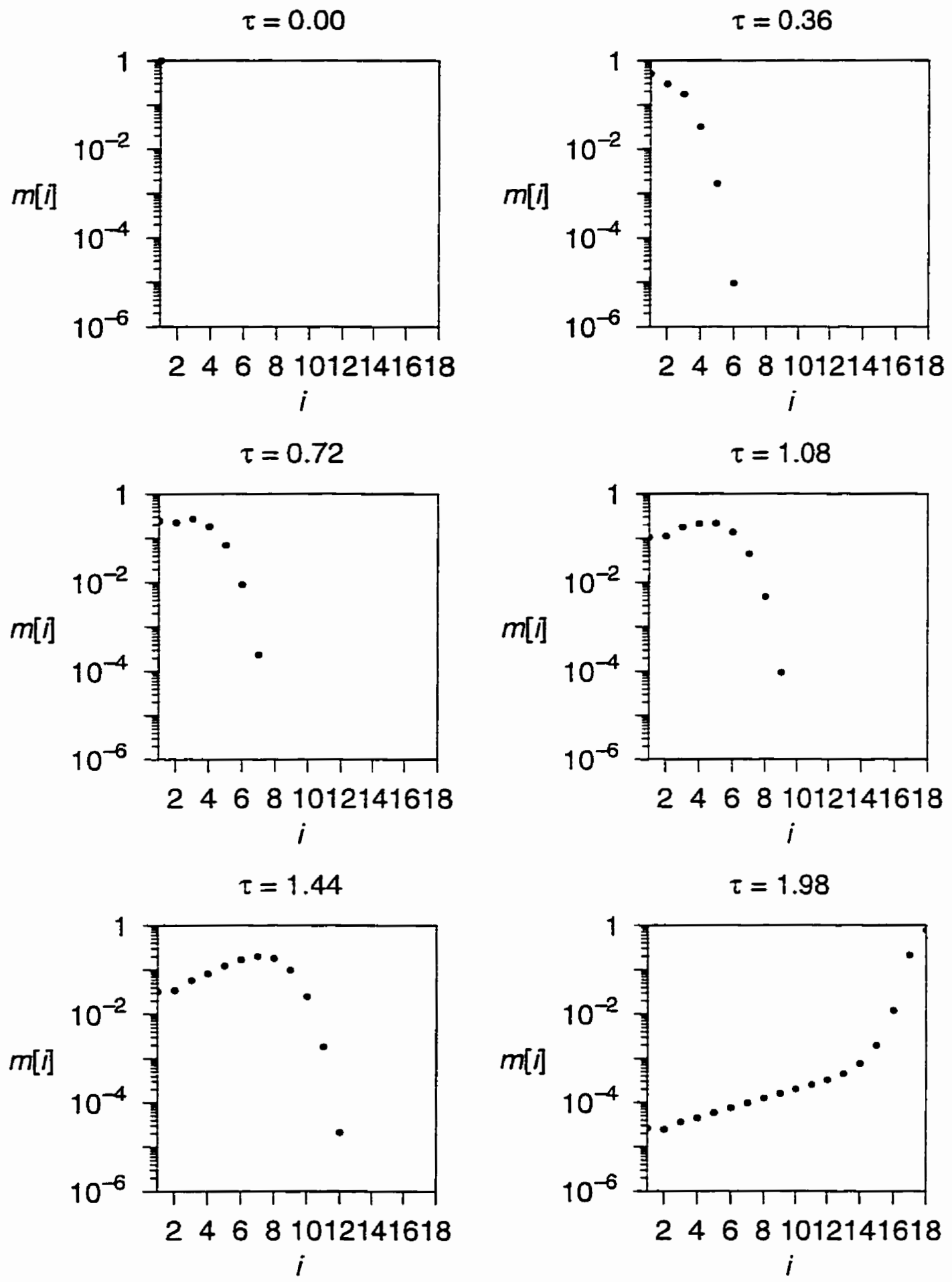

Figure D.3: Nondimensional mass distributions at various times throughout its evolution for case $\mathrm{K} 3, G=1 \mathrm{~s}^{-1}$. The flocculation time is $\tau_{\text {floc }}=1.805$. 

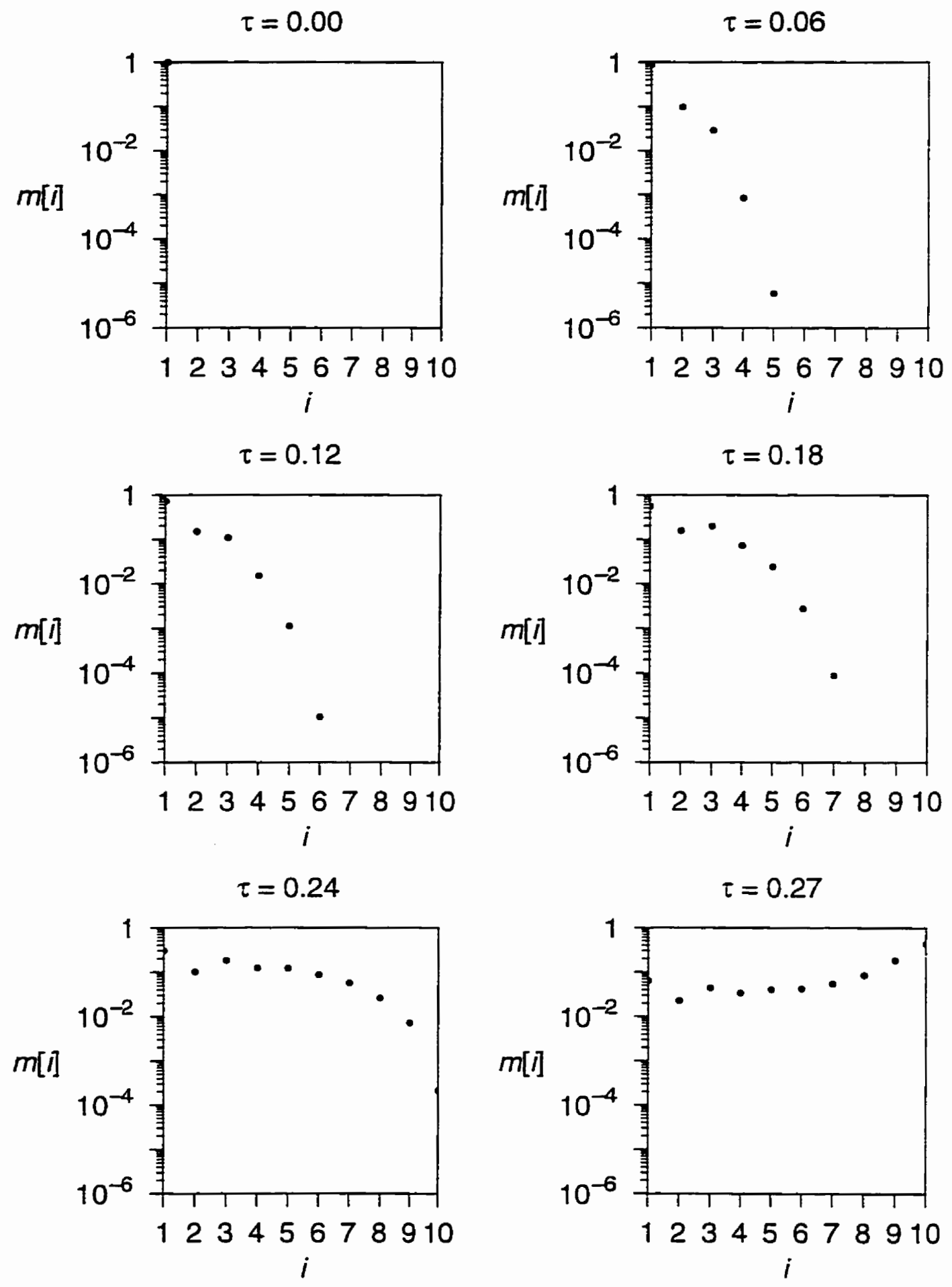

Figure D.4: Nondimensional mass distributions at various times throughout its evolution for case A2, $G=1 \mathrm{~s}^{-1}$. The flocculation time is $\tau_{\text {floc }}=0.268$. 

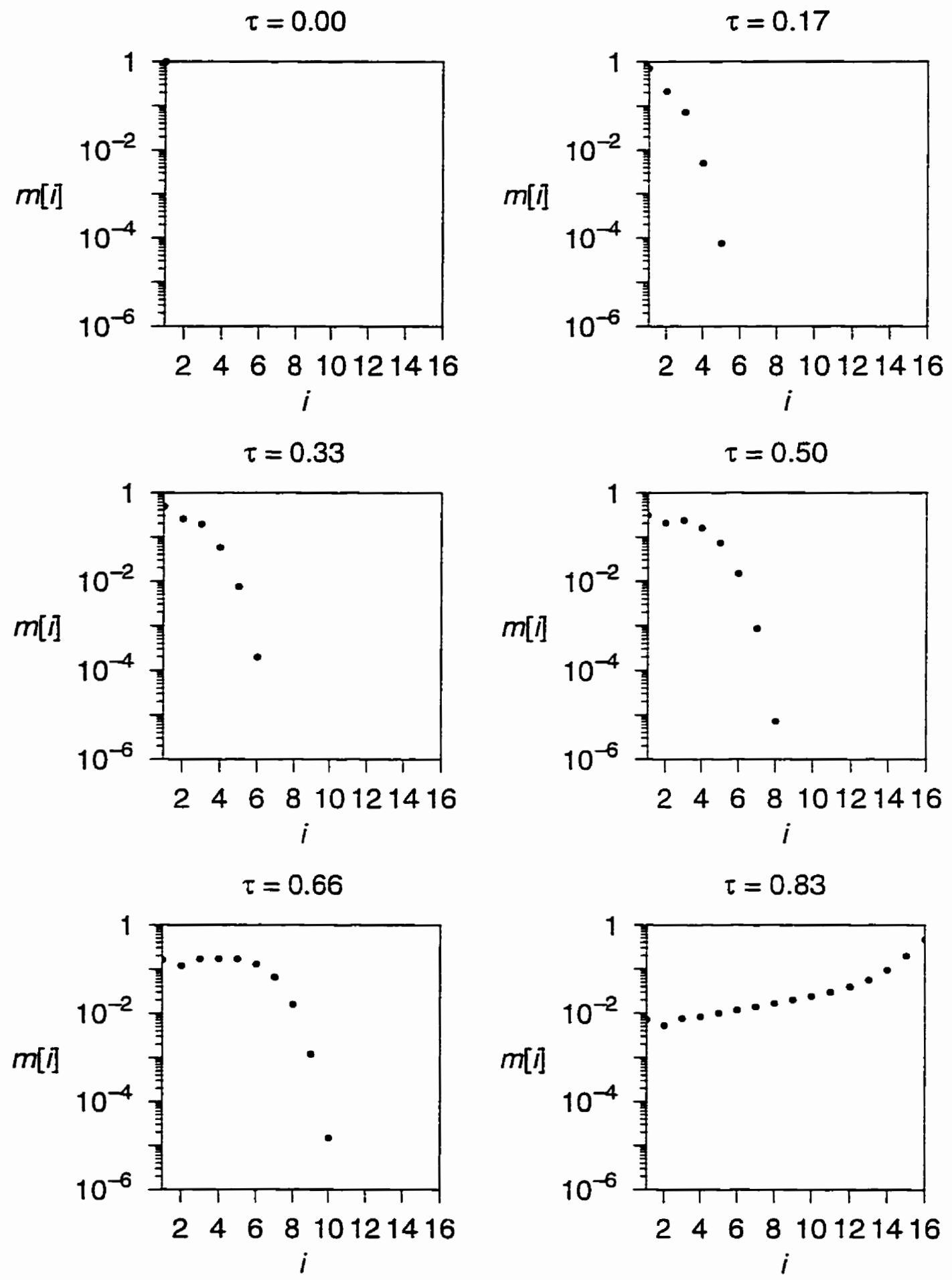

Figure D.5: Nondimensional mass distributions at various times throughout its evolution for case Q2, $G=1 \mathrm{~s}^{-1}$. The flocculation time is $\tau_{\text {floc }}=0.824$. 
67
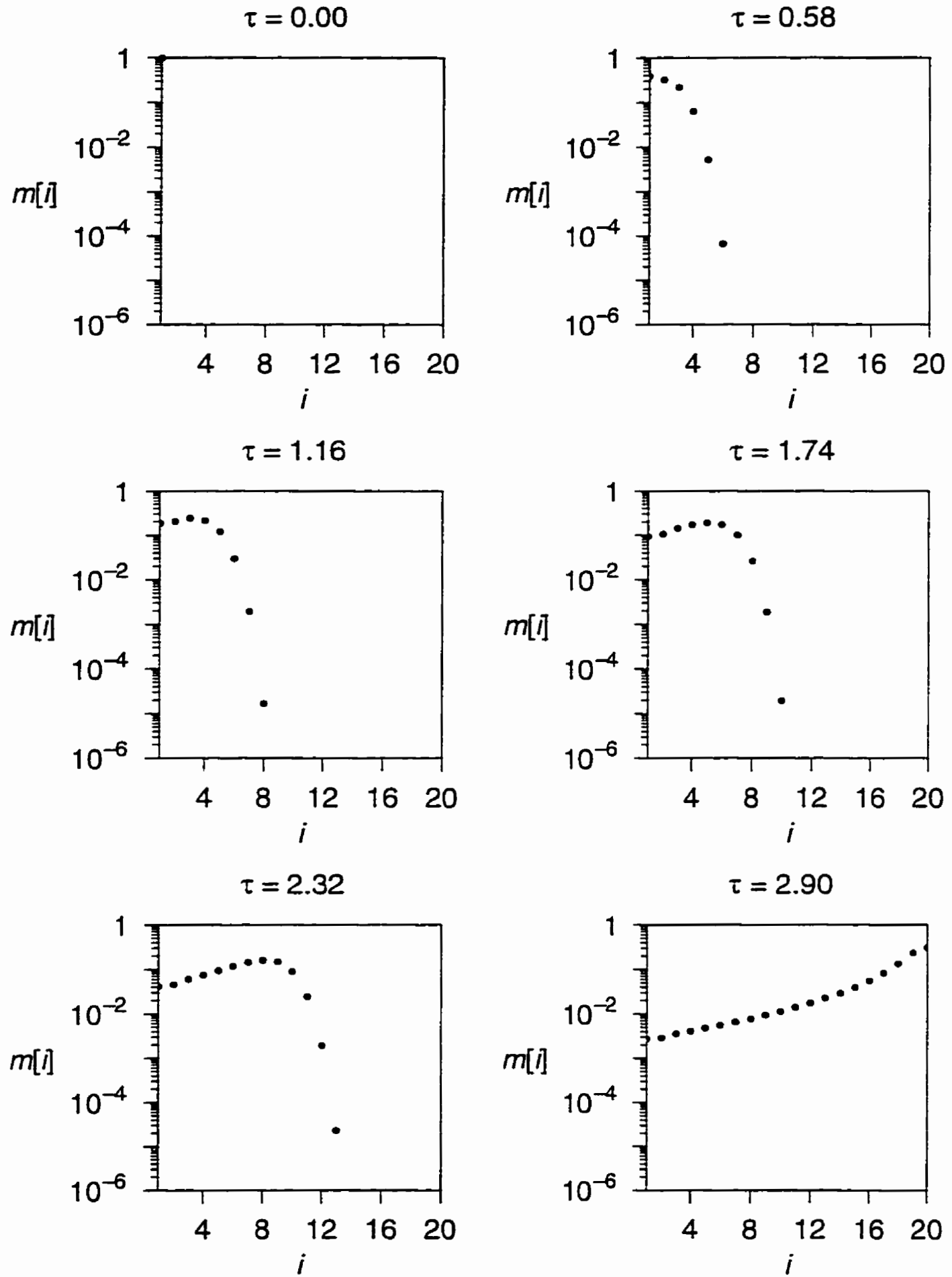

Figure D.6: Nondimensional mass distributions at various times throughout its evelotion for case CC2. $G=1 \mathrm{~s}^{-1}$. The flocculation time is $\tau_{\text {floc }}=2.887$. 
Appendix E

MINITAB Output 


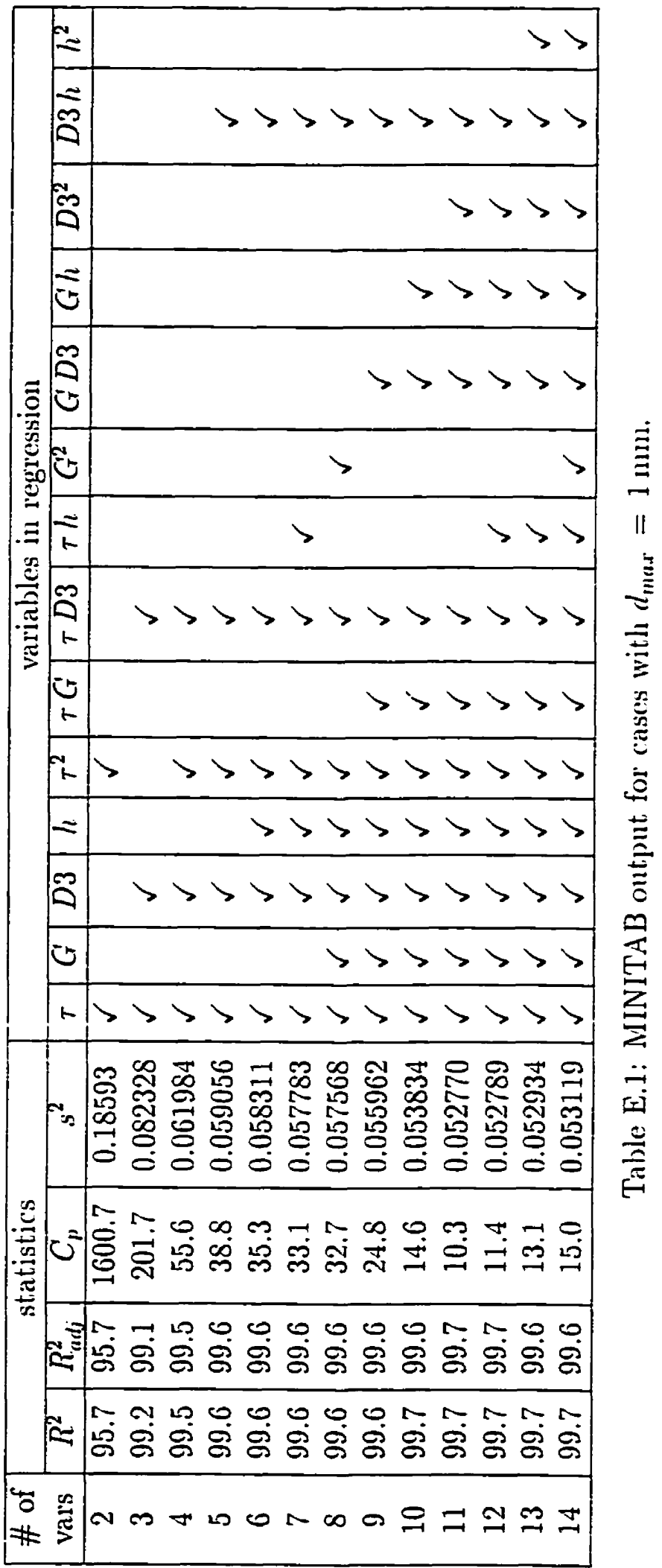




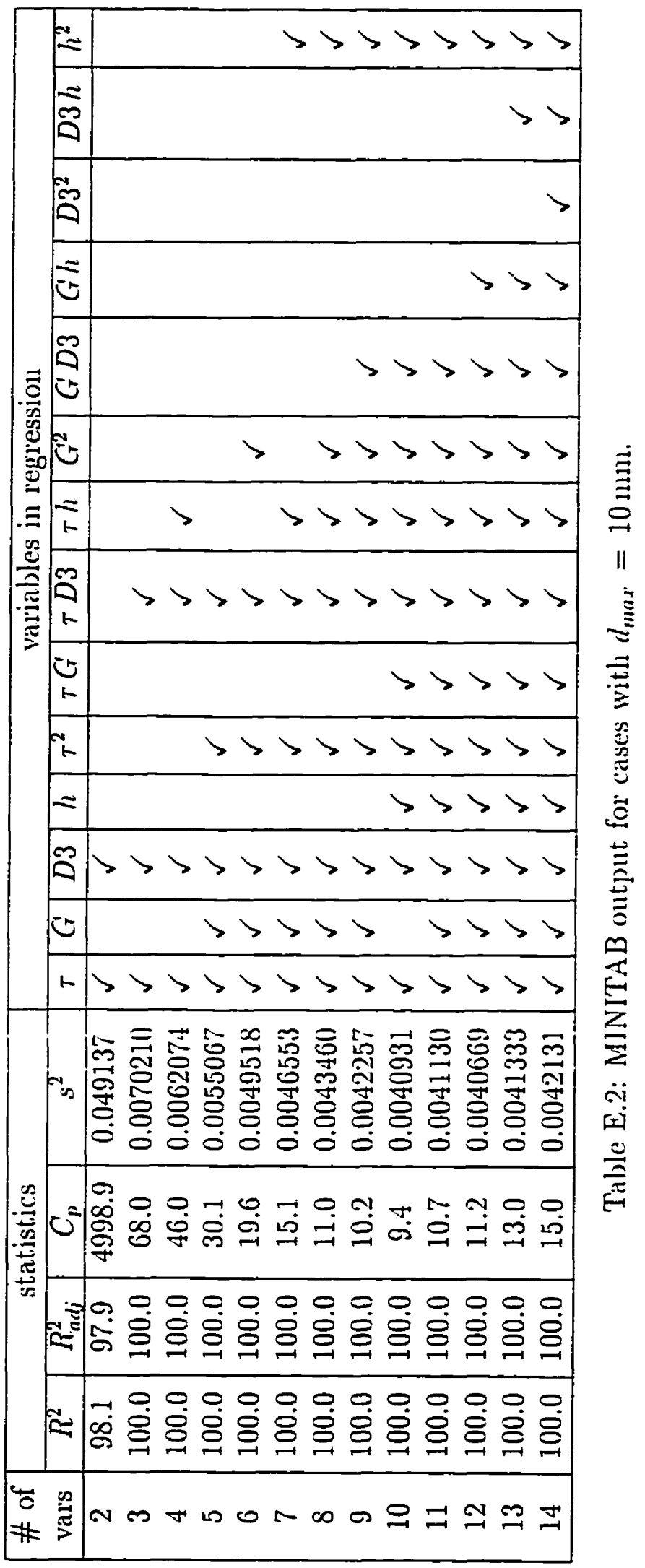




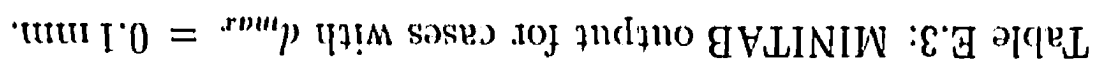

\begin{tabular}{|c|c|c|c|c|c|c|c|c|c|c|c|c|c|c|c|c|c|c|}
\hline$r$ & $\uparrow$ & 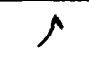 & $r$ & $\uparrow$ & $\uparrow$ & $r$ & $\uparrow$ & 个 & $\mu$ & $\mu$ & $\Lambda$ & $\mu$ & 1 & $8090 E 0^{\circ} 0$ & $0.9 I$ & 6.66 & 6.66 & $D[$ \\
\hline$\Lambda$ & $\uparrow$ & $\wedge$ & $r$ & 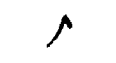 & & 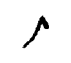 & $\wedge$ & $\wedge$ & $\wedge$ & $\mu$ & $\Lambda$ & $\wedge$ & 1 & SED0C0 0 & $6 . \varepsilon I$ & 6.66 & 6.66 & $\varepsilon I$ \\
\hline$\uparrow$ & $\uparrow$ & & $r$ & $\uparrow$ & & $\wedge$ & $\wedge$ & $\wedge$ & 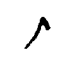 & 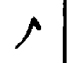 & $\wedge$ & 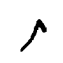 & $\uparrow$ & $0 \angle \angle O C 0^{\circ} 0$ & 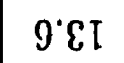 & 6.66 & 6.66 & $Z I$ \\
\hline & 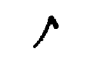 & & $r$ & 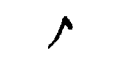 & & $r$ & $\wedge$ & $\wedge$ & $r$ & $\mu$ & $\mu$ & $r$ & $r$ & $\angle D G Z E 0^{\circ} 0$ & $\varepsilon .8 I$ & 6.66 & 6.66 & II \\
\hline & $\wedge$ & & 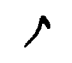 & $\uparrow$ & $\wedge$ & & & $\wedge$ & 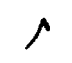 & $\mu$ & $\wedge$ & r & $r$ & $098 \varepsilon \varepsilon 0^{\circ} 0$ & $0.0 \bar{z}$ & 6.66 & 6.66 & $0 \tau$ \\
\hline & $\wedge$ & & 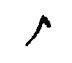 & & $\wedge$ & $r$ & $\wedge$ & & & $\wedge$ & $r$ & $\wedge$ & $r$ & TLLLEO 0 & $\varepsilon^{\prime} I \varepsilon$ & 6.66 & $6^{\prime} 66$ & 6 \\
\hline & & & $r$ & & 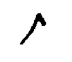 & $r$ & $\wedge$ & & & $\uparrow$ & 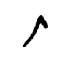 & 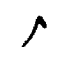 & $r$ & $\angle S E B S 0^{\circ} 0$ & I'E & 6.60 & 6.66 & 8 \\
\hline & & & & & $r$ & 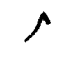 & 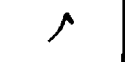 & & & 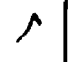 & $\wedge$ & $\wedge$ & $\wedge$ & $\varepsilon 800 \mp 0^{\circ} 0$ & $98 \varepsilon$ & 6.66 & 0.66 & $L$ \\
\hline & $\uparrow$ & & 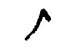 & 1 & & & & & 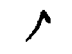 & & $\wedge$ & & 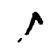 & $Z \angle G D 60^{\circ} 0$ & 899 & 860 & 6.66 & 9 \\
\hline & & $\boldsymbol{r}$ & & & & & & 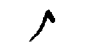 & 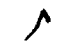 & & & $\Lambda$ & $\wedge$ & $\varepsilon \angle \hbar 090^{\circ} 0$ & 578 & 866 & $8^{\circ} 60$ & $g$ \\
\hline & & & & & & & & 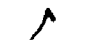 & 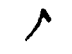 & & & 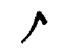 & 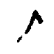 & 9909900 & $9.90 \mathrm{I}$ & $\angle 66$ & 8.66 & D \\
\hline & & & & & & & & & $r$ & & & $\wedge$ & 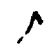 & S8GEL0 0 & $9.9 z Z$ & 960 & 9.66 & $\varepsilon$ \\
\hline & & & & & & & & & $\Lambda$ & & & & 1 & $00 \varepsilon I^{\prime}{ }^{*} 0$ & $\angle 009$ & 6.86 & 0.66 & $z$ \\
\hline 24 & $4 \varepsilon a$ & ${ }_{2} \varepsilon G$ & 4.1 & $\varepsilon(D)$ & 2i) & 41 & $\varepsilon a \perp$ & i) 1 & $a^{\perp}$ & $y$ & $\varepsilon a$ & i) & $\perp$ & $z^{s}$ & dD & $?{ }_{2}^{p w} y$ & $z$ & s.ten \\
\hline & & & & & & $\mathrm{tu}$ & qut.te & & & & & & & & 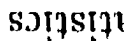 & & & fo \# \\
\hline
\end{tabular}




\section{Appendix F}

\section{New cases for Model Validation}

\begin{tabular}{|c|c|c|c|c|c|c|}
\hline$\#$ & $h$ & $d_{\max }[\mathrm{mm}]$ & $D 3$ & $G\left[\mathrm{~s}^{-\mathrm{i}}\right]$ & $d_{0}[\mu \mathrm{m}]$ & $\rho_{s}\left[\mathrm{~kg} \mathrm{~m}^{-3}\right]$ \\
\hline 1 & 11 & 0.10 & 2.41 & 6.68 & 5.635 & 2036 \\
2 & 18 & 1.0 & 2.04 & 4.31 & 3.100 & 1504 \\
3 & 16 & 1.0 & 1.81 & 1.42 & 3.201 & 2742 \\
4 & 11 & 1.0 & 1.54 & 1.68 & 11.10 & 2345 \\
5 & 17 & 1.0 & 2.07 & 7.82 & 4.712 & 1302 \\
6 & 10 & 1.0 & 1.88 & 7.91 & 36.22 & 1110 \\
7 & 19 & 10.0 & 1.80 & 5.81 & 9.766 & 1110 \\
$S$ & 15 & 1.0 & 1.90 & 2.13 & 6.052 & 1540 \\
9 & 12 & 1.0 & 2.00 & 5.95 & 22.10 & 1118 \\
10 & 15 & 1.0 & 1.76 & 9.13 & 4.031 & 2744 \\
11 & 11 & 1.0 & 1.76 & 3.28 & 19.48 & 1277 \\
12 & 10 & 1.0 & 1.86 & 1.14 & 34.95 & $111 \mathrm{~S}$ \\
13 & 13 & 1.0 & 2.07 & 3.95 & 17.98 & 1112 \\
14 & 10 & 1.0 & 1.66 & 5.52 & 23.33 & 1317 \\
15 & 11 & 0.10 & 2.39 & 5.01 & 5.501 & 2111 \\
16 & 17 & 10.0 & 1.59 & 9.68 & 9.349 & 1377 \\
17 & 19 & 1.0 & 2.10 & 5.50 & 2.629 & 1420 \\
18 & 16 & 10.0 & 1.56 & 9.55 & 12.75 & 1305 \\
19 & 18 & 10.0 & 1.70 & 4.06 & 9.766 & 1185 \\
20 & 11 & 0.10 & 2.27 & 7.49 & 4.719 & 2739 \\
\hline
\end{tabular}

Table F.1: Model inputs for new cases not used in the development of the predictive regression equations. 


\section{References}

Alldredge, A.L. and McGillivary, P., "The Attachment Probabilities of Marine Snow and Their Implications for Particle Coagulation in the Ocean". Deep-Sea Research, Vol. 38, No. 4. 1991

Batterham, R.J, Hall, J.S., and Barton, G.. Pelletizing Kinetics and Simulation of Full-Scale Balling Circuits", in Proceedings. 3rd International Symposium on Agglomeration. Nurnberg, Federal Republic of Germany. 1981

Bremer. L.G.B., Walstra, P., and van Vliet. T.. "Estimations of the Aggregation Time of Various Colloidal Systems", Colloids and Surfaces A: Physicochemical and Engineering Aspects, Vol. 99, 1995

Bonner, J.S., Ernest. A.N., Hernandez. D.S., and Autenrieth. R.L.. "Transport of Sewage Sludge in a Mixed Water Column”. Chemistry and Ecology, Vol. 7, 1992

Dealy, J.MI., "Official Nomenclature for Material Functions Describing the Response of a Viscoelastic Fluid to Various Shearing and Extensional Deformation”. Journal of Reology, Vol. 28, 1984

Delichatsios, M.A. and Probstein, R.F., "Coagulation in Turbulent Flow: Theory and Experiment", Journal of Colloid and Interface Science. Vol. 51, No. 3, 1975

Drake, R.L., "A General Mathematical Survey of the Coagulation Equation", in Topics in Current Aerosol Research, Volume 3 (Part 2), edited by G.M. Hidy, 
and J.R. Brock, pp. 203-376. Pergamon Press, New York. 1972

Dyer, K.R., Cornelisse, J.. Dearnaley, M.P., Fennessy, M.J.. Jones, S.E., Kappenberg, J., McCave, I.N.. Pejrup, M.. Puls, W., van Leussen. W.. and Wolfstein. K.. -A Comparison of In Situ Techniques for Estuarine Floc Settling Velocity Measurements". Journal of Sea Research, Vol. 36. 1996

Farley, K.J. and Morel, F.M.M.. "Role of Coagulation in the Kinetics of Sedimentation". Environmental Science and Technology, Vol. 20. No. 2. 1986

Fowler. S.W. and Knauer. G.A.. - Role of Large Particles in the Transport of Elements and Organic Compounds Through the Oceanic Water Column in Oceanography. Vol.16. 1986

Friedlander. S.K.. Smoke. Dust. and Haze: Fundamentals of Aerosol Behavior. Wiley-Interscience. New York. 197\%

Garnier. J.-MI., Martin, J.-MI., Mouchel. J.-MI., and Thomas, A.J.. “Surface Properties Characterization of Suspended Matter in the Ebro Delta (Spain): With an Application to Trace Metal Sorption", Estuarine, Coastal and Shelf Science. Vol. 36. 1993 Density". Journal of Geophysical Research. Vol. 90. No. C2. 1985

Han. M. and Lawler. D.F. "The (Relative) Insignificance of G in Flocculation". Journal of the American Water Works Association. Vol. S4. 1992 Kinetics of Coagulation". Journal of Colloid Science, Vol. 20, 1965

Hill, P.S. and Nowell, A.R.M., -The Potential Role of Large, Fast-Sinking Particles in Clearing Nepheloid Layers", Philosophical Transactions of the Royal Society. London. Vol. 331. 1990

Hill, P.S. and Nowell, A.R.M.. "Comparison of Two Models of Aggregation in Continental-Shelf Bottom Boundary Layers", Journal of Geophysical Research, Vol. 100, No. C11, 1995 
Hill, P.S., Nowell. A.R.M., and Jumars. P.A., "Encounter Rate by Turbulent Shear of Particles Similar in Diameter to the Kolmogorov Scale". Journal of Marine Research, Vol. 50, 1992 "In situ Measurements of Particle Settling Velocity on the Northern California Continental Shelf", Continental Shelf Research. Vol. 14, No. $10 / 11,1994$

Hill, P.S., Syvitski, J.P. Cowan, E.A., and Powell, R.D. . "Floc Settling Velocities Under a Buoyant Discharge Plume in Glasier Bay, Alaska, Marine Geology. accepted 1997

Hollister. C.D., Nowell, A.R.M., and Jumars, P.A., "The Dynamical Abyss", Scientific American, Vol. 250, No. 3, 1984 Population Balance for Nucleation, Growth, and Aggregation”. American Institute of Chemical Engineers Journal. Vol. 34, No. 11, 1988

Hunt, C.D.. McDowell, S.E., Shea. D.. Hillman. R.. Trulli, W.. Berger. T., Redford. D.. and Pabst. D., -Transport of Sewage Sludge from the 106-Mile Site - Results from an October Survey", Chemistry and Ecology, Vol. T. 1992

Hunt, J.R., "Prediction of Oceanic Particle Size Distributions from Coagulation and Sedimentation Mechanisms". in Particulates in Water edited by Kavanaugh M.C.. and Leckie. J.O.. pp. 243-25T. American Chemical Society, 1980

Hurlbut, Jr., C.S. and KIein, C., Manual of Mineralogy, 19th Ed.. John Wiley \& Sons, Toronto, 1977

Jackson, G.A., "A Model of the Formation of Marine Algal Flocs by Physical Coagulation Processes", Deep-Sea Research, Vol. 37, No. 8, 1990

Junge, L.E., Air Chemistry and Radioactivity, Academic Press, New York, 1963

Koh, P.T.L., Andrews, J.R.G, and Uhlherr, P.H.T., "Modelling Shear-Flocculation by Population Balances”. Chemical Engineering Science. Vol. 42, No. 2. 1987 
Kostoglou, MI. and Karabelas, A.J., "Evaluation of Zero Order Methods for Simulating Particle Coagulation”, Journal of Colloid and Interface Science, Vol. 163. 1994

Kranck, K. and Milligan, T.E., "Characteristics of Suspended Particles at an 11Hour Anchor Station in San Francisco Bay, California”. Journal of Geophysical Research, Vol. 97, No. C7, 1992

Lerman. A., Carder, K.L., and Betzer. P.R.. "Elimination of Fine Suspendoids in the Oceanic Water Column", Earth and Planetary Science Letters. Vol. 3i. $19 \pi$

Li, X. and Logan, B.E.. "Collision Frequencies of Fractal Aggregates with Small Particles by Differential Sedimentation", Environmental Science and Technology, Vol. 31, 1997

Li, X. and Logan, B.E., "Collision Frequencies of Fractal Aggregates with Small Particles in a Turbulently Sheared Fluid", Environmental Science and Technology, Vol. 31,1997

Lick, W., Lick, J.. and Ziegler, C.K., "Flocculation and its Effect on the Vertical Transport of Fine-Grained Sediments", Hydrobiologia, Vol. 235/236. 1992

Lick, W. and Huang, H., "Flocculation and the Physical Properties of Flocs", in Nearshore and Estuarine Cohesive Sediment Transport, edited by A.J. Mehta, pp.21-39. American Geophysical Union. Washington. DC, 1993

Logan, B.E. and Wilkinson, D.G., "Fractal Geometry of Marine Snow and Other Biological Aggregates", Limnology and Oceanography, Vol. 35, 1990

Logan, B.E., Passow, U., Alldredge, A.L., Grossart, H.-P., and Simon, M., "Rapid Formation and Sedimentation of Large Aggregates in Predictable from Coagulation Rates (Half-Lives) of Transparent Exopolymer Particles (TEP)", Deep-Sea Research, Vol. 42, No. 1, 1995 
Luettich, Jr., R.A., Wells, J.T., and Kim, S.-Y., "In Situ Variability of Large Aggregates: Preliminary Results on the Effects of Shear". in Nearshore and Estuarine Cohesive Sediment Transport, edited by A.J. Mehta. pp.21-39. American Geophysical Union, Washington, DC, 1993

McCave, I.N., "Size Spectra and Aggregation of Suspended Particles in the Deep Ocean”, Deep Sea Research, Vol. 31, No. 4. 1984

McCave, I.N., "Mechanics of Deposition of Fine-Grained Sediments from Nepheloid Layers", Geo-Marine Letters, Vol. 4, 1985

Meakin, P., "Fractal Aggregates in Geophysics". Reviews of Geophysics. Vol. 29, 1991

Milligan, T.G.. "A Laboratory Assessment of the Relative Importance of Turbulence, Particle Composition, and Concentration in Limiting Maximal Floc Size and Settling Behaviour". Master's Thesis. Dalhousie Univerisity, 1996

Müller, H.. "Zurallgemeinen Theorie der raschen Koagulation". Kolloidchemische Beihefte, Vol. 27, 1928.

Oles, V., "Shear-Induced Aggregation and Breakup of Polystyrene Latex Particles". Journal of Colloid and Interface Science, Vol. 154, No. 2, 1992

O'Melia, C.R. and Tiller, C.L.. "Physicochemical Aggregation and Deposition in Aquatic Environments", in Environmental Particles. Vol. 2, edited by Buffle. J. and van Leeuwan, H.P., Lewis Publishers, 1993

Press, W.H., Teukolsky, S.A., Vetterling, W.T., and Flannery, B.P., Numerical Recipes in C: The Art of Scientific Computing, 2nd Ed., Cambridge University Press, Melbourne, 1992

Pruppacher, H.R. and Klett, J.D., Microphysics of Clouds and Precipitation. D. Reidel, Dordrecht, 1980 
Saffman, P.G. and Turner, J.S.. "On the Collision of Drops in Turbulent Clouds". Journal of Fluid Mechanics, Vol. 1, 1956

Scott, W.T., "Analytic Studies of Cloud Droplet Coalescence I". Journal of the Atmospheric Sciences, Vol. 25, 1968

Smayda, T.J., "The Suspension and Sinking of Phytoplankton in the Sea". Oceanography and Marine Biology Annual Review, Vol. 8, 1970

Smetacek, V.S.. "Role of Sinking in Diatom Life-History Cycles: Ecological. Evolutionary and Geological Significance”, Marine Biology, Vol. 84. 1985

Smoluchowski, M., "Versuch einer mathematischen Theorie der Koagulationskinetic kolloider Lösungen”. Z. Phys. Chemie. Vol. 92. $191 \bar{\imath}$

Spicer, P.T. and Pratsinis. S.E., "Shear-Induced Flocculation: The Evolution of Floc Structure and the Shape of the Size Distribution at Steady State". Water Research, Vol. 30, No. 5, 1996

Sternberg. R.W., Ogston, A.. and Johnston, R., “A Video System for In Situ .Measurement of Size and Settling Velocity of Suspended Particulates”. Journal of Sea Research. Vol. 36. 1996

Stolzenbach, K.D.. “Scavenging of Small Particles by Fast-Sinking Porous Aggregates". Deep-Sea Research, Vol. 40, 1993

Syvitski. J.P.M.. Asprey. K.W.. and LeBlanc. K.W.G. "In Situ Characteristics of Particles Settling within a Deep-Water Estuary”. Deep-Sea Research. II, Vol. 42. 1995 Systems". in Comprehensive Chemical Kinetics. Vol 2: The Theory of Kinetics, edited by C.H. Bamford and C.F.H. Tipper, Elsevier Publishing Company, New York, 1969

ten Brinke, W.B.M. "Settling Velocities of Mud Aggregation in the Oosterschelde Tidal Basin (The Netherlands), Determined by a Submersible Video System". Estuarine Coastal and Shelf Science, Vol. 39, 1994 
Tennekes, H. and Lumley, J.L., A First Course in Turbulence. The MIT Press. Cambridge, MA, 1972 , Vol. 47. No. 24. 1990

Villadsen, J. and Michelsen. M.L., Solution of Differential Equation Models by Polynomial Approximation. Prentice-Hall. New York. 1978

Walpole, R.E. and Myers, R.H.. Probability and Statistics for Engineers and Scientists, 4th ed.. MacMillan Publishing Company. New York, 1989

Weilenmann, U., O'Melia. C.R., and Stumm, W., "Particle Transport in Lakes: Models and Measurements", Limnology and Oceanography, Vol. 34. No. 1. 1989 

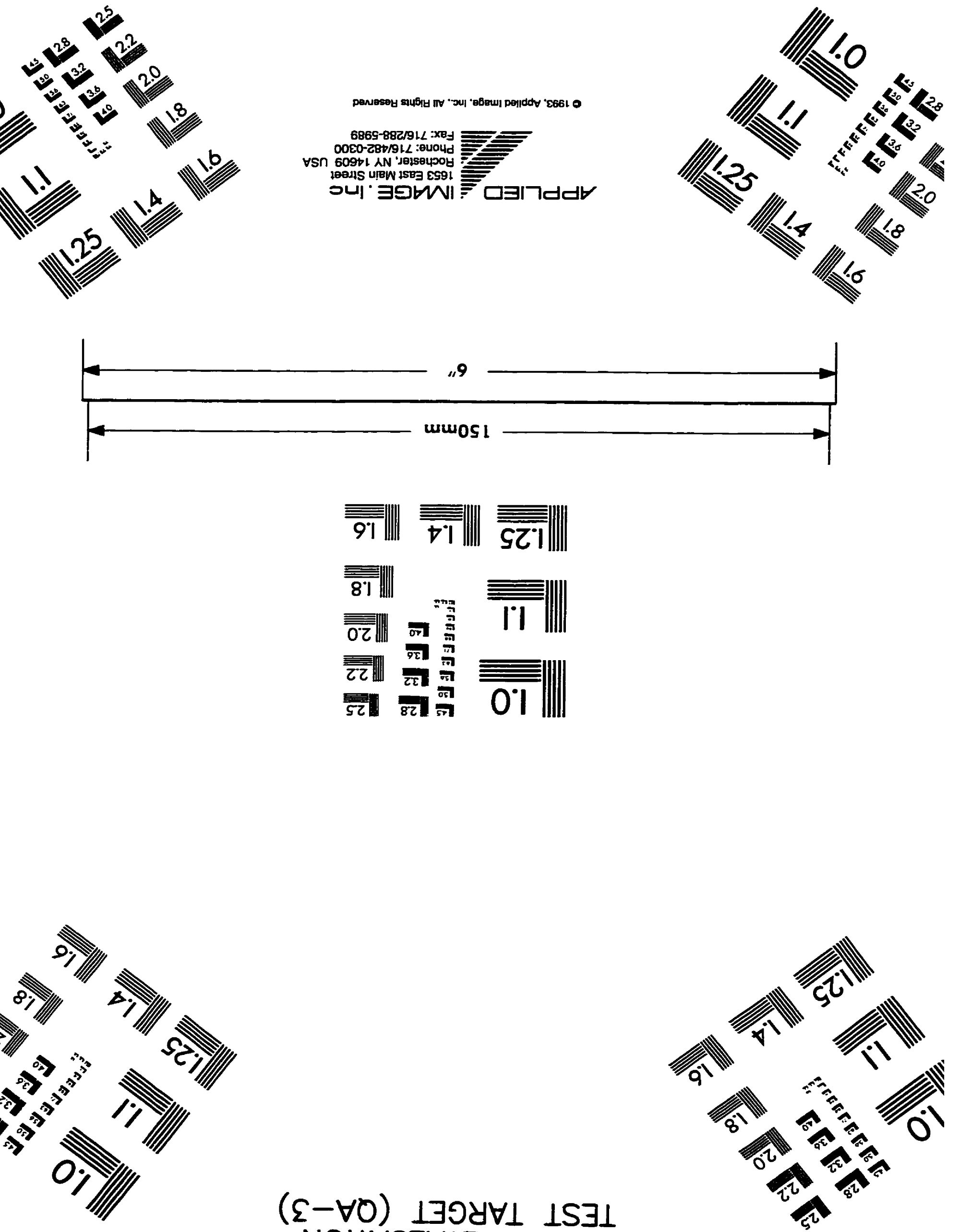